$$
\text { Universidad de Lima }
$$

Facultad de Ingeniería y Arquitectura

Carrera de Ingeniería Industrial

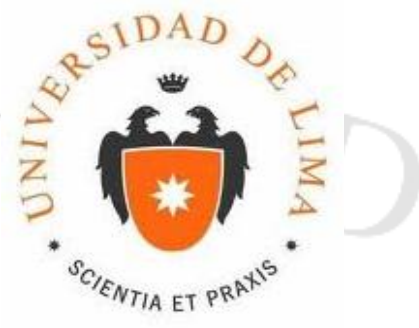

\title{
ESTUDIO DE PRE FACTIBILIDAD PARA LA INSTALACIÓN DE UNA PLANTA PROCESADORA DE PAPA AMARILLA (Solanum goniocalix) PRECOCIDA Y PREFRITA CONGELADA
}

Trabajo de investigación para optar el Título profesional de Ingeniero Industrial

\author{
Juan Carlos Matta Vega
}

Código 20110751

\section{Asesor:}

Álvaro León-Gambetta Martin-Arranz

$$
\text { Lima - Perú }
$$

Febrero del 2019 


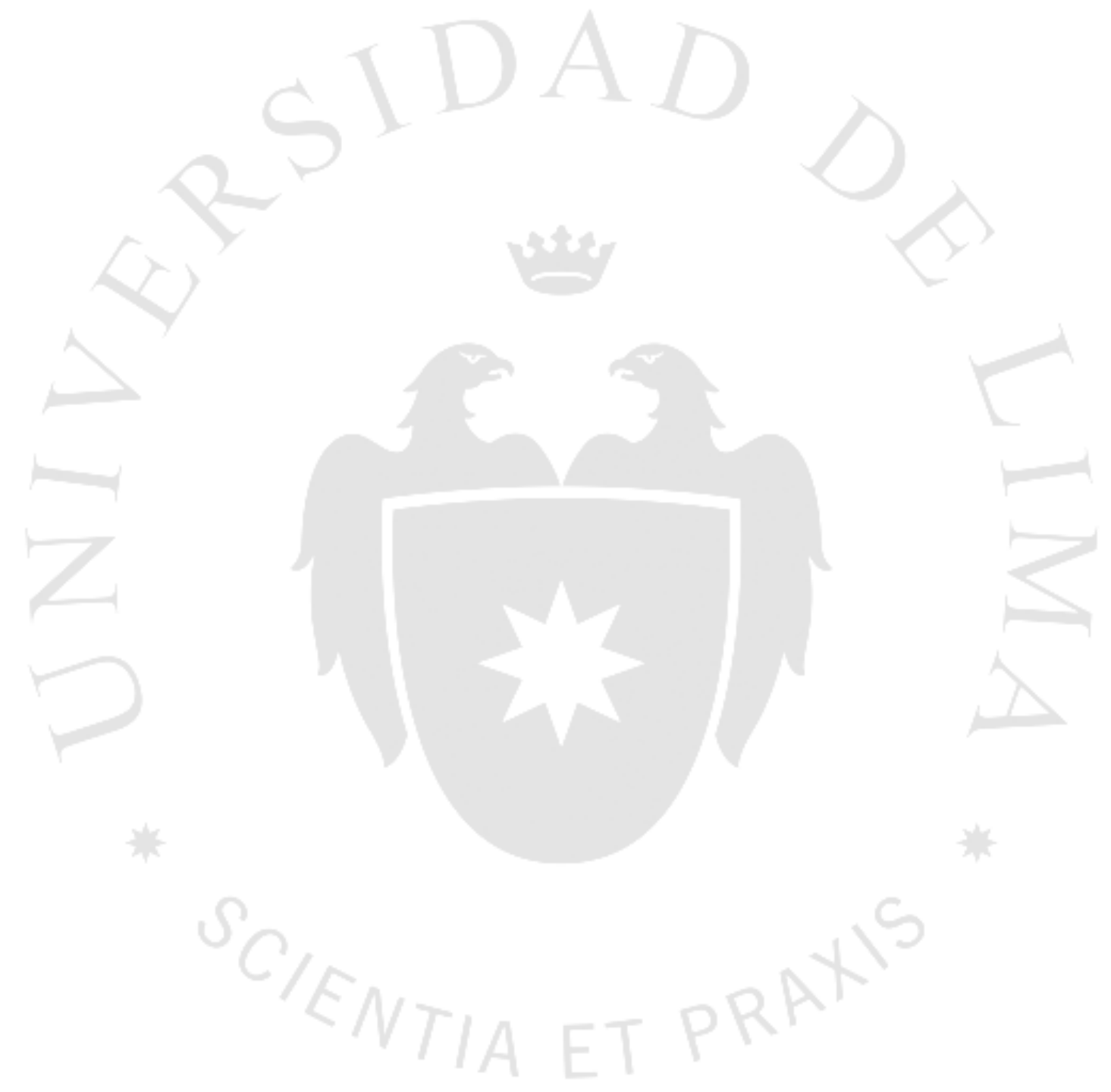




\section{ESTUDIO DE PRE FACTIBILIDAD PARA LA}

INSTALACIÓN DE UNA PLANTA

\section{PROCESADORA DE PAPA AMARILLA}

(Solanum goniocalix) PRECOCIDA Y PREFRITA CONGELADA 


\section{TABLA DE CONTENIDO}

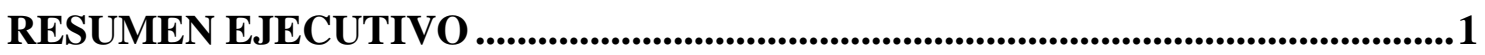

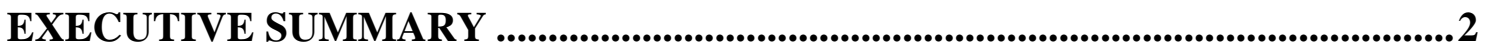

CAPÍTULO I: ASPECTOS GENERALES................................................................3

1.1. Problemática..........................................................................................

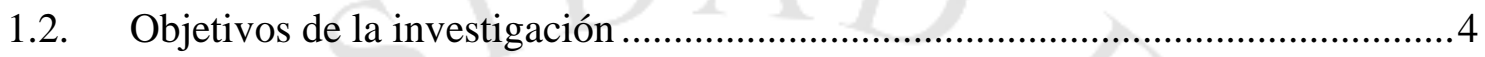

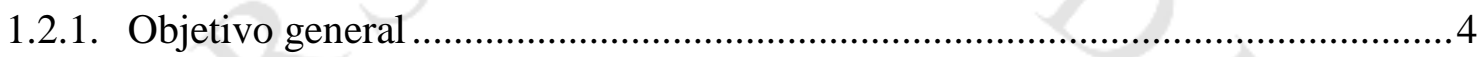

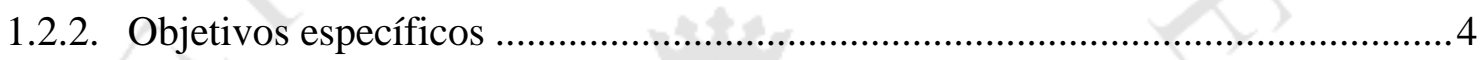

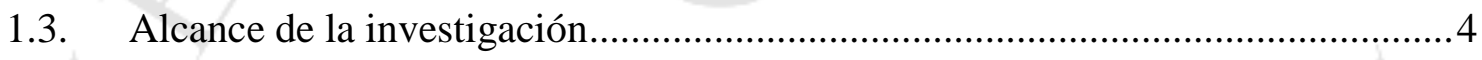

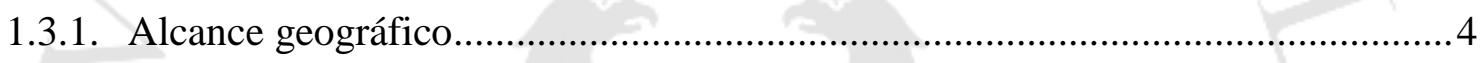

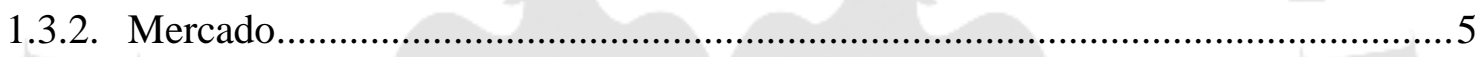

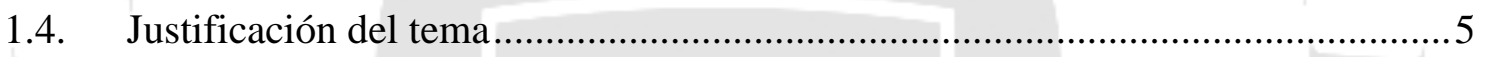

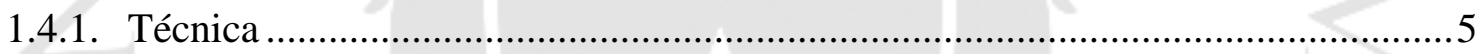

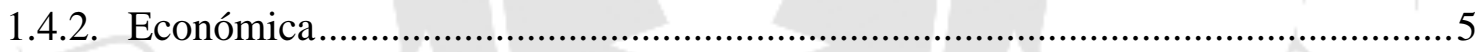

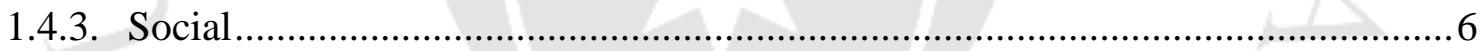

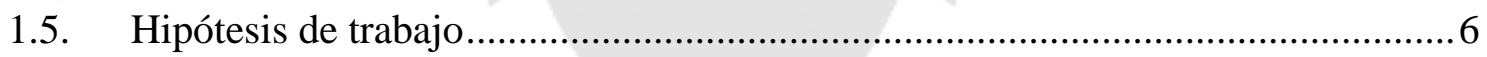

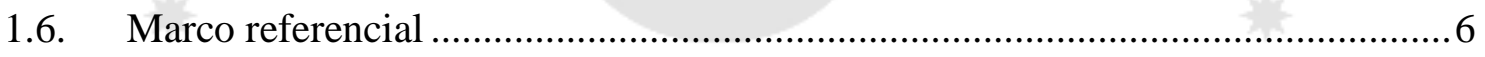

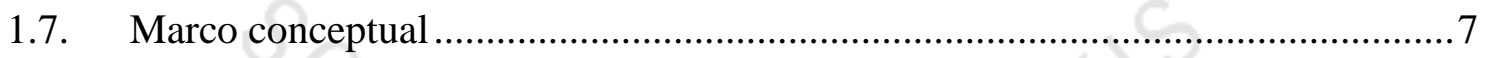

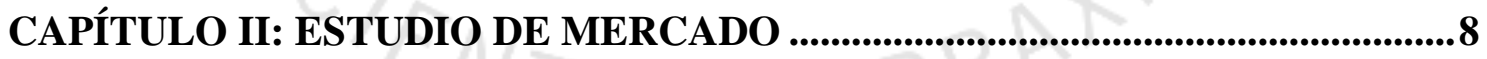

2.1. Aspectos generales del estudio de mercado ...................................................

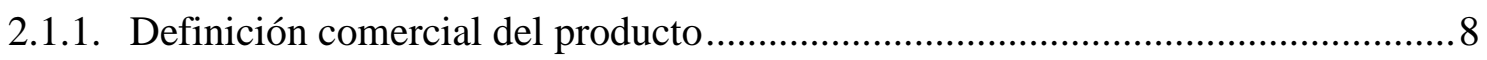

2.1.2. Usos del producto, bienes sustitutos y complementarios ................................ 8

2.1.3. Determinación del área geográfica que abarcará el estudio ............................... 9

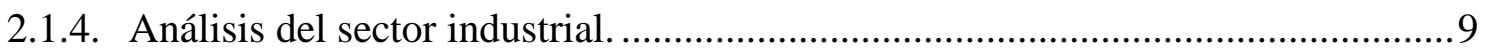

2.1.5. Metodología a emplear en la investigación de mercado ................................... 11 
2.2. Análisis de la demanda 11

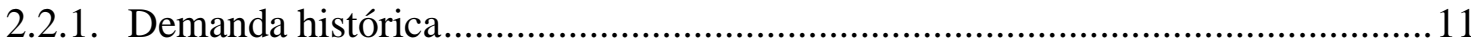

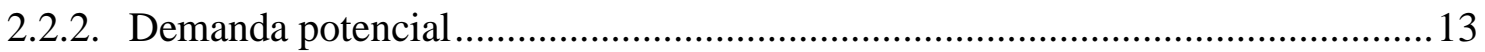

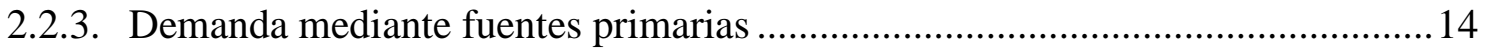

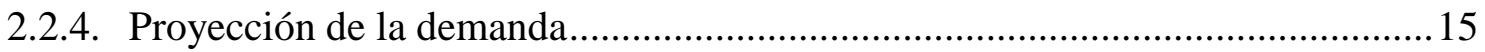

2.2.5. Consideraciones sobre la vida útil del proyecto............................................. 16

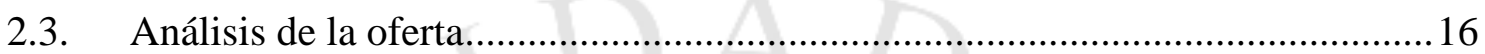

2.3.1. Empresas productoras, importadoras y comercializadoras ............................... 16

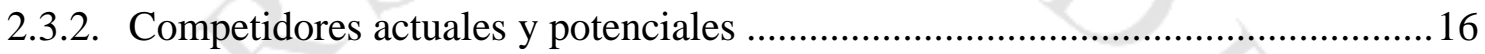

2.4. Determinación de la Demanda para el proyecto ............................................. 17

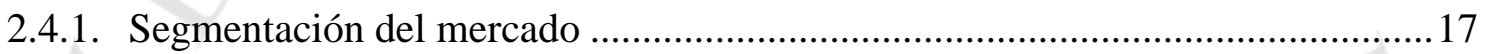

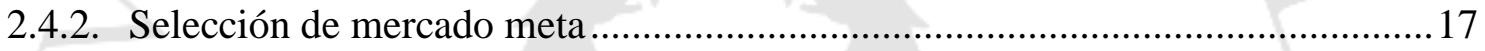

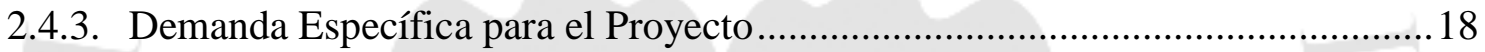

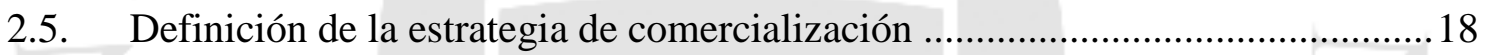

2.5.1. Políticas de comercialización y distribución ...................................................... 18

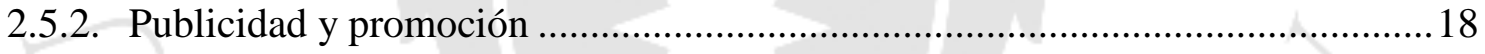

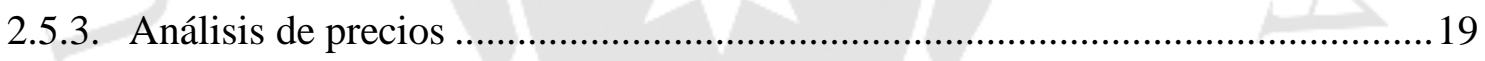

CAPÍTULO III: LOCALIZACIÓN DE LA PLANTA ..................................................222

3.1. Identificación y análisis detallado de los factores de localización......................22

3.2. Identificación y descripción de las alternativas de localización ..........................22

3.3. Evaluación y selección de localización............................................................2

3.3.1. Evaluación y selección de macrolocalización......................................................23

3.3.2. Evaluación y selección de microlocalización .....................................................24

CAPÍTULO IV: TAMAÑO DE PLANTA ............................................................25

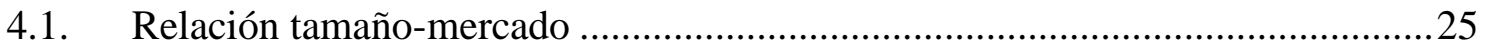

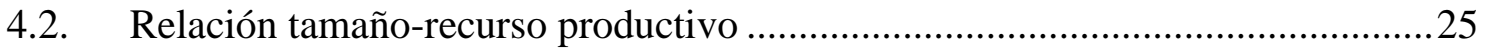

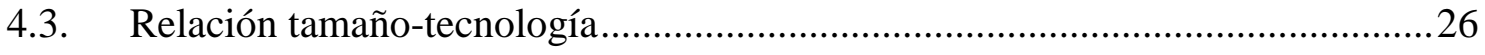




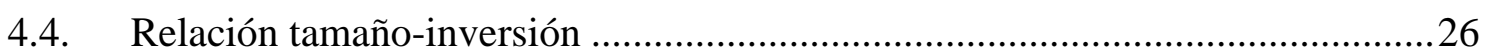

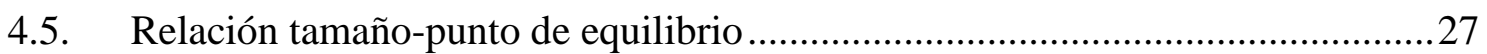

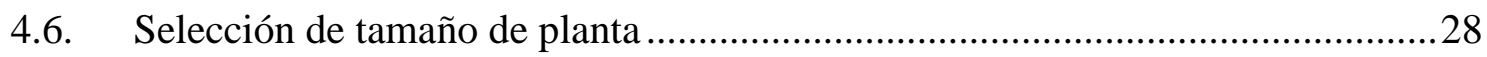

CAPÍTULO V: INGENIERÍA DEL PROYECTO.....................................................29

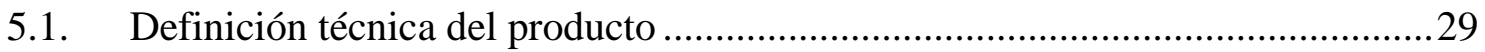

5.1.1. Especificaciones técnicas, composición y diseño del producto .........................29

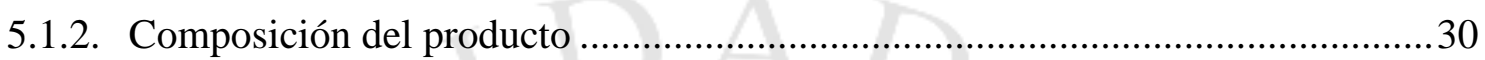

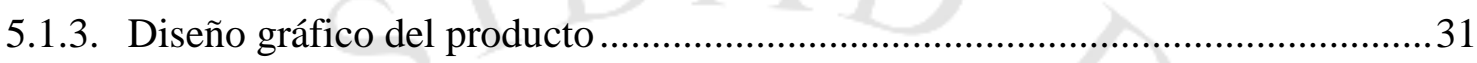

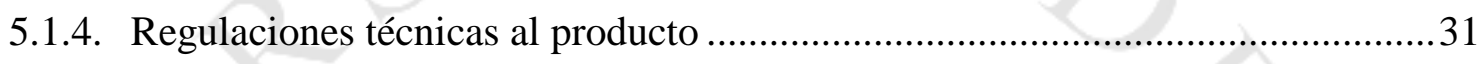

5.2. Tecnologías existentes y procesos de producción.............................................. 32

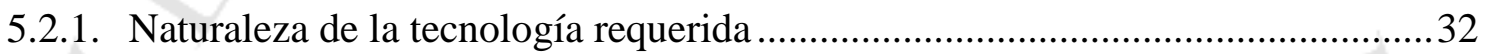

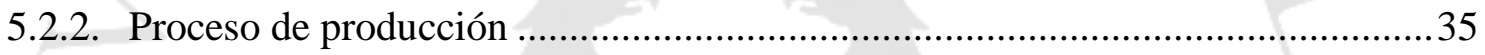

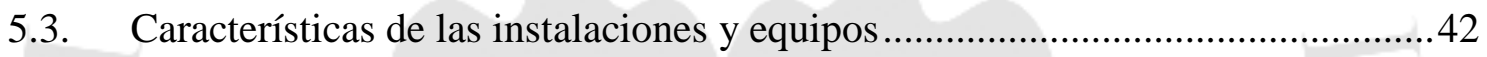

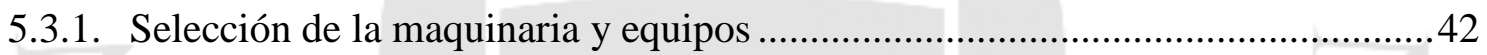

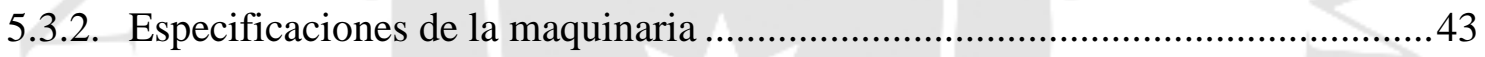

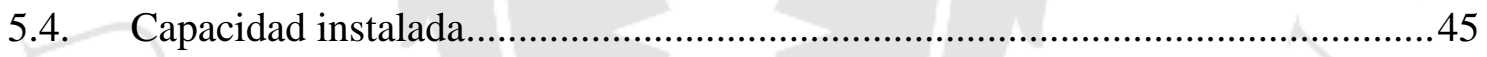

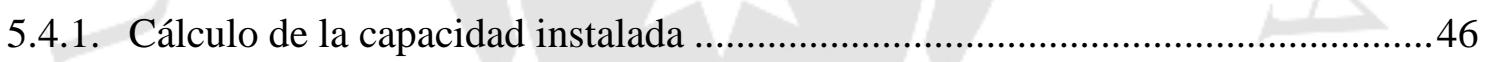

5.4.2. Cálculo detallado del número de máquinas requeridas....................................46

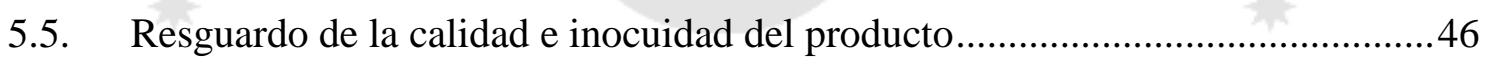

5.5.1. Calidad de la materia prima, de los insumos, del proceso y del producto ..........47

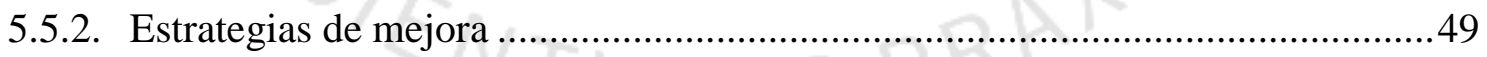

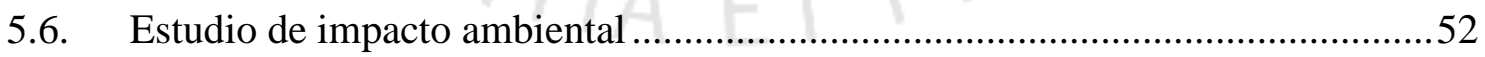

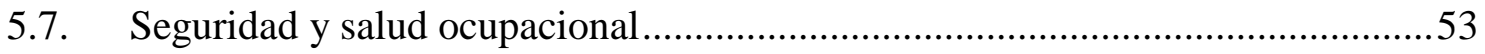

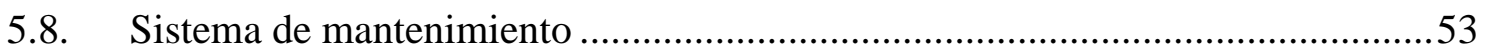

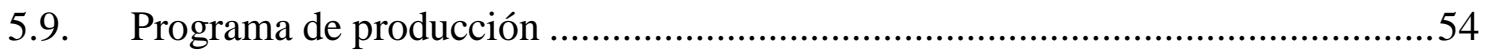

5.9.1. Factores para la programación de la producción..................................................54

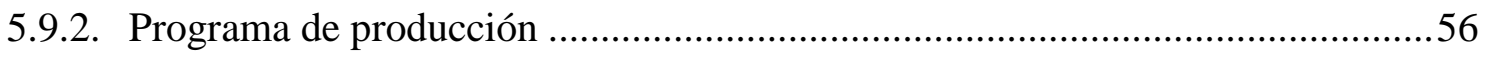


5.10.1. Materia prima, insumos y otros materiales ….................................................57

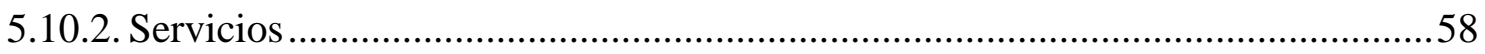

5.10.3. Determinación del número de operarios y trabajadores indirectos ......................59

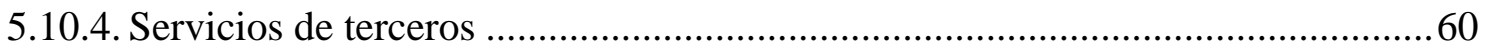

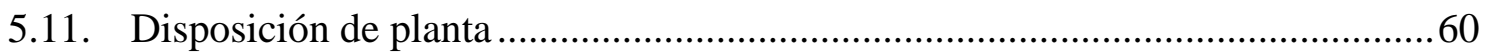

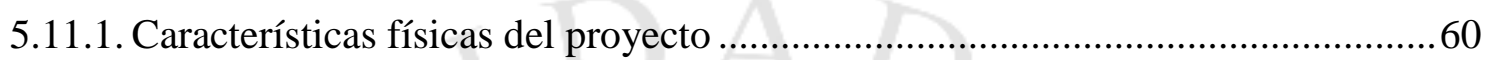

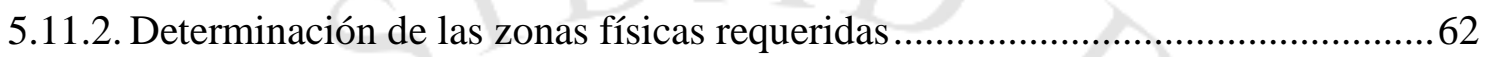

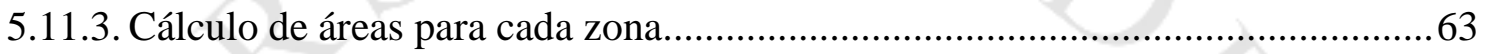

5.11.4. Dispositivos de seguridad industrial y señalización...........................................64

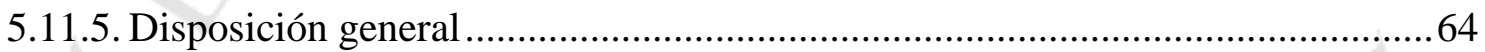

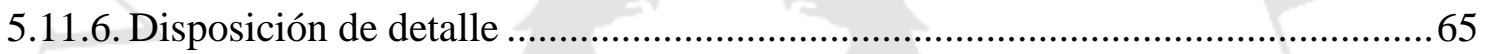

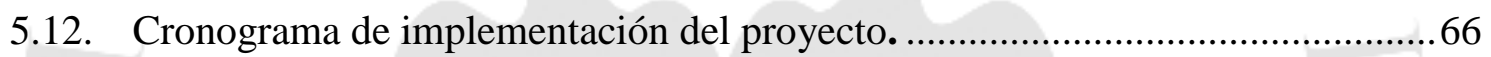

CAPÍTULO VI: ORGANIZACIÓN Y ADMINISTRACIÓN....................................67

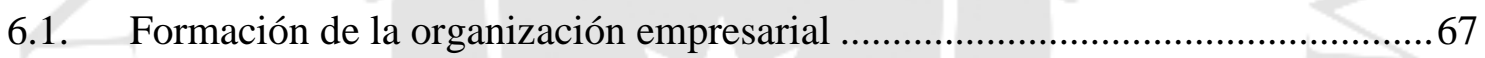

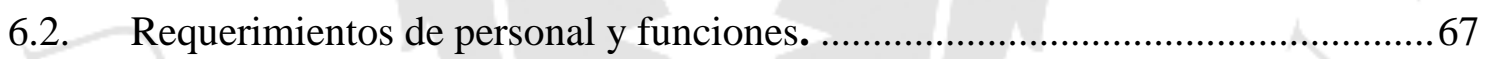

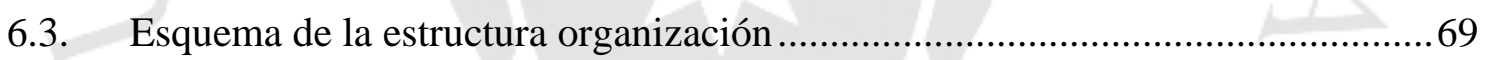

CAPÍTULO VII: PRESUPUESTO Y EVALUACIÓN DEL PROYECTO............70

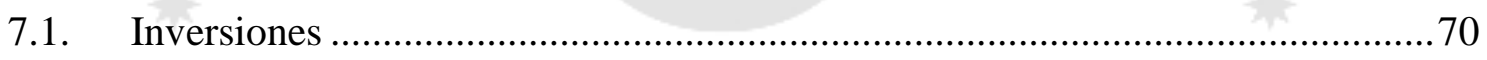

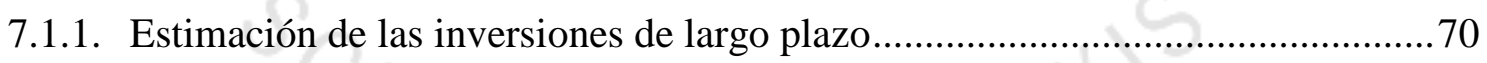

7.1.2. Estimación de las inversiones de corto plazo..................................................... 70

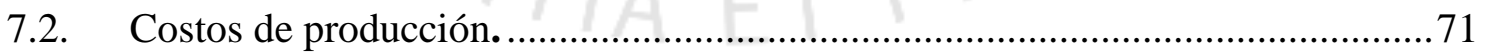

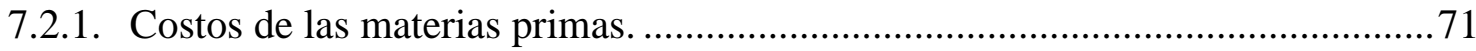

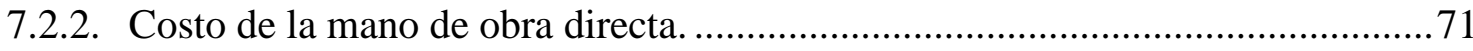

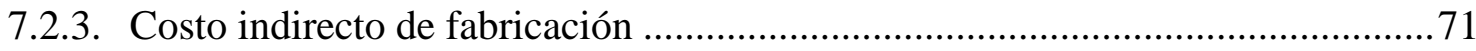

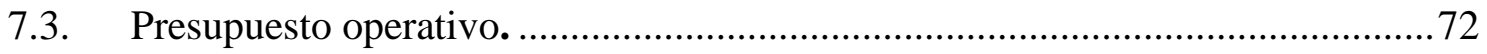

7.3.1. Presupuesto de ingreso por ventas. .......................................................... 72 
7.3.2. Presupuesto operativo de costos

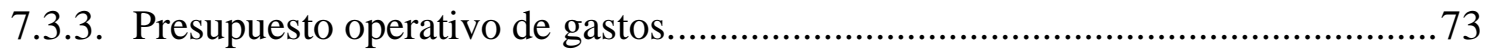

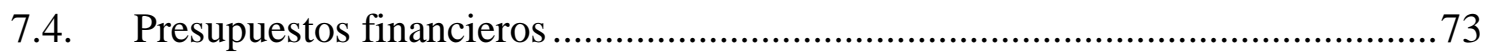

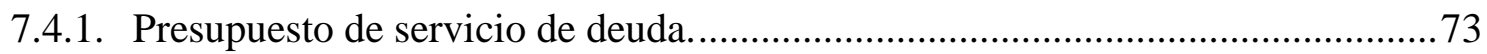

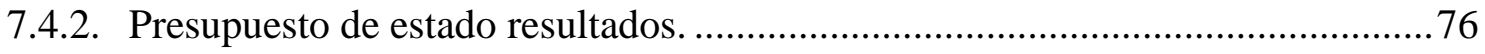

7.4.3. Presupuesto de estado de situación financiera ..................................................76

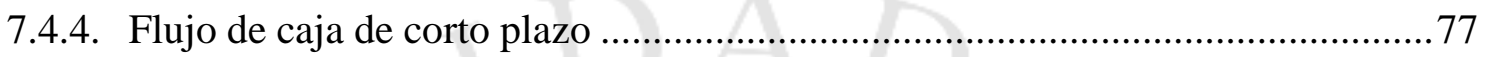

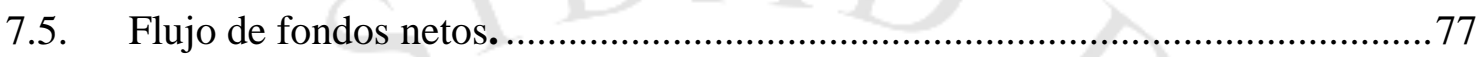

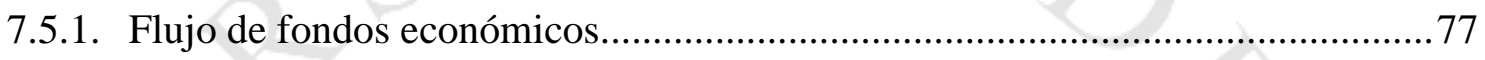

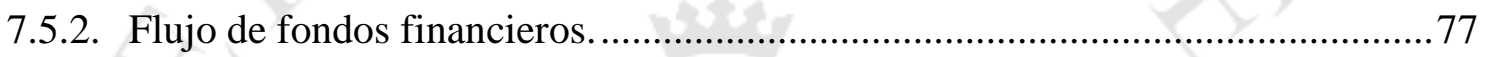

CAPÍTULO VIII: EVALUACION ECONÓMICA Y FINANCIERA .....................78

8.1. Evaluación económica: VAN, TIR, B/C, PR ................................................. 78

8.2. Evaluación financiera: VAN, TIR, B/C, PR ................................................. 79

8.3. Análisis de ratios e indicadores económicos y financieros del proyecto.............79

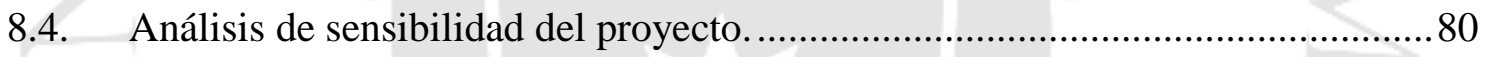

CAPÍTULO IX: EVALUACION SOCIAL .........................................................8

9.1. Identificación de las zonas y comunidades de influencia. ............................... 82

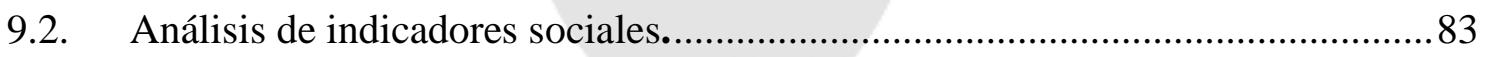

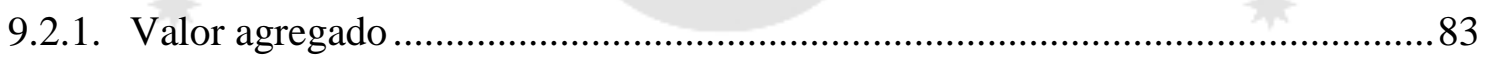

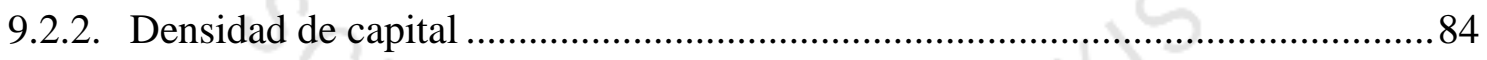

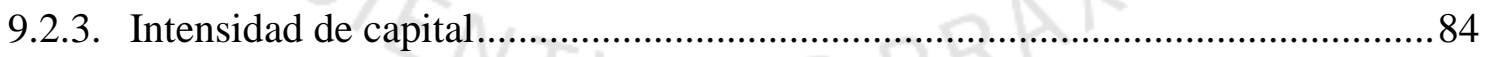

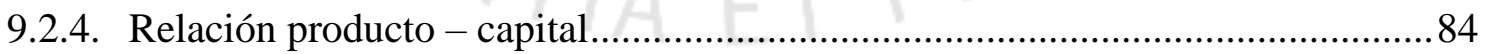

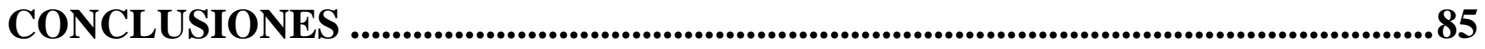

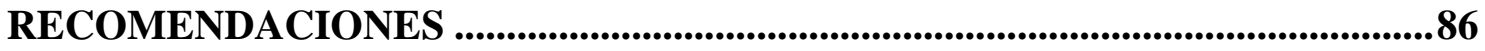

REFERENCIAS ..........................................................................................................................8 87

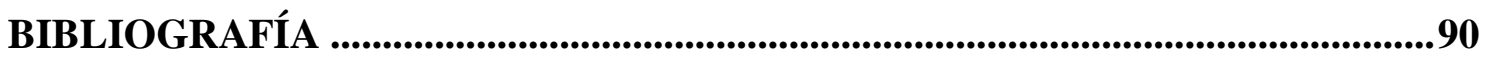

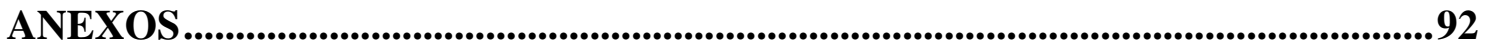




\section{ÍNDICE DE TABLAS}

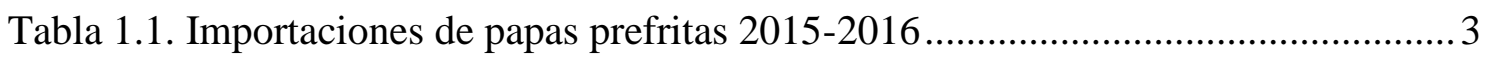

Tabla 2.1. Importaciones de papas preparadas por empresas ...................................... 10

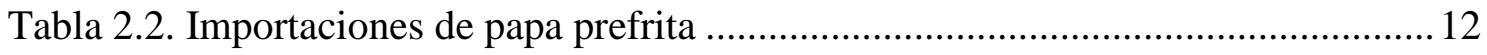

Tabla 2.3. Demanda interna aparente de la papa prefrita .............................................. 13

Tabla 2.4. Demanda potencial en base a patrón de consumo ....................................... 14

Tabla 2.5. Cantidad de habitantes y distribución de los NSE en Lima........................... 15

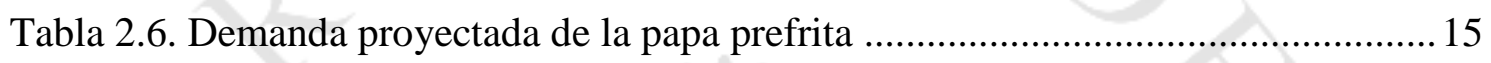

Tabla 2.7. Demanda del proyecto de la papa amarilla precocida y prefrita ................... 18

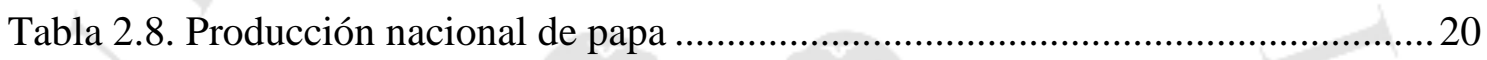

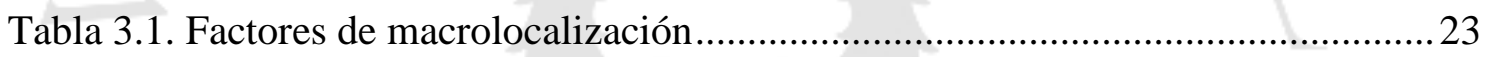

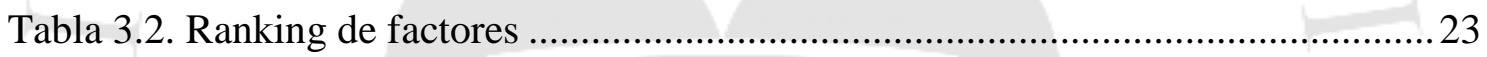

Tabla 3.3. Tabla de enfrentamiento de macrolocalización .............................................2 24

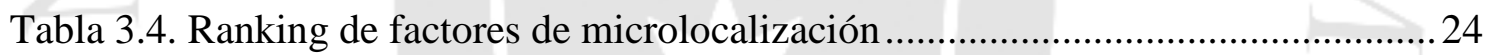

Tabla 3.4. Tabla de enfrentamiento de microlocalización.............................................2 24

Tabla 4.1. Demanda de papa precocida y prefrita proyectada.....................................2.

Tabla 4.2. Capacidad teórica de la maquinaria ..........................................................2 26

Tabla 4.3. Precio de venta, costo variable y fijo en Soles ............................................ 27

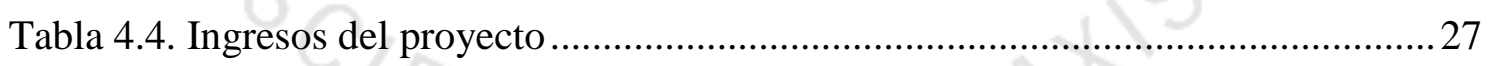

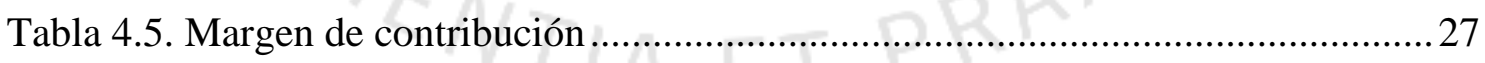

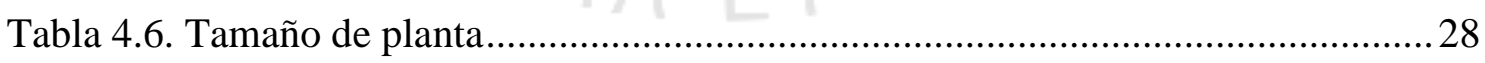

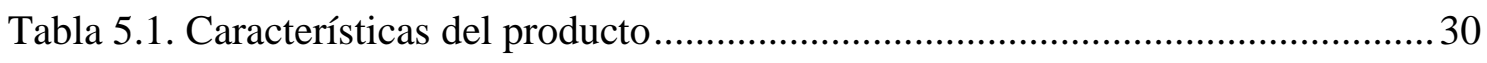

Tabla 5.2. Composición de la papa amarilla.............................................................. 30

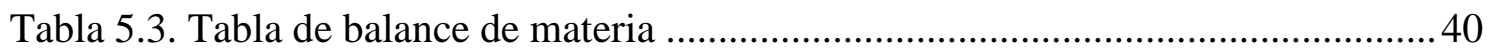

Tabla 5.4. Especificaciones técnicas de la lavadora .................................................... 43

Tabla 5.5. Especificaciones técnicas de la peladora ..................................................... 43 
Tabla 5.6. Especificaciones técnicas de la cortadora 43

Tabla 5.7. Especificaciones técnicas de la escaldadora 44

Tabla 5.8. Especificaciones técnicas de la freidora ..................................................... 44

Tabla 5.9. Especificaciones técnicas del secador ....................................................... 44

Tabla 5.10. Especificaciones técnicas de la congeladora ….........................................45

Tabla 5.11. Especificaciones técnicas de la empacadora.............................................45

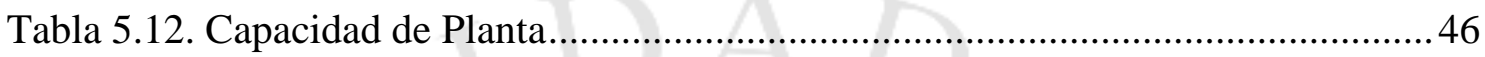

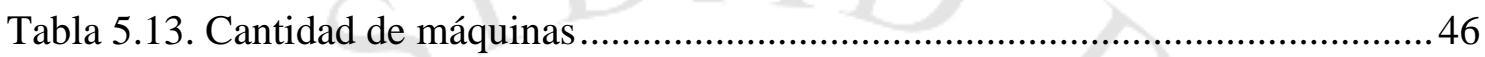

Tabla 5.14. Requisitos de sanidad, aspecto y tolerancias según calibres ....................... 48

Tabla 5.15. Cuadro de especificaciones técnicas de calidad de la papa amarilla ...........48

Tabla 5.16. Cuadro de especificaciones técnicas de calidad de la papa prefrita ............49

Tabla 5.17. Cuadro de puntos críticos de control ...................................................... 51

Tabla 5.18. Matriz de Aspectos e Impactos Ambientales............................................52

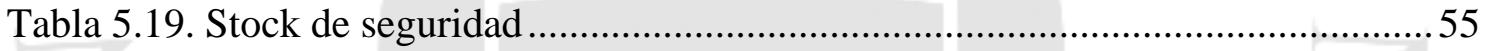

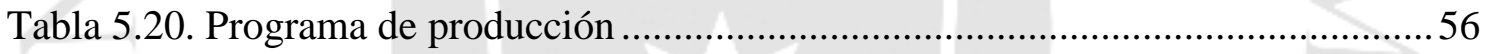

Tabla 5.21. Cálculo de rendimiento de materiales.......................................................56

Tabla 5.22. Cálculo de rendimiento de materia prima...............................................57

Tabla 5.23. Cálculo de rendimiento de otros insumos..................................................57

Tabla 5.24. Cálculo de la cantidad necesaria de otros insumos .....................................58

Tabla 5.25. Cálculo de potencia anual requerida para la producción .............................58

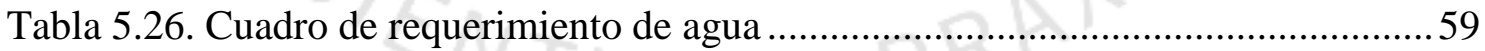

Tabla 5.27. Cuadro de requerimiento de combustible ...................................................59

Tabla 5.28. Cantidad de operarios para los procesos comunes ....................................59

Tabla 5.29. Cantidad de operarios para la papa prefrita ..............................................6 60

Tabla 5.30. Cantidad de operarios para la papa precocida ...........................................60

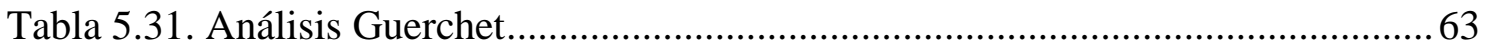

Tabla 5.32. Cálculo de áreas que no pertenecen a producción .........................................64 
Tabla 6.1. Cantidad de personal requerido y funciones

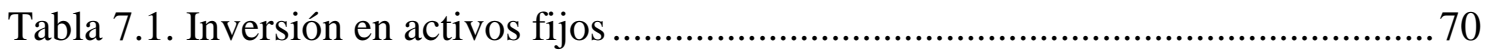

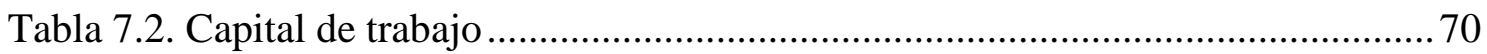

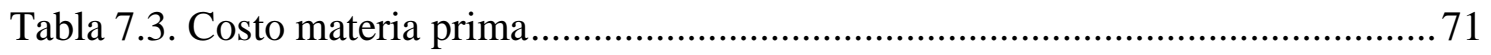

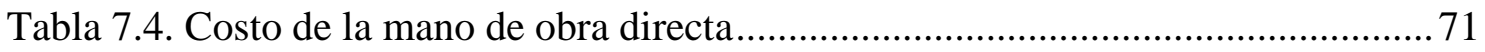

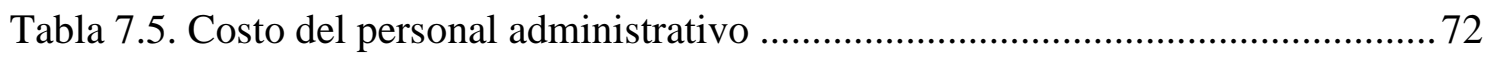

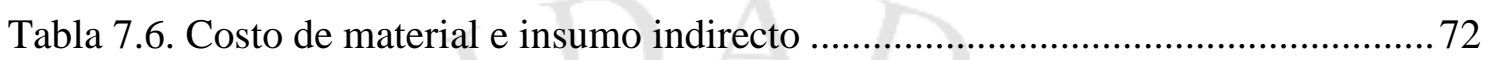

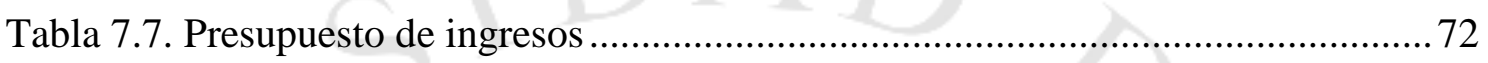

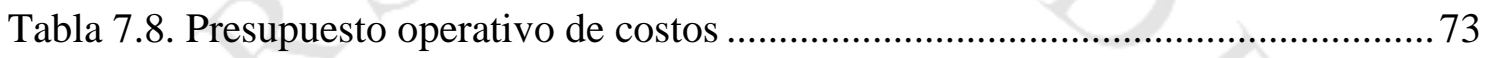

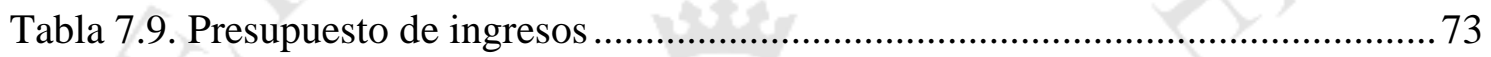

Tabla 7.10. Información entidades bancarias privadas ................................................... 74

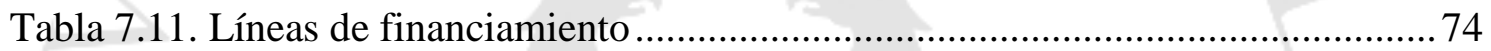

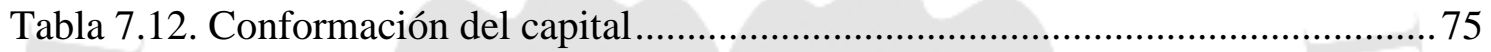

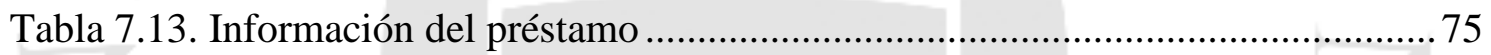

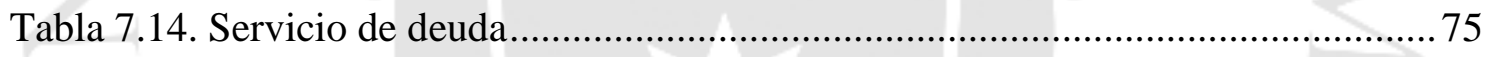

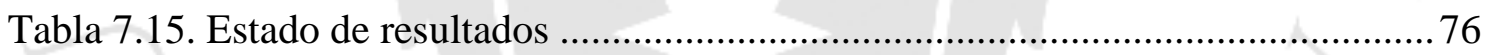

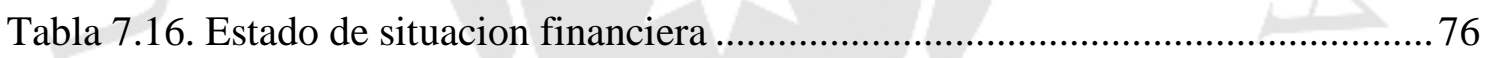

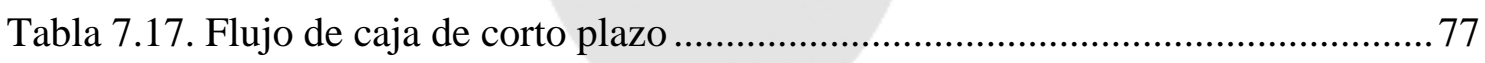

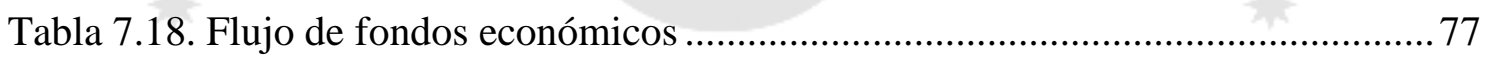

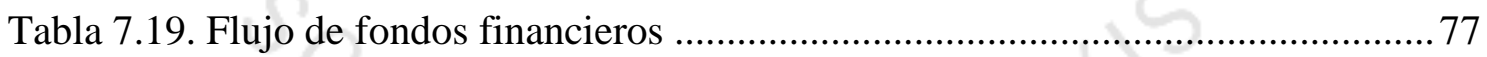

Tabla 8.1. Calculo de VAN, TIR, B/C, PR económico .................................................. 78

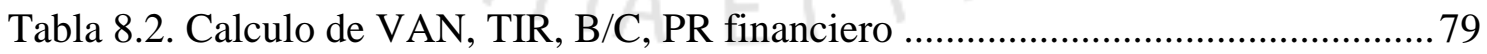

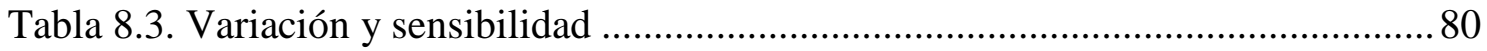

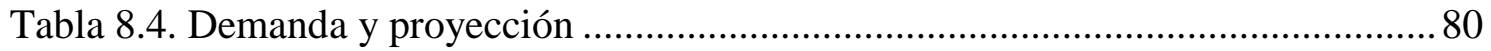

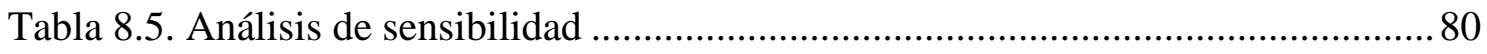

Tabla 9.1. Características de las necesidades básicas de Huancayo .............................. 82

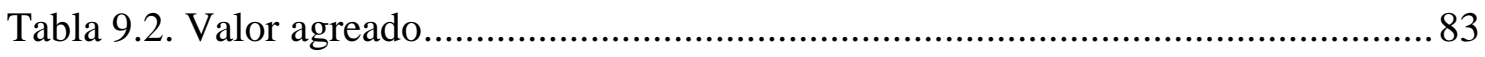




\section{ÍNDICE DE FIGURAS}

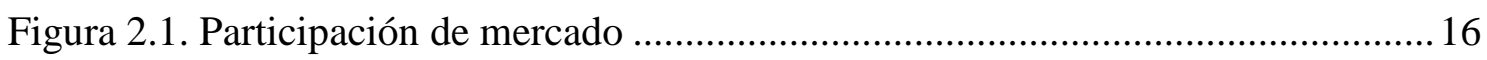

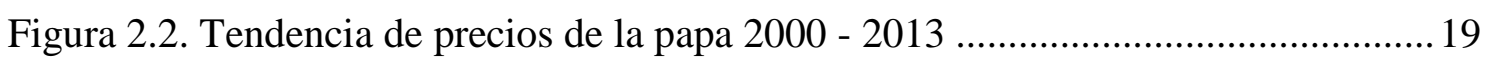

Figura 2.3. Tendencia de precios de la papa amarilla septiembre - diciembre 2017 ... 21

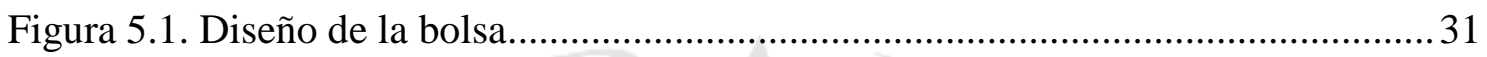

Figura 5.2. Diagrama de proceso de la papa prefrita congelada .................................. 38

Figura 5.3. Diagrama de proceso de la papa precocida congelada ................................ 39

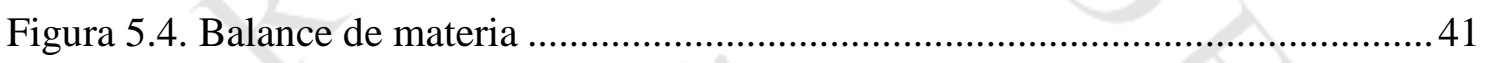

Figura 5.5. Rangos de diámetro y peso según variedad de papa ................................. 47

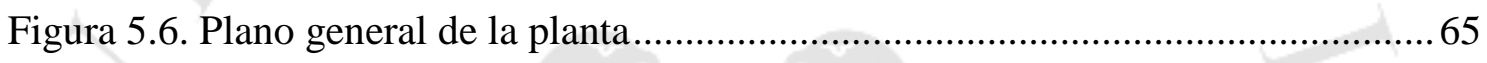

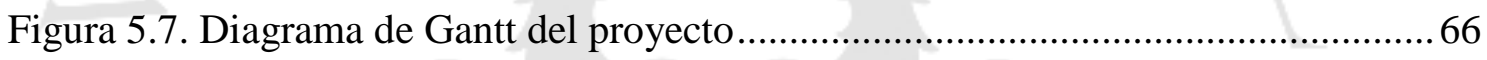

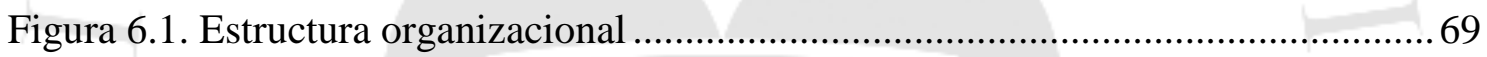




\section{ÍNDICE DE ANEXOS}

Anexo 1: Encuesta sobre demanda de papa amarilla precocida y prefrita congelada en Lima Moderna

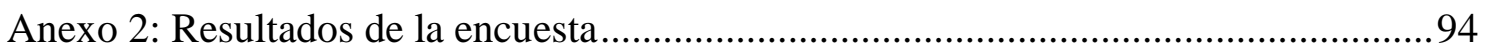

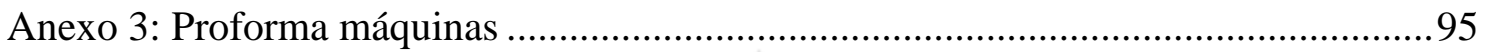

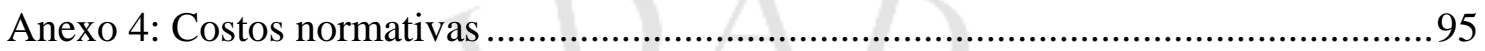

Anexo 5: Diagrama de flujo para la eleccion de los PCC …......................................96

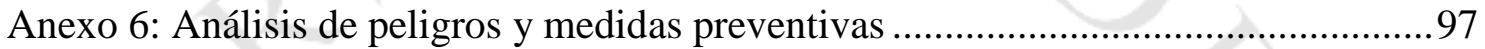




\section{RESUMEN EJECUTIVO}

En el presente estudio de prefactibilidad para la elaboración de papa amarilla prefrita y precocida fue motivado por el crecimiento de las importaciones de la papa prefrita de países como Holanda y Bélgica, a pesar de que Perú, es uno de los más importantes productores de papa en la región. El producto básico es la papa amarilla precocida en rodajas y la prefrita en forma de bastón, que vendrán en empaques termocontraibles cerrados al vacío, lo que permitirá mantenerse en buenas condiciones hasta por 4 meses congelados.

En el estudio de macrolocalización se decidió que Lima sea el departamento para localizar la empresa y Ate sea la microlocalización elegida. La cantidad de máquinas y operarios que se requerirá será de 11 y 16 respectivamente y su capacidad de planta de 123 toneladas/año.

El impacto ambiental de la planta será bajo gracias al uso de generadores con gas natural, focos ahorradores y el uso de refrigerantes no contaminantes. El programa de producción para el año 2022 es 88,6 toneladas y el área total será de $706 \mathrm{~m}^{2}$ aproximadamente.

La empresa cuyo nombre será Amkha se registrará como una EIRL (Empresa individual de responsabilidad limitada). La inversión total del proyecto será de aproximadamente de S/433 844 que considera a los activos tangibles e intangibles con un capital de trabajo de S/199 157. Finalmente, la evaluación financiera arrojó un VAN de S/375 547, una TIR de 113,1\% y un periodo de recupero de 2,64 años, lo que significa que el proyecto es rentable, viable y sostenible. 


\section{EXECUTIVE SUMMARY}

In the present pre-feasibility study to produce pre-fried and pre-cooked yellow potatoes was motivated due to the growth of imports of pre-fried potatoes from countries like Holland, although Peru is one of the main potato producers in the region. The basic product is a pre-cooked yellow potato in slices and pre-fried in the form of a cane, which will come in heat-shrinkable packages closed in the vacuum, allowing to stay in good condition for up to 4 months frozen.

With the study of the macro localization it was decided that Lima is the department to locate the company and Ate is the micro-localization chosen. The number of machines and operators that will be required will be 11 and 16 respectively, and its plant capacity of 192 tons / year.

The environmental impact of the plant will be low thanks to the use of generators with natural gas, light bulbs and the use of non-polluting refrigerants. The production program for the year 2022 is 88,6 tons and the total area will be approximately $706 \mathrm{~m} 2$.

The company whose name will be Amkha will be constituted as an Individual limited liability company (E.I.R.L.) and will have one shareholder. The total investment in the project will be S/433 844, which considers tangible and intangible assets with a working capital of S/199 157. Finally, the financial evaluation showed an NVP (Net Present Value) of S/375 547; an IRR (Internal rate of return) of 113,1\% and a payback of 2,05 years, which means that the project is profitable, viable and sustainable. 


\section{CAPÍTULO I: ASPECTOS GENERALES}

\subsection{Problemática}

Actualmente el Perú es reconocido por contar con una enorme variedad de papas. Según Reynaldo Trinidad (2016), de las 5000 que existen en el mundo, Perú tiene alrededor de 3 250. Sin embargo, aún está por detrás de países como China y Holanda en la producción de papa. Por ejemplo, en el 2014, dichos países tuvieron una producción de alrededor de 96 y 7 millones de toneladas respectivamente según la FAO (2015). En cambio, el Perú tuvo una producción de 4,7 millones toneladas según Minagri (2015). Esta es una de las causas que, junto a la poca importancia para la creación de industrias de papas prefritas o precocidas peruanas, ha impulsado la importación y que estas tengan un gran porcentaje de participación en el mercado (Solo Alicorp tiene $47 \%$ de toda la importación). Según Carrasco (2016), en los últimos 12 años el consumo per cápita de papa en el Perú ha crecido de $76 \mathrm{~kg}$ a $89 \mathrm{~kg}$ al año. Es por este aumento que existe una gran demanda de papa precocida y prefrita congelada por restaurantes, cadenas de comida rápida y público en general.

Tomando en cuenta la información de Carrasco (2016), Minagri (2016) y La República (2016) la papa ha experimentado tres fenómenos importantes en los últimos años que favorecen al proyecto: i) el aumento del consumo per cápita de la papa; ii) el incremento de la producción y reducción del precio, y iii) el mercado peruano cada vez más busca comprar productos peruanos. Véase la Tabla 1.1

Tabla 1.1

Importaciones de papas prefritas los años 2016-2017

\begin{tabular}{|c|c|c|c|c|c|c|}
\hline \multirow{2}{*}{ Mes } & \multicolumn{2}{|c|}{$\mathbf{2 0 1 7}$} & \multicolumn{3}{c|}{ 2016 } \\
\cline { 2 - 7 } & CIF & KILOS & $\begin{array}{c}\text { PREC. } \\
\text { PROM }\end{array}$ & CIF & KILOS & $\begin{array}{c}\text { PREC. } \\
\text { PROM }\end{array}$ \\
\hline ENERO & 1399630 & 1764819 & 0,79 & 1757790 & 2155843 & 0,82 \\
\hline FEBRERO & 2336352 & 2958301 & 0,79 & 1889634 & 2377748 & 0,79 \\
\hline MARZO & 2116229 & 2623440 & 0,81 & 2795679 & 3460581 & 0,81 \\
\hline ABRIL & 2614938 & 3262551 & 0,80 & 2444334 & 2971743 & 0,82 \\
\hline MAYO & 2675591 & 3313212 & 0,81 & 2172935 & 2523902 & 0,86 \\
\hline JUNIO & 2274090 & 2687033 & 0,85 & 1978803 & 2390321 & 0,83 \\
\hline JULIO & 2283588 & 2641961 & 0,86 & 2488584 & 3094461 & 0,80 \\
\hline AGOSTO & 1966442 & 2149922 & 0,91 & 2569649 & 3094052 & 0,83 \\
\hline
\end{tabular}

(continúa) 
(continuación)

\begin{tabular}{|c|c|c|c|c|c|c|}
\hline SETIEMBRE & 2334198 & 2709602 & 0,86 & 2384835 & 2893573 & 0,82 \\
\hline OCTUBRE & 1702289 & 1887153 & 0,90 & 2385768 & 2890841 & 0,83 \\
\hline NOVIEMBRE & 2578680 & 3302918 & 0,78 & 2100811 & 2487444 & 0,84 \\
\hline DICIEMBRE & 2129698 & 2648123 & 0,80 & 2513153 & 3182249 & 0,79 \\
\hline TOTALES & 26411725 & 31949035 & 0,83 & 27481975 & 33522758 & 0,82 \\
\hline $\begin{array}{c}\text { PROMEDIO } \\
\text { MES }\end{array}$ & 2200977 & 2662420 & & 2290165 & 2793563 & \\
\hline $\begin{array}{c}\text { \% CREC } \\
\text { PROM. }\end{array}$ & $-4 \%$ & $-5 \%$ & $1 \%$ & $25 \%$ & $20 \%$ & $4 \%$ \\
\hline
\end{tabular}

Fuente: Agrodata, (2017).

\subsection{Objetivos de la investigación}

\subsubsection{Objetivo general}

Determinar la viabilidad de mercado, tecnológica, económica, financiera y social para la instalación de una planta productora de papa amarilla precocida y prefrita congelada para el consumo masivo.

\subsubsection{Objetivos específicos}

- Determinar la aceptación y la intención de compra de la papa amarilla precocida y prefrita congelada en Lima.

- Encontrar un proceso productivo eficiente de bajo costo y amigable con el medio ambiente.

- Demostrar la factibilidad económica - financiera del proyecto, considerando las condiciones del mercado existente y la tecnología disponible.

- Demostrar la viabilidad social de la instalación de una planta procesadora de papa amarilla precocida y prefrita congelada.

\subsection{Alcance de la investigación}

\subsubsection{Alcance geográfico}

La venta de productos estará enfocada a la ciudad de Lima en la que, según el INEI (2016) desde el 2015, residen más de 10 millones de ciudadanos. 


\subsubsection{Mercado}

Serán vendidos a los segmentos A y B de la ciudad de Lima Metropolitana, que según CPI (2016) son alrededor de 2,4 millones de personas, a través de los Supermercados y bodegas.

\subsection{Justificación del tema}

\subsubsection{Técnica}

Los productos por elaborar son papa amarilla precocida y prefrita congelada. El proceso de producción es mayoritariamente físico, por ello se aplicará una línea continua que requerirá equipos para el lavado, pelado, cortado, precocción, freído y congelado los cuales se pueden conseguir en el Perú.

Para el proyecto se tomará en cuenta las normas técnicas peruana y algunas internacionales:

- NTP 011.119 2010: Definiciones y requisitos de la papa.

- NTP 209.038: Relacionado al etiquetado de alimentos.

- NTS N. ${ }^{\circ}$ 071. 2008 MINSA/DIGESA: norma que establece los criterios y limites microbiológicos de calidad sanitaria e inocuidad en los alimentos.

- NTC 4481: norma técnica colombiana sobre papas prefritas congeladas.

- CODEX STAN 114-1981: norma internacional para las papas fritas congeladas

- USDA: Norma de color.

\subsubsection{Económica}

Existen muchos factores que permitirán que el proyecto sea factible económica y financieramente. El primer factor es el incremento del $14 \%$ de las importaciones promedio mensuales en el primer semestre del 2016. Otro factor importante es el menor precio de la papa amarilla que junto con el boom de la gastronomía peruana permitirá venderlos a un precio que pueda competir con la papa importada (el precio de la papa importada está a \$ 0,82 dólares y la papa amarilla varía de 0,5 a $5 \mathrm{~S} / \mathrm{kg}$ ). 


\subsubsection{Social}

En el aspecto social se apoyará a los pobladores de los lugares más pobres del país como Puno donde, según el INEI (2016), 145680 productores están dedicados al cultivo de papa, o también Cajamarca donde 92350 también se dedican a su cultivo. Además, se podrá ayudar a las comunidades quechua hablantes que tienen a su cargo el " $47,8 \%$ de la superficie sembrada" (Minagri, 2016).

\subsubsection{Hipótesis de trabajo}

La instalación de una planta dedicada a la producción de papa precocida y prefrita congelada es tecnológica, económica, financiera y socialmente viable ya que existe un mercado que va a aceptar el producto.

\subsection{Marco referencial}

Para la elaboración de este estudio de prefactibilidad se hará uso de los siguientes trabajos:

- Burga Alarcón, Luis Miguel (1998). "Estudio de prefactibilidad para la implementación de una planta procesadora de papa prefritas congeladas”. Universidad de Lima. Lima, Perú.

La tesis presentada se utilizará como referencia en el proceso, tamaño, distribución y capacidad de planta. En cuanto a las diferencias, las más obvia es que al ser antigua tiene datos de mercado y tecnología que ya no tiene relevancia, y también el insumo principal.

- Giraldo, Claudia María (2009). "Estudio de prefactibilidad para el montaje de una planta procesadora de papa criolla de carácter mixto en el departamento de Cundinamarca". Colombia.

En este estudio de prefactibilidad se puede encontrar las etapas del proceso productivo, balance de materia y la viabilidad de la línea del proceso. En cuanto a las diferencias se puede notar, la distinta realidad y mercado con lo que se hizo este estudio y los datos están desactualizados (datos internacionales sobre otros países). 
- Moscoso Vergara, Daniela Miroslava (2010). "Elaboración de un plan de marketing para la corporación CODESTAAE de la provincia de CARCHI, para la comercializar el producto pre procesado, papa bastón, en el sector centro norte de QUITO”. Universidad Internacional SEK. Quito, Ecuador.

En esta tesis los planes de marketing usados para la papa prefrita pueden ser tomados como referencia, aunque fueran hechos en base a la realidad ecuatoriana. Lo importante de esta tesis son las preguntas del estudio de mercado y las estrategias de posicionamiento y se explica brevemente el proceso de producción. En cuanto a las diferencias, la más obvia es que ha sido hecho en otro país y que el consumidor no es el mismo en el Perú.

\subsection{Marco conceptual}

La papa tiene una serie de micronutrientes importantes para el ser humano, entre los principales se encuentra el niacina, tiamina, riboflavina.

- Escaldado: Consiste en cocer los alimentos en agua hirviendo durante un corto tiempo y tiene por finalidad la inactivación de las enzimas del alimento.

- Niacina: es esencial para el sistema digestivo, la piel, el sistema nervioso y convierte los alimentos en energía.

- Riboflavina: tipo de vitamina B esencial para el crecimiento corporal y la creación de glóbulos rojos y está presente al liberar energía de los carbohidratos.

- Tiamina: tipo de vitamina B, que ayuda a transformar el carbohidrato en energía para suministrarlo a todo el cuerpo, principalmente para el cerebro y el sistema nervioso. 


\section{CAPÍTULO II: ESTUDIO DE MERCADO}

\subsection{Aspectos generales del estudio de mercado}

\subsubsection{Definición comercial del producto}

- Producto básico: el producto básico es la papa amarilla en forma de bastón precocida y prefrita.

- Producto real: la papa es una fuente de energía, tiene alto contenido de carbohidratos, mediana concentración de vitaminas C, antioxidantes, ácido fólico, hierro, entre otros; que ayudan a que el cuerpo realice todas sus actividades.

Siguiendo las indicaciones de las normas técnicas peruanas, se usarán empaques termocontraibles cerrados al vacío, lo que le permitirá al producto mantenerse en buenas condiciones hasta por 4 meses congelado que es el tiempo promedio que duran las papas importadas. La caja contendrá 10 kilogramos divididos en 20 bolsas de 500 gramos. Además, en el empaque se encontrará la información nutricional, la fecha de vencimiento, el registro sanitario y los datos de la empresa.

- Producto aumentado: ambos productos podrían ser exportados llevando la marca Perú, pues son productos peruanos. Además, se podrían tener otras versiones como snacks y formas como ondulada y con diferentes condimentos (ají, huancaína, etc.) para agradar el paladar del cliente en el futuro. También tendrán nuevas presentaciones y tamaños. Finalmente se contará con un servicio postventa para recibir reclamo y sugerencias de los clientes.

\subsubsection{Usos del producto, bienes sustitutos y complementarios}

\subsubsection{Usos y características del producto}

La papa amarilla prefrita es el acompañamiento ideal del pollo a la brasa, lomo saltado, entre otros platos. Para el caso de la papa precocida es para ser usada en distintas dietas o platos típicos como la papa a la huancaína. 


\subsubsection{Bienes sustitutos y complementarios}

Algunos de los productos que pueden ser sustitutos son las papas pre fritas importadas y el camote frito tipo bastón (se sirve en algunos locales de Lima). Pueden ser acompañadas por cremas, las sopas y ensaladas.

\subsubsection{Determinación del área geográfica que abarcará el estudio}

El área geográfica que comprenderá el proyecto será Lima Metropolitana. Según el CPI (2016) el total de habitantes es de 10269613 (donde la mayoría de las viviendas pertenecen a los sectores económicos $\mathrm{C}$ y D).

\subsubsection{Análisis del sector industrial.}

- Amenaza de nuevos ingresos: en el Perú existen muchas empresas con una economía de escala grande como es el caso de Alicorp, Delosi y Bembos (cada uno importa cerca de 7500,1590 y 640 toneladas respectivamente en lo que va del año 2016).

Una barrera de ingreso es el difícil acceso a distribuidores, debido a que al existir muchas empresas grandes (algunas de ellas tienen su propia empresa distribuidora), tienen alianzas con varios distribuidores para que solo se transporte sus productos o también se puede dar el caso que a los distribuidores les conviene hacer negocios con ellos. Sin embargo, el requisito de capital es bajo ya que al ser un proceso sencillo y de maquinaria no muy especializada. Por lo tanto, es alta.

- Poder de negociación de los clientes: los clientes son los intermediarios entre el consumidor y la empresa y estos son los supermercados. Estas empresas al tener muchos establecimientos y alianzas estratégicas con los principales importadores de papa prefrita tienen mucho poder de negociación. Por lo que su poder es muy alto.

- Amenaza de productos sustitutos: los productos sustitutos de las papas prefritas y precocidas, son camote y la yuca frita o cocida y la papa natural. Pero, al no ser muy llamativos, y además no ser ofrecidos en los restaurantes en general, no son una amenaza importante. Por otro lado, nuestro producto 
es muy diferente al del importado debido a que es con papa amarilla cosechada en los valles bajos del Perú. En conclusión, la amenaza es media.

- Poder de negociación de los proveedores: los proveedores (agricultores) tienen un poder de negociación alto, ya que existe mucha demanda por parte de los mayoristas que luego estos venden a los mercados y supermercados, por otra parte, al no haber muchas empresas productoras de papa prefrita o precocida en el Perú, el sector no es un cliente importante y existiría la posibilidad de que se integren hacia adelante por ser un proceso sencillo y de baja inversión.

Actualmente el Perú es el primer productor de papa en Latinoamérica produciendo más de 4,5 millones de toneladas al año según Carrasco (2016), por lo que al no haber una planta de producción conocida de papas prefritas o precocida, en consecuencia, su poder es alto.

- Rivalidad entre los actuales competidores: en el Perú actualmente existen 16 empresas dedicadas a la importación de papas prefritas, los principales competidores son Alicorp, Mrc Excel, Delosi, Oregon Foods, entre otros; por lo que su participación en el mercado local es muy alta casi el 100\%. Y cada año van importando más, lo que significa que cada año tienen más demanda. Un ejemplo de esto es MRC EXCEL S.A.C que en el año 2015 importó 264\% más que el año 2014 en kilos (Agrodata). Véase la Tabla 2.1. En consecuencia, la rivalidad es alta.

Tabla 2.1

Importación de papas preparadas por empresa.

\begin{tabular}{|c|c|c|c|c|c|}
\hline Año & $\begin{array}{c}\text { ALICORP } \\
(\mathrm{kg})\end{array}$ & $\begin{array}{c}\text { DELOSI } \\
(\mathrm{kg})\end{array}$ & $\begin{array}{c}\text { MRC EXCEL } \\
(\mathrm{kg})\end{array}$ & $\begin{array}{c}\text { OREGON FOODS } \\
(\mathrm{kg})\end{array}$ & $\begin{array}{c}\text { BEMBOS } \\
(\mathrm{kg})\end{array}$ \\
\hline 2013 & 8560 & 2680 & 838 & 1877 & 1293 \\
\hline 2014 & 10260 & 3802 & 1488 & 2189 & 888 \\
\hline 2015 & 11903 & 4323 & 4155 & 1887 & 1357 \\
\hline
\end{tabular}

Fuente: AgroData Perú, (2016). 


\subsubsection{Metodología a emplear en la investigación de mercado}

\subsubsection{Fuentes primarias}

Para desarrollar el proyecto mencionado se hará uso de las siguientes fuentes primarias:

- Encuestas con preguntas sobre la intención e intensidad de compra, el precio que podrá pagar el cliente por el producto, entre otros.

- Se hará un focus groups para conocer qué piensan sobre el producto desde la presentación hasta el sabor y entrevistas a expertos.

\subsubsection{Fuentes secundarias}

- INEI: se usará esta base de datos porque contiene información estadística importante oficial del estado peruano sobre la población, producción y sembrado de papa.

- Euromonitor: Se usará esta base de datos debido a que contiene vital información del mercado. Se buscará información sobre la cuota de mercado de la competencia, cómo ha crecido el mercado, entre otros.

- Veritrade y Datatrade: se utilizará estas 2 bases de datos porque brindarán información importante para hallar la demanda del mercado. Estas bases de datos proporcionarán información sobre el número de papas importadas.

- Anuario de la Minagri: se utilizarán porque tienen información importante sobre los cultivos, rendimientos, precios y superficie cosechada a nivel nacional. De esta base de dato se buscará información sobre la papa amarilla con la finalidad más sobre ella.

\subsection{Análisis de la demanda}

\subsubsection{Demanda histórica}

Debido a que hay una gran demanda de papa prefrita a nivel nacional, se desarrollará el análisis de la demanda históricos. 


\subsubsection{Importaciones/exportaciones}

\section{Exportaciones}

No se exporta papa prefrita ni precocida ya que no existe este tipo de negocio.

Importación

Se tomó en cuenta la partida arancelaria 2004100000 correspondiente a "papas (patatas), preparadas y conservadas en vinagre/acético y congeladas". A continuación, se presenta las importaciones en toneladas métricas de los últimos 5 años (2013 al 2017). No existen importaciones de papas precocidas.

Tabla 2.2

Importaciones de la papa prefrita (ton)

\begin{tabular}{|c|c|}
\hline Año & Importaciones de papa prefrita (ton) \\
\hline 2013 & 19942,4 \\
\hline 2014 & 23870,6 \\
\hline 2015 & 27960,3 \\
\hline 2016 & 33522,8 \\
\hline 2017 & 31949,0 \\
\hline
\end{tabular}

Fuente: adaptado de SUNAT, (2018).

\subsubsection{Producción nacional}

Existen muy pocas empresas dedicadas a la producción de papas precocidas y prefritas, por lo que considerará no importante para el cálculo de la DIA al ser insignificante en comparación con la importación.

\subsubsection{Demanda interna aparente (DIA)}

La fórmula para hallar DIA será:

\section{DIA = Producción + Importación - Exportación}

En los puntos anteriores se determinó la importación de la papa prefrita de los últimos cinco años y que no existe exportación de papa prefrita, por lo que se halló la siguiente DIA: 


\section{Tabla 2.3}

Demanda interna aparente de la papa prefrita (ton)

\begin{tabular}{|c|c|c|}
\hline Año & Importaciones de papa prefrita (ton) & DIA de la papa prefrita (ton) \\
\hline 2013 & 19942,4 & 19942,4 \\
\hline 2014 & 23870,6 & 23870,6 \\
\hline 2015 & 27960,3 & 27960,3 \\
\hline 2016 & 33522,8 & 33522,8 \\
\hline 2017 & 31949,0 & 31949,0 \\
\hline
\end{tabular}

Fuente: adaptado de SUNAT, (2018).

\subsubsection{Demanda potencial}

\subsubsection{Patrones de consumo}

Según el INEI (2016), Lima crece a una razón de 1,3\% anualmente. Al ser un producto no estacional, no sufrirá ningún tipo de factor estacional.

Por otro lado, en los últimos años, la gastronomía peruana ha ido ganando premios internacionales como Perú Travel:

- Mejor destino gastronómico otorgado por la destacada revista Top Travel de China.

- Mejor destino culinario del año otorgado en World Travel Awards coronó por quinta vez consecutivamente en el 2017.

Todos estos premios han logrado que haya un aumento en el consumo de la comida peruana. Y siendo más específico sobre el pollo a la brasa; en el año 2004 fue considerado patrimonio de la Nación y en el año 2010 se declaró mediante resolución ministerial que el tercer domingo de junio sea el día del pollo a la brasa. Gracias a esto ha impulsado las ventas del pollo y por ende el consumo de papas fritas al ser su acompañante preferido.

\subsubsection{Determinación de la demanda potencial}

Para la determinar la demanda potencial se tomará en cuenta el consumo per cápita de papa congelada en Argentina. Además, se considerará que el consumo de las papas prefritas aumentó en relación directa con el aumento de la población. La población de Lima metropolitana ha crecido 6,5\% desde el año 2011 al año 2015. La Tabla 2.4 presenta los datos de la demanda potencial en base al patrón de consumo elegido. 
Tabla 2.4

Demanda potencial en base a patrón de consumo

\begin{tabular}{|c|c|c|c|}
\hline Años & $\begin{array}{c}\text { Consumo } \\
\text { Per } \\
\text { Cápita }\end{array}$ & $\begin{array}{c}\text { Población total de Lima } \\
\text { Metropolitana }\end{array}$ & Demanda potencial \\
\hline 2011 & 1,3 & 8348403 & 10852924 \\
\hline 2015 & 1,45 & 8890792 & 12891648 \\
\hline
\end{tabular}

Fuente: adaptado de WordPress (2015).

\subsubsection{Demanda mediante fuentes primarias}

\subsubsection{Diseño y aplicación de encuestas u otras técnicas.}

En el anexo 1 y 2 se encuentra la encuesta realizada que consta de 5 preguntas, donde el objetivo de cada una es recopilar la mayor información del cliente para ofrecer un mejor producto y servicio.

Lo que se busca determinar con las preguntas propuestas es la frecuencia que consume papas cocidas o fritas, la intención de compra, información sobre el precio al cual se deberá vender el producto y su intensidad de compra.

El método matemática a emplear para hallar el tamaño de la muestra será:

La encuesta se hará a personas que viven en los distritos de Lima Moderna con un intervalo de confianza de $90 \%$, un margen de error de $10 \%$, un p y q de 0,5 . Como consecuencia, se halló que el tamaño de muestra es 68 . Luego de tomar la encuesta, se encontró que:

$$
\frac{\frac{z^{2} \times p(1-p)}{e^{2}}}{1+\left(\frac{z^{2} \times p(1-p)}{e^{2} N}\right)}
$$

- El promedio de intensidad e intención de compra fue afirmativa con 76\%, y $67 \%$ respectivamente, donde la demanda que se obtendrá para el proyecto es de $51 \%$.

\subsubsection{Determinación de la demanda del proyecto}

La demanda del proyecto tomará en cuenta el resultado de la encuesta y la distribución de los NSE del Perú. 
Tabla 2.5

Cantidad de habitantes y distribución de los NSE en Lima

\begin{tabular}{|c|c|c|c|c|}
\hline NSE & $\begin{array}{c}\text { LIMA } \\
\text { METRO. }\end{array}$ & $\%$ & $\begin{array}{c}\text { LIMA } \\
\text { MODERNA }\end{array}$ & $\%$ \\
\hline NSE A & 3078 & $3,7 \%$ & 2846 & $32,2 \%$ \\
\hline NSE B & 10116 & $12,2 \%$ & 4651 & $52,6 \%$ \\
\hline NSE C & 28300 & $34,1 \%$ & 1164 & $13,2 \%$ \\
\hline NSE D & 28357 & $34,2 \%$ & 131 & $1,5 \%$ \\
\hline NSE E & 13065 & $15,8 \%$ & 45 & $0,5 \%$ \\
\hline Total & 82916 & $100 \%$ & 8837 & $100 \%$ \\
\hline
\end{tabular}

\begin{tabular}{|c|c|c|}
\hline $\begin{array}{c}\text { Habitantes y } \\
\text { Manzanas }\end{array}$ & $\begin{array}{c}\text { Lima } \\
\text { Metropolitana }\end{array}$ & $\begin{array}{c}\text { Lima } \\
\text { Moderna }\end{array}$ \\
\hline Total de Habitantes & 9893245 & 1273377 \\
\hline $\begin{array}{c}\text { \% respecto al total } \\
\text { de habitantes }\end{array}$ & $100 \%$ & $12,9 \%$ \\
\hline $\begin{array}{c}\text { Total de manzanas } \\
\text { de viviendas }\end{array}$ & 82916 & 8837 \\
\hline $\begin{array}{c}\% \text { respecto al Total } \\
\text { de manzanas }\end{array}$ & $100 \%$ & $10,7 \%$ \\
\hline
\end{tabular}

Fuente: adaptado de WordPress (2015).

\subsubsection{Proyección de la demanda}

Se empleará una regresión potencial debido a que es el mejor que representa el comportamiento de los datos con una correlación $\left(\mathrm{R}^{2}\right)$ de 0,948 . La ecuación para la proyección de la DIA (demanda interna aparente) se presenta a continuación:

$$
y=19694 x^{0,3281}
$$

Con la ecuación presentada, se calculó la demanda de papa amarilla prefrita para los siguientes cinco años. En la Tabla 2.6 se presenta la demanda proyectada de la papa prefrita.

Tabla 2.6

Demanda proyectada de la papa prefrita

\begin{tabular}{|c|c|}
\hline Año & Demanda proyectada de la papa amarilla prefrita (ton.) \\
\hline 2018 & 35452,38 \\
\hline 2019 & 37291,56 \\
\hline 2020 & 38961,69 \\
\hline 2021 & 40496,82 \\
\hline 2022 & 41921,22 \\
\hline
\end{tabular}

Fuente: adaptado de SUNAT, (2018). 


\subsubsection{Consideraciones sobre la vida útil del proyecto}

El proyecto tendrá una vida útil inicial de 5 años. En los primeros años del proyecto, se hará un control de diversos indicadores como volumen de ventas, cantidad de nuevos clientes, ratios financieras, gastos de publicidad y marketing, costo de la materia prima, etc., con la finalidad de hacer los ajustes o cambios necesarios para un mejor desarrollo del proyecto.

\subsection{Análisis de la oferta}

\subsubsection{Empresas productoras, importadoras y comercializadoras}

Las principales empresas importadoras del sector son:

- Alicorp S.A.A RUC 20100055237 con su producto: El cocinero.

- Delosi S.A RUC 20100123330 con su producto: Farm Frites

- Oregon Foods S.A.C RUC 20503727405 con su producto: Lambweston

- MRC EXCEL S.A.C RUC 20427339034 con su producto: Lutosa

\subsubsection{Competidores actuales y potenciales}

En el mercado actual, los principales importadores de las papas prefritas son Alicorp, Delosi, Oregon Foods y MRC Excel (tienen 69\% entre los 3). En la Figura 2.1 se mostrará la participación de mercado de las empresas de este sector.

Figura 2.1

Participación de mercado

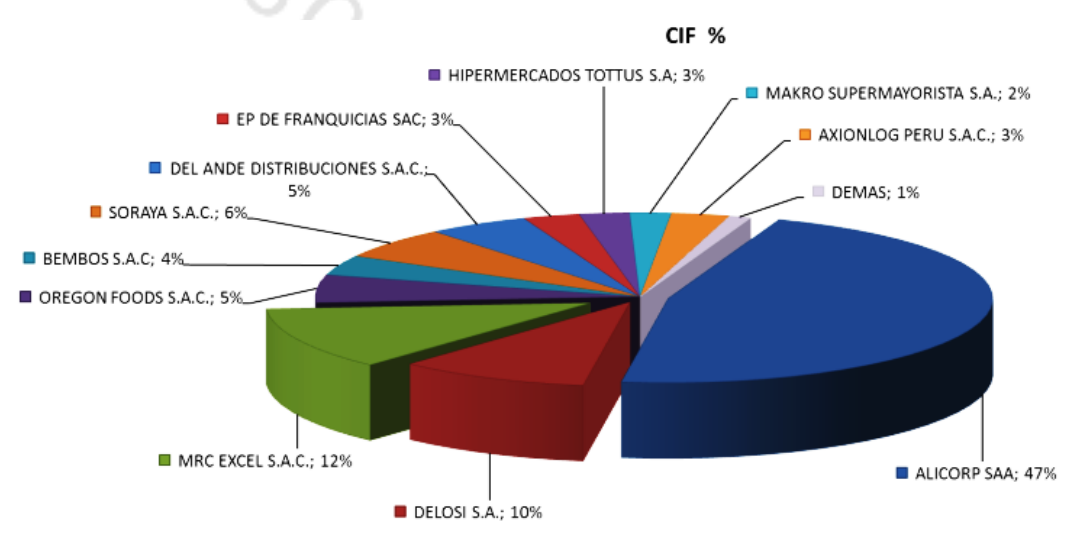

Fuente: Agrodata, (2016). 


\subsection{Determinación de la Demanda para el proyecto}

\subsubsection{Segmentación del mercado}

Para la definición del mercado meta se tendrá en cuenta estas segmentaciones:

- Geográfica: las papas prefritas se venden a nivel nacional en supermercados. Para el propósito del trabajo de investigación el área geográfica que se analizara es Lima.

- Demográfica: nos consumidores de las papas precocidas y prefritas son todas las personas que gustan de la papa tanto cocida como frita. Según el INEI, en Lima hay más de 9 millones de personas.

- Psicográfica: para esta segmentación el consumidor es del nivel socioeconómico A y B ya que al tener poco tiempo para prepararlos prefiere estos productos ya que se logran cocer o freír rápidamente y tienen el dinero para comprarlos.

- Conductual: la mayoría de los consumidores (personas y restaurantes) buscan con este producto que sea rápido, económico y de calidad.

- Tecnológica: En el mercado peruano existen 2 tipos principales de papas precocidas o prefritas:

$\checkmark \quad$ Las importadas son las que más se consumen y venden en el país por ser rápidas al freírse.

$\checkmark$ Las nacionales se consumen y venden poco comparado con las importadas, en cuanto a sus características el tiempo que se demora en freírse no difiere tanto de las otras, pero las nacionales son más económicas.

\subsubsection{Selección de mercado meta}

El mercado meta se definirá a continuación con el propósito de hallar la demanda del proyecto:

Son todas las personas que pertenecen al NSE A y B, que viven en Lima moderna y les gusta comprar y consumir productos peruanos. 
Para la demanda del proyecto se tomará el resultado de la encuesta realizada y el mercado meta los siguientes porcentajes:

- El 32\% de la población del Perú vive en Lima Metropolitana.

- El 12,9\% de Lima Metropolitana pertenecen a Lima Moderna, del cual el 84,9\% pertenece al NSE A y B.

\subsubsection{Demanda Específica para el Proyecto}

Se utilizará lo hallado en la Tabla 2.6 y los porcentajes obtenidos anteriormente y la encuesta.

Dem. proyecto $=$ Dem. proyectada $\times 32 \% \times 12,9 \% \times 84,9 \% \times 51 \%$

Tabla 2.7

Demanda del proyecto de la papa amarilla precocida y prefrita

\begin{tabular}{|l|l|l|l|l|l|l|}
\hline Año & $\begin{array}{l}\text { Demanda } \\
\text { Proyectada } \\
\text { (ton) }\end{array}$ & $\begin{array}{l}\text { Lima } \\
\text { Metropolitana } \\
\text { (ton) } \\
\mathbf{3 2 \%}\end{array}$ & $\begin{array}{l}\text { Lima } \\
\text { Moderna } \\
\text { (ton) } \\
\mathbf{1 2 , 9 \%}\end{array}$ & $\begin{array}{l}\text { NSE A y } \\
\text { B (ton) } \\
\mathbf{8 4 , 9 \%}\end{array}$ & $\begin{array}{l}\text { Encuesta } \\
\text { (ton) } \\
\mathbf{5 1 \%}\end{array}$ & $\begin{array}{l}\text { Demanda del } \\
\text { Proyecto } \\
\text { (Unidades) }\end{array}$ \\
\hline 2018 & 3545,24 & 1134,48 & 146,35 & 124,10 & 63,29 & 126585 \\
\hline 2019 & 3729,16 & 1193,33 & 153,94 & 130,54 & 66,58 & 133152 \\
\hline 2020 & 3896,17 & 1246,77 & 160,83 & 136,39 & 69,56 & 139115 \\
\hline 2021 & 4049,68 & 1295,90 & 167,17 & 141,76 & 72,30 & 144597 \\
\hline 2020 & 4192,12 & 1341,48 & 173,05 & 146,75 & 74,84 & 149683 \\
\hline
\end{tabular}

Elaboración Propia

\subsection{Definición de la estrategia de comercialización}

\subsubsection{Políticas de comercialización y distribución}

Tendrá como puntos base lo siguiente:

- La distribución del producto es mayorista.

\subsubsection{Publicidad y promoción}

Se usarán varias estrategias de promoción con la finalidad de atraer clientes y ganar una cuota de mercado. Primero, al ser un proyecto que recién empieza se usarán las redes sociales, página web, afiches web, etc.

Las estrategias que se usarán son la venta personal, promoción de ventas y estrategias de empujar. Al ser un mercado muy competitivo, una manera de ganar 
mercado es mediante estrategias de publicidad y promoción ya mencionadas anteriormente, ya que con solo el producto no es suficiente porque siempre hay la posibilidad de una guerra de precios (mediante ofertas agresivas por la competencia).

\subsubsection{Análisis de precios}

\subsubsection{Tendencia histórica de los precios}

En la Figura 2.4 se observa que el precio de la papa amarilla ha aumentado en los últimos años, lo que puede interpretarse que la papa amarilla tiene mucha demanda. Al no contar con los precios históricos de papa prefrita y precocida que se vende en el mercado peruano, se tomará en cuenta estos precios por ser la materia prima del producto a elaborar.

Figura 2.2

Tendencia de precios de la papa 2000-2013

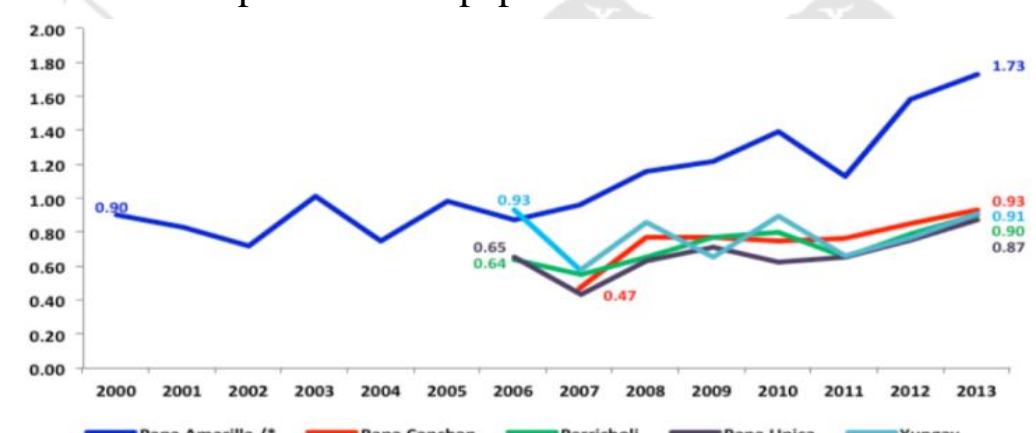

/* Incluye tumbay, tornillo y otros

Fuente: Minagri-OEE, (2013)

\subsubsection{Precios actuales}

En el Perú, se importan muchas papas prefritas, pero al hacer la mayoría de ellos para mercado de negocios se desconoce los precios, para efectos de la investigación se tomarán los precios actuales de las papas prefritas que se venden en los supermercados como Plaza Vea, Metro, etc.

- Papas "El cocinero": 9 soles

- Papa Prefrita congelada Canchan "Bell's":10,99 soles

- Papa Prefrita congelada Canchan con cáscara "Bell's":11,99 soles 


\subsubsection{Estrategia de precio}

Para el precio se usará una estrategia de diferenciación, esto quiere decir que el producto entrará al mercado con un precio más alto que los demás.

La estrategia de precios estará orientada a la competencia con el propósito de lograr diferenciarse con un precio alto, y transmitir al cliente una imagen de calidad y exclusividad además de promover el consumo de productos peruanos a fin de captar los segmentos del mercado meta.

Con lo descrito anteriormente, el precio de las papas amarillas prefritas será de S/16 el primero año y los siguientes años se disminuirá $5 \%$ anual para obtener más clientes.

\subsection{Análisis de Disponibilidad de los insumos principales}

\subsubsection{Características principales de la materia prima}

- Tubérculo oval-alargado, con color de piel amarillo.

- Origen peruano, procedente de la sierra.

- Textura ligeramente casposa.

- Contiene betacaroteno (pigmento que provee gran cantidad de vitamina A).

\subsubsection{Disponibilidad de la materia prima}

En la Tabla 2.8 se observa que, en los últimos años, la producción de papa ha aumentado, debido principalmente al apoyo del gobierno en los departamentos que cosechan este tubérculo. Según datos del Minagri, la producción de papa se ha incrementado 19\% desde el 2010, por lo que se puede deducir que cada año habrá más materia prima. Por lo que, su disponibilidad no será un limitante en el proyecto.

Tabla 2.8

Producción nacional de papa

\begin{tabular}{|c|c|c|c|c|c|}
\hline $\begin{array}{c}\text { Producción } \\
\text { (ton) }\end{array}$ & $\mathbf{2 0 1 0}$ & $\mathbf{2 0 1 1}$ & $\mathbf{2 0 1 2}$ & $\mathbf{2 0 1 3}$ & $\mathbf{2 0 1 4}$ \\
\hline Papa & 3805,5 & 4067,5 & 4473,5 & 4569,6 & 4704,5 \\
\hline
\end{tabular}

Fuente: adaptado de INEI, (2016). 


\subsubsection{Costos de la materia prima}

La tendencia del costo de la materia se ha mantenido bajo en los últimos años debido al mayor consumo de las papas en las familias.

Figura 2.3

Tendencia de precios de la papa amarilla septiembre - diciembre 2017

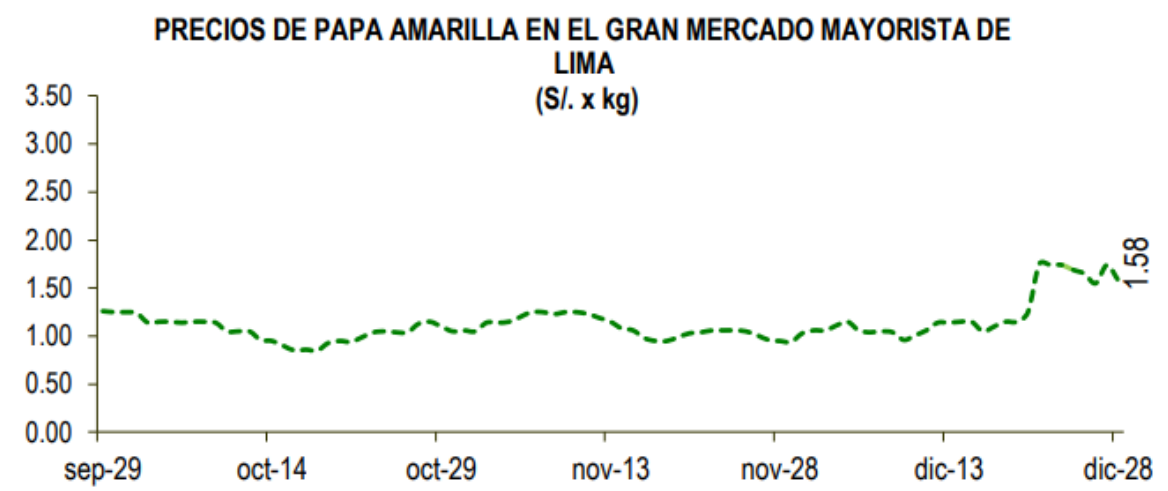

Fuente: Minagri, (2017). 


\section{CAPÍTULO III: LOCALIZACIÓN DE LA PLANTA}

\subsection{Identificación y análisis detallado de los factores de localización}

- Materia prima: se comprará se cosecha en la sierra y produce todo el año, no obstante, en abril y mayo son los meses donde más producen. Según datos del Minagri del 2016, el volumen que se comercializa, por ejemplo, en el mercado central de Lima, supera ampliamente la necesidad de materia prima proyectada. El precio de la papa amarilla se encuentra alrededor en 3,25 S/ $\mathrm{kg}$ en Lima.

- Disponibilidad de terreno: es importante, ya que se dispone de un presupuesto limitado. Entonces, se debe esperar que terreno sea lo más económico posible.

- Cercanía al mercado: cumple un rol importante, ya que de esta derivan costos como los fletes, pérdida de valor de productos y otros.

- Suministro de agua: el lavado de las papas necesita agua, por tanto, se debe evaluar el costo por su consumo

- Trata de desechos: la planta requiere de empresas para tratar o gestionar los desechos de la producción, y apoyar al cuidado del medio ambiente.

\subsection{Identificación y descripción de las alternativas de localización}

Las alternativas para la macro localización son Huancayo, Cusco y Lima.

\section{Huancayo}

La ciudad de Huancayo cuenta con áreas de cosecha de papa, además, se encuentra a aproximadamente, 360 kilómetros de Lima. Adicionalmente, tiene bastantes terrenos disponibles y a bajo precio. Cuenta con una red de agua limitada, por lo que la planta necesitaría de reservorios para poder operar y no existen empresas dedicadas a la trata de desechos. 


\section{$\underline{\text { Cusco }}$}

Cusco tiene una gran producción de papa, cuenta con los servicios básicos, pero está alejado del mercado objetivo y al igual que Huancayo no existen empresas dedicadas al manejo de desechos.

\section{Lima}

Lima cuenta con todos los servicios necesarios y a pesar de que no cuenta con áreas de producción, la papa llega a los mercados lo que provoca sobrecostos de la materia prima y gracias a que la producción es constante debido a que se siembra por lotes para asegurar que haya papa todo el año, según productores de papa. Además, es donde se encuentra nuestro mercado objetivo, por lo que es tiene una ventaja importante.

\subsection{Evaluación y selección de localización}

\subsubsection{Evaluación y selección de macrolocalización}

Tabla 3.1

Factores de macrolocalización

\begin{tabular}{|l|l|}
\hline A & Materia prima \\
\hline B & Disponibilidad de terreno \\
\hline C & Cercanía al mercado \\
\hline D & Suministro de agua \\
\hline E & Infraestructura Industrial \\
\hline
\end{tabular}

Elaboración Propia

A continuación, se presenta el ranking de factores para la macrolocalización, donde el ganador es el departamento de Lima con 9,15 puntos.

Tabla 3.2

Ranking de factores para macrolocalización

\begin{tabular}{|c|c|c|c|c|c|c|}
\hline & A & C & D & E & Conteo & $\begin{array}{c}\text { Puntaje para } \\
\text { Macro }\end{array}$ \\
\hline A & & 1 & 1 & 1 & 3 & $42,7 \%$ \\
\hline C & 0 & & 1 & 1 & 2 & $28,7 \%$ \\
\hline D & 0 & 0 & & 1 & 1 & $14,3 \%$ \\
\hline E & 0 & 1 & 0 & & 1 & $14,3 \%$ \\
\hline
\end{tabular}


Tabla 3.3

Tabla de enfrentamiento de macrolocalización

\begin{tabular}{|c|c|c|c|c|c|c|c|}
\hline & & & & & & & \\
\hline & Ponder. & Calif. & Punt. & Calif. & Punt. & Calif. & Punt. \\
\hline A & $42,7 \%$ & 10 & 4,27 & 10 & 4,27 & 8 & 2,56 \\
\hline $\mathrm{C}$ & $28,7 \%$ & 8 & 2,3 & 4 & 1,15 & 10 & 2.87 \\
\hline $\mathrm{D}$ & $14,3 \%$ & 6 & 0,86 & 8 & 1,14 & 10 & 1,43 \\
\hline $\mathrm{E}$ & $14,3 \%$ & 6 & 0,86 & 4 & 0,57 & 10 & 1,43 \\
\hline & TOTAL & 4 & 8,28 & & 7,1 & & 9,15 \\
\hline
\end{tabular}

Elaboración Propia

\subsubsection{Evaluación y selección de microlocalización}

Para evaluar la microlocalización se ha elegido 3 distritos con áreas industriales: Ate, Lurín y Chorrillos. En la tabla 3.4 y 3.5, se muestra el ranking de factores.

Tabla 3.4

Ranking de factores para microlocalización

\begin{tabular}{|c|c|c|c|c|c|c|}
\hline & A & B & D & E & Conteo & $\begin{array}{c}\text { Puntaje para } \\
\text { Macro }\end{array}$ \\
\hline A & & 1 & 1 & 1 & 3 & $42,7 \%$ \\
\hline B & 0 & & 1 & 1 & 2 & $28,7 \%$ \\
\hline D & 0 & 0 & & 1 & 1 & $14,3 \%$ \\
\hline E & 0 & 1 & 0 & & 1 & $14,3 \%$ \\
\hline
\end{tabular}

Elaboración Propia

Tabla 3.5

Tabla de enfrentamiento de microlocalización

\begin{tabular}{|c|c|c|c|c|c|c|c|}
\hline \multicolumn{2}{|c|}{} & \multicolumn{2}{c|}{ Ate } & \multicolumn{2}{c|}{ Lurín } & \multicolumn{2}{c|}{ Chorrillos } \\
\hline & Ponder & Calif & Punt & Calif & Punt & Calif & Punt \\
\hline A & $42,7 \%$ & 10 & 4,27 & 6 & 2,56 & 6 & 2,56 \\
\hline B & $28,7 \%$ & 4 & 1,15 & 10 & 2,87 & 8 & 2,30 \\
\hline D & $14,3 \%$ & 8 & 1,14 & 6 & 0,86 & 8 & 1,14 \\
\hline E & $14,3 \%$ & 10 & 1,43 & 6 & 0,86 & 8 & 1,14 \\
\hline & Total & & 7,99 & & 7,15 & & 7,15 \\
\hline
\end{tabular}

Elaboración Propia

Por lo tanto, la planta se ubicará en Ate con un total 7,99 puntos. 


\section{CAPÍTULO IV: TAMAÑO DE PLANTA}

\subsection{Relación tamaño-mercado}

Se considera el factor mercado como un elemento importante debido a que se deberá verificar que la demanda no sea inferior a esta, en caso contrario, no se aceptaría el proyecto. Más adelante, se mostrará la demanda del proyecto de los dos productos que previamente ha sido evaluada en el capítulo 2.4, el cual indicará el tamaño que deberá tener la planta.

\section{Tabla 4.1}

Demanda de papa precocida y prefrita proyectada

\begin{tabular}{|c|c|c|c|}
\hline Año & D.I.A (ton) & Demanda del proyecto (ton) & Demanda del proyecto (unid.) \\
\hline 2022 & 41921,22 & 86,59 & 173188 \\
\hline
\end{tabular}

Fuente: adaptado de SUNAT, (2018).

En conclusión, el tamaño de planta será menor o igual que la demanda para el proyecto, tomando como base el año 2022; es decir 86594 kg/ año de papa precocida y prefrita o 173188 unidades.

\subsection{Relación tamaño-recurso productivo}

Son todos los recursos que participan en el proceso de producción, en este proyecto los recursos son: materia prima e insumos, mano de obra, agua y energía eléctrica.

La materia prima no es un factor limitante; esto se debe a que la papa amarilla se produce en una cantidad adecuada en varios departamentos (4 704260 toneladas en el 2015, según INEI) y por ende no habrá ningún problema en el abastecimiento de dicha materia prima; asimismo, los insumos requeridos también son accesibles.

La mano de obra no será un inconveniente, ya que no se requerirán personal de alta calificación; sin embargo, se contará con técnicos especializados en el manejo de la maquinaria. Además, Lima cuenta con la mayor población económicamente activa del país, por lo que no será un problema al momento de buscar personal adecuado.

Finalmente; el abastecimiento de agua y de energía eléctrica no será ninguna restricción, ya que Lima cuenta con el río Mantaro y Rímac en lo que respecta al recurso 
hídrico y con lo que se refiere a la energía eléctrica cuenta con una central eléctrica. Esto representa una ventaja y por ende no es un limitante para la producción.

\subsection{Relación tamaño-tecnología}

El proceso productivo de los productos no es tan complejo, por lo que no necesitara grandes dimensiones y a la vez tendrán cierta ventaja al momento de adquirirlos. Además; se cuenta con la maquinaria y tecnología suficiente para llevar a cabo un producto de alta calidad. Las capacidades teóricas de la maquinaria a usar son: (Para el cálculo de esta Tabla: se usó la densidad del agua $1 \mathrm{~kg} / \mathrm{L}$ y cada bolsa pesa $0,5 \mathrm{~kg}$ y el año tendrá 240 días laborables con 8 horas de operación diaria)

Tabla 4.2

Capacidad teórica de la maquinaria

\begin{tabular}{|l|c|}
\hline \multicolumn{2}{|c|}{ Capacidades teóricas de la maquinaria } \\
\hline Equipos & Capacidad de procesamiento (ton/año) \\
\hline Lavadora & 231 \\
\hline Peladora & 231 \\
\hline Cortadora & 192 \\
\hline Escaldadora & 384 \\
\hline Secadora & 288 \\
\hline Freidora & 288 \\
\hline Congelador IQF & 384 \\
\hline Empacadora & 231 \\
\hline
\end{tabular}

Fuente: adaptado de: Zhucheng Honest Industry (2016).

Para determinar el tamaño tecnología, se ha calculado la producción anual de acuerdo a cada uno de los procesos de los procesos de producción; por lo tanto, se toma como base el cuello de botella identificado en la operación de la cortadora con: 192000 kg/año.

\subsection{Relación tamaño-inversión}

La inversión no sería un limitante, pues en su totalidad es accesible debido a que una parte es capital propio y el restante será financiado con una entidad financiera. 


\subsection{Relación tamaño-punto de equilibrio}

Es una variable muy importante por considerar, ya que para que una planta sea rentable, debe producir una cantidad superior a la del punto de equilibrio, de modo que genere un ingreso mayor a sus gastos de producción requeridos. El punto de equilibrio se define como el tamaño mínimo que debe de tener la planta.

Para hallar los precios de ventas unitarias y los costos variables unitarios de la papa amarilla precocida y prefrita, se ha tomado como referencia la tesis para la implantación de una agroindustria de congelados de papa de Gabriel Larrea y el precio de los productos de la competencia. Así, tenemos:

Tabla 4.3

Precio de venta, costo variable y fijo en soles

\begin{tabular}{|l|c|}
\hline Papa precocida y prefrita & Nuevos soles \\
\hline Precio de venta & 13 \\
\hline Costo variable & $6,30 /$ bolsa \\
\hline Costo fijo & 351600 \\
\hline
\end{tabular}

Elaboración Propia

El costo fijo promedio en base a los trabajos de investigación fue de 351600 nuevos soles. Asimismo, con los datos de la demanda proyectada y tomando como base en último año de esta proyección se puede observar que:

Tabla 4.4

Ingresos del proyecto

\begin{tabular}{|c|c|c|c|c|}
\hline Producto & $\begin{array}{c}\text { Demanda proyectada } \\
\text { de ventas }(2022)\end{array}$ & $\begin{array}{c}\text { Ventas en } \\
\text { unidades }\end{array}$ & $\begin{array}{c}\text { Precio de } \\
\text { venta }(\mathrm{S} /)\end{array}$ & $\begin{array}{c}\text { Ventas } \\
(\mathrm{S} /)\end{array}$ \\
\hline $\begin{array}{c}\text { Papa precocida o } \\
\text { prefrita }(0,5 \mathrm{~kg})\end{array}$ & $86594 \mathrm{~kg}$ & 173188 & 13 & 2251444 \\
\hline
\end{tabular}

Elaboración Propia

Tabla 4.5

Margen de contribución

\begin{tabular}{|l|c|c|c|}
\hline Producto & $\begin{array}{c}\text { Precio de venta } \\
(2022)\end{array}$ & Costo variable & Margen contribución \\
\hline Papa precocida o prefrita $(0,5 \mathrm{~kg})$ & 13 & 6,30 & 6,7 \\
\hline
\end{tabular}

Elaboración Propia

Después de los cálculos efectuados, el punto de equilibrio será: 
$\mathrm{Q}_{\mathrm{eq}}=52480$ bolsas $=682240$ soles

\subsection{Selección de tamaño de planta}

En el siguiente cuadro se presenta un resumen con los tamaños de planta de cada factor, donde el tamaño de planta será de 173188 bolsas/año para las papas precocidas y prefritas congeladas.

Tabla 4.6

Tamaño de Planta

\begin{tabular}{|l|l|}
\cline { 2 - 2 } \multicolumn{1}{c|}{} & \multicolumn{1}{c|}{ Tamaño de planta } \\
\hline Factor limitante & Papa precocida y prefrita congelada (bolsas/año) \\
\hline Mercado & 173188 \\
\hline Recursos productivos & No relevante \\
\hline Tecnología & 192000 \\
\hline Tamaño Pto. Eq. & 52478 \\
\hline
\end{tabular}

Elaboracion Propia 


\section{CAPÍTULO V: INGENIERÍA DEL PROYECTO}

\subsection{Definición técnica del producto}

\subsubsection{Especificaciones técnicas, composición y diseño del producto}

Para el proyecto en estudio, se definen dos productos diferentes: papa prefrita congelada y papa precocida congelada. Estos dos serán envasados en bolsas termo contraíbles de barrera. Estos estarán contenidos en cajas de cartón corrugado con capacidad de veinte bolsas. Estas cajas a su vez se empacarán con film al momento de ser puestos en pallets. El tamaño del pallet estándar, para transporte por vía marítima es de 120 x $100 \mathrm{~cm}$, según la norma ISO 3394.

Según las normas de la organización internacional del trabajo, el peso máximo que puede manipular una persona es $25 \mathrm{~kg}$. El tamaño de cajas estándar es de 60 x $40 \mathrm{~cm}$ según la norma ISO 3394. Según los cálculos de espacio se ha llegado a la conclusión de que pueden entrar 50 bolsas de producto, en cajas de dichas dimensiones. Para verificar que no incumple las reglas ergonómicas, se halla el peso resultante de las cajas máster con 50 bolsas dentro. El peso resultante, luego de haber utilizado el peso de las bolsas, es de $25 \mathrm{~kg}$, sin tener en cuenta el peso del empaque. Es decir, si las cajas máster contuvieran 99 bolsas, no podrían ser manipuladas por los operarios. Ya que la norma ISO 3394 indica que las cajas máster pueden tener el tamaño indicado o cualquier múltiplo de este, se ha decidido reducir el tamaño de la caja a 30x20 cm. Este tipo de caja puede contener 29 bolsas; es decir, una caja de este tipo pesará, aproximadamente $14,5 \mathrm{~kg}$.

El tamaño de las papas lo definen las medidas que se muestran debajo. El ancho de la bolsa es de, aproximadamente, $1 \mathrm{~cm}$. El tamaño de la bolsa es de 19 x 26,46 en el exterior. 


\subsubsection{Composición del producto}

Ya que existen dos productos se definirán en conjunto sus características.

Tabla 5.1

Características de los productos

\begin{tabular}{|l|l|}
\hline Materia prima & $\begin{array}{l}\text { Papa amarilla. Variedad: Amarilla peruana. Tamaño estándar: } \\
8,5 \mathrm{~mm} \text { de diámetro. Tiempo de vida: } 168 \text { días. }\end{array}$ \\
\hline Embolsado y empacado & $500 \mathrm{~g}$. \\
\hline - Capacidad de bolsa & $9 \mathrm{~cm} \times 26,46 \mathrm{~cm} \mathrm{x1} \mathrm{cm}$ \\
\hline - Dimensión de la bolsa & $\begin{array}{l}\text { Impreso fecha de vencimiento, código de barras y valor } \\
\text { nutricional. }\end{array}$ \\
\hline - Características & Caja de cartón $30 \mathrm{~cm}$ x $20 \mathrm{~cm}$ x $30 \mathrm{~cm}$ \\
\hline - Tamaño de empaque & 25 bolsas por caja \\
\hline - cantidad de bolsas por caja & Impreso el tipo y marca del producto. \\
\hline Almacenamiento y distribución & $-18^{\circ} \mathrm{c}$ o menor temperatura \\
\hline Temperatura & 168 días almacenado. \\
\hline El producto no debe estar más de &
\end{tabular}

Elaboracion Propia

Tabla 5.2

Composición de la papa amarilla (en porcentajes)

\begin{tabular}{|l|l|}
\hline Composición & $5,0 \mathrm{~g}$ \\
\hline Grasas totales & $1,5 \mathrm{~g}$ \\
\hline Grasa saturada & 0 \\
\hline Grasas trans & $0 \mathrm{mg}$ \\
\hline Colesterol & $330 \mathrm{mg}$ \\
\hline Sodio & $400 \mathrm{~g}$ \\
\hline Potasio & $21 \mathrm{~g}$ \\
\hline Carbohidratos totales & $2 \mathrm{~g}$ \\
\hline Fibra dietética & Menos de $1 \mathrm{~g}$ \\
\hline Azúcares & $2 \mathrm{~g}$ \\
\hline Proteína & \\
\hline
\end{tabular}

Elaboracion Propia 
Ya que no se tienen valores comprobados sobre la información nutricional, se elegirá el segundo para el empaque, por ser el más genérico y legalmente aceptado para empaque de productos.

\subsubsection{Diseño gráfico del producto}

Figura 5.1

Diseño de la bolsa

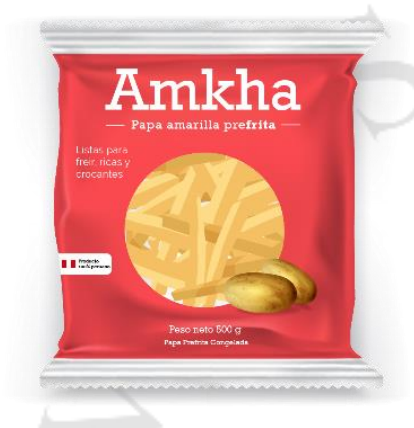

Elaboracion Propia

\subsubsection{Regulaciones técnicas al producto}

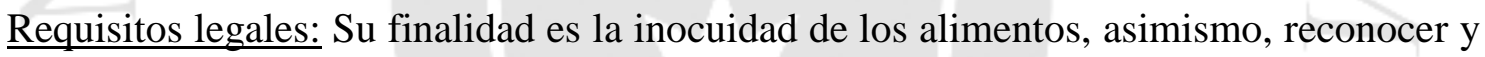
asegurar los derechos de los consumidores y promover la competitividad. Ellos son:

- Ley de inocuidad de alimentos, ley $\mathrm{N}^{\circ}$ 1062: Esta ley establece los requisitos los principios de higiene del Codex alimentarius como el principio de higiene de los alimentos.

- Reglamento de la Ley- DS 034-2008 AG (27 diciembre de 2008)

- Resolución Ministerial N. ${ }^{\circ}$ 222-2009/MINSA: Procedimiento para la atención de alertas sanitarias de todo producto de consumo humano.

- La norma metrológica peruana NMP 001 y NMP 002: Indica como debe ser el rotulado y cantidad de producto en preenvases respectivamente.

$\underline{\text { Reglamentos regionales e internacionales }}$

- Código de protección y defensa del consumidor. "Ley 29571"

- IICA-FDA: Codex Alimentarius y OMC 
- Decreto Supremo N. ${ }^{\circ}$ 007-98-SA Control sanitario de alimentos y bebidas.

- DIGESA: responsable en la vigilancia de la inocuidad de alimentos industriales de producción nacional o extranjera.

\subsection{Tecnologías existentes y procesos de producción}

\subsubsection{Naturaleza de la tecnología requerida}

Para llevar a cabo todas las etapas del proceso de producción de las papas precocidas y prefritas congelada se deberá tener la tecnología adecuada para su elaboración. Las líneas de producción varían de planta en planta, pero en general cumplen con las operaciones de lavado, pelado, cortado, blanqueado, escurrido, freído, desgrasado, enfriado y congelado.

En la actualidad, las papas precocidas y prefritas son producidas en línea de procesamiento; existiendo la posibilidad del procesamiento en máquinas y equipos en serie, que cumplan con las operaciones anteriormente mencionadas.

\subsubsection{Descripción de la tecnología existente}

\section{$\underline{\text { Selección }}$}

Es el proceso por el cual se separa la materia prima que no cumple con los estándares mínimos de calidad requeridos. Esta operación puede ser manual o automática. La operación manual es realizada en mesas donde cada unidad de materia prima es evaluada visualmente por el operario y rechazada por el mismo. La operación automática es realizada por máquinas especializados que verifican peso, color, textura, etc. Algunos parámetros a tener en cuenta en este proceso son: las papas no deben tener golpes, daño patológico y/o fisiológico (que estén descomponiéndose) o que tengan corazón negro (mancha negra por falta de oxígeno), entre otros.

\section{$\underline{\text { Lavado }}$}

El lavado de la materia prima se realiza mediante la exposición a un flujo intenso de chorros de agua, al interior de una cámara. Esta operación puede ser apoyada con escobillas móviles dentro de los cilindros giratorios, las cuales mejoran la remoción de las partículas sólidas. 


\section{$\underline{\text { Pelado }}$}

El pelado se realiza con la finalidad de separar la cáscara, se puede realizar mediante la fricción en cilindro rotativos revestidos de material abrasivo; con soda caustica, que emplea una solución de lejía a una temperatura y tiempo dado para luego exponer el producto a chorros de agua con la finalidad de eliminar la cáscara o con vapor, que calienta la superficie del producto que se encuentra a 15 atm durante unos segundos en el interior de una cámara y luego mediante una súbita descomprensión, se consigue desprender la cáscara.

\section{$\underline{\text { Enjuagado }}$}

Se utiliza chorros de agua en caída, los cuales facilitan el desprendimiento de las cáscaras que aún no han sido desprendidas.

\section{Cortado}

El cortado se realiza con la finalidad de obtener la forma deseada al producto. Puede ser realizado mediante el tradicional corte mecánico con cuchillos dispuestos en rejillas, con presión hidráulica que consiste en alimentar el producto a un conducto donde circula una corriente de agua a gran velocidad que lo impulsa hacia el extremo de salida, donde van montadas unas cuchillas de la forma deseada que las corta; el corte eléctrico con hojas rectas giratorias para obtener rebanadas de forma de láminas y longitudinal.

\section{$\underline{\text { Escaldado }}$}

Se realiza para inactivar las enzimas causantes del oscurecimiento del producto y obtener una reducción en el nivel de azucare reductores, con la finalidad de fijar un color y textura uniforme y reducir el tiempo de fritura y absorción de grasas. Se puede llevar a cabo mediante la inmersión en un baño caliente de agua a temperatura $80^{\circ} \mathrm{C}$ a $100^{\circ} \mathrm{C}$ en un tambor rotativo de tornillo interno, donde el producto atraviesa el baño sobre el transportador de tornillo, a través de una atmosfera de vapor o el uso de microondas o aire caliente. También se puede añadir preservantes químicos como el bisulfito de sodio o una solución de azucares reductores.

\section{$\underline{\text { Freído }}$}

Puede ser realizado por contacto con aceite en una superficie o plancha de frituras, por inmersión en aceite al interior de una tina o por aspersión de aceite caliente a $200^{\circ} \mathrm{C}$ sobre el producto que es transportado al interior de una cámara mediante un sistema de fajas. 
La freidora puede ser abastecida con fuente caloríficas internas o externas, existen varios tipos de sistemas usados para conducir el producto a lo largo de la cámara, como fajas de alambre o canastilla en cadena. La freidora de flujo continuo tiene una operación cerrada donde el calor es controlado y el aceite es filtrado y recirculado al intercambiador de calor. Para el caso de las papas prefritas el parámetro recomendable es 3 minutos a $180^{\circ} \mathrm{C}$.

\section{$\underline{\text { Desgrasado }}$}

Se realiza en fajas de Mallas de alambre vibratorio, siendo posible la ayuda de corrientes de aire por ventiladores para agilizar la remoción del exceso de aceite adherido al producto. También se puede usar el método de rociarlo con agua caliente, donde el aceite quedara en la superficie. El aceite que se recupera puede ser filtrado y bombeado al tanque de la freidora para ser recirculado o se puede separar por decantación con el agua.

\section{Congelado}

IQF (Individual Quick Freezing) es el proceso de congelado recomendado para mantener las propiedades y calidad del producto, su principal diferencia con el congelado normal es el tamaño de los cristales que se forman en las células. La temperatura en el IQF baja súbitamente entre $-18^{\circ} \mathrm{C}$ a $30^{\circ} \mathrm{C}$ por lo que los cristales de hielo son muy pequeños y no rompen las paredes celulares del tejido del producto. Una característica importante es que al descongelar el producto no se expulsan fluidos celulares y esto permite garantizar el sabor, valor nutritivo y textura; asimismo no se necesita utilizar químicos y persevantes en el producto y se reduce en gran cantidad los microorganismos.

\section{Embolsado y empacado}

El embolsado y empacado es hecho por operarios o máquinas. Es importante seleccionar un envase que mantenga en excelentes condiciones al producto. El empaque es un recipiente que se utiliza con el objetivo de contener un producto, protegerlo y preservarlo en condiciones óptimas. Para los productos congelados, los envases más comunes están las bolsas de polietileno, envasado al vacío, entre otros.

\section{$\underline{\text { Almacenado congelado }}$}

El almacenamiento permite mantener sus cualidades nutricionales y propiedades organolépticas con temperaturas menores a $0^{\circ} \mathrm{C}$. 


\subsubsection{Selección de la tecnología}

Se considerará como criterios aquellos que permitan obtener el máximo rendimiento económico. En tal sentido, la tecnología a ser seleccionada para la producción de las papas prefritas y precocidas congeladas se presentará más adelante.

\subsubsection{Proceso de producción}

\subsubsection{Descripción del proceso de producción de la papa prefrita}

Recepción y selección: Esta etapa es manual donde la papa, tamaño mínimo de la primera, (ver figura 5.5) ingresa en bolsas de 50kg para ser almacenada en un ambiente que oscile entre los 13 y $18^{\circ} \mathrm{C}$ y con humedad relativa entre 90 y $95 \%$ para que no aumente la proporción de azucares reductores. Antes de entrar en el proceso, se evalúa su calidad (defectos internos y externos, peso específico, color, etc.) de acuerdo con la Norma técnica colombiana 4481.

Lavado: La papa se descarga a una cinta transportadora que la llevara a la lavadora donde por canales con circulación de agua se extraerá la mayor cantidad de tierra, impurezas y carga bacteriana que pueda tener y por medio de osciladores se va desechando las papas pequeñas.

Pelado: Esta etapa consiste en desprender la piel de la papa y dejarla lista para la siguiente etapa. El método por utilizar es a través de vapor a alta presión y temperatura que calienta la papa y su cáscara, luego por diferencia en la concentración de calor, la cáscara se desprende y se retira mecánicamente en un cilindro con chorros de agua.

Cortado: Antes de pasar por la cortadora las papas pasan por otra inspección; luego serán cortadas en forma de bastón de 9 × $9 \mathrm{~mm}$ en donde una pistola de agua gira las papas a gran velocidad hacia la cuchilla. Luego del corte, la merma se podrá vender para la producción de puré o en un futuro la producción de puré.

Escaldado: las papas cortadas son cocidas en la escaldadora en agua caliente $\left(70^{\circ} \mathrm{C}\right)$ durante un breve tiempo, para que las células y las papas se hinchen dando una textura esponjosa y arenosa, con la finalidad de reducir la cantidad de grasa que se absorbe en la fritura por la gelatinización de la capa de almidón que previene que se pegue al ser freída, reduce su tiempo de fritura y previene la alteración microbiana. Para el control del oscurecimiento de la papa en la fritura se puede usar el pirofosfato acido de sodio y el lactato de calcio para mejorar la textura. 
$\underline{\text { Secado: }}$ en esta etapa el exceso de humedad se remueve mediante ventiladores de aire tibio en un túnel de secado antes de entrar a la freidora. Una parte de la papa que sale de este proceso se lleva a la etapa de congelado para ser empacado como papa precocida.

Freído: la papa en forma de bastón seca es sumergida en la freidora en aceite vegetal no hidrogenado a $190^{\circ} \mathrm{C}$ por 3 minutos aproximadamente ( 2 lt de aceite por $1 \mathrm{~kg}$ de papa). Después, se deja escurrir y enfriar con aire hasta temperatura ambiente.

Congelado: las papas prefritas son congeladas en el equipo IQF que mediante el sistema de congelación rápido permite congelar el producto, en 5 a 20 minutos, entre $2^{\circ} \mathrm{C} \mathrm{y} \mathrm{-}$ $40^{\circ} \mathrm{C}$.

Empaquetado: una vez que las papas prefritas están congeladas pasan a ser empaquetadas con bolsas termocontraibles cerradas al vacío y empacadas manualmente en cajas.

$\underline{\text { Almacenamiento: }}$ las cajas se colocan en el almacén, hasta ser despachadas.

\subsubsection{Descripción del proceso de producción de papa precocida}

Recepción y selección: Esta etapa es manual donde la papa, tamaño mínimo de la primera, (ver figura 5.5) ingresa en bolsas de 50kg para ser almacenada en un ambiente que oscile entre los 13 y $18^{\circ} \mathrm{C}$ y con humedad relativa entre 90 y $95 \%$ para que no aumente la proporción de azucares reductores. Antes de entrar en el proceso, se evalúa su calidad (defectos internos y externos, peso específico, color, etc.) de acuerdo con la Norma técnica colombiana 4481 .

Lavado: La papa se descarga a una cinta transportadora que la llevara a la lavadora donde por canales con circulación de agua se extraerá la mayor cantidad de tierra, impurezas y carga bacteriana que pueda tener y por medio de osciladores se va desechando las papas pequeñas.

Pelado: Esta etapa consiste en desprender la piel de la papa y dejarla lista para la siguiente etapa. El método por utilizar es a través de vapor a alta presión y temperatura que calienta la papa y su cáscara, luego por diferencia en la concentración de calor, la cáscara se desprende y se retira mecánicamente en un cilindro con chorros de agua.

Cortado: Antes de pasar por la cortadora las papas pasan por otra inspección; donde serán cortadas en tajadas; donde una pistola de agua gira las papas a gran velocidad hacia la 
cuchilla. Luego del corte, la merma se podrá vender para la producción de puré o en un futuro la producción de puré.

Escaldado: las papas cortadas son cocidas en la escaldadora en agua caliente $\left(70^{\circ} \mathrm{C}\right)$ durante un breve tiempo, para que las células y las papas se hinchen dando una textura esponjosa y arenosa, con la finalidad de reducir la cantidad de grasa que se absorbe en la fritura por la gelatinización de la capa de almidón que previene que se pegue al ser freída, reduce su tiempo de fritura y previene la alteración microbiana. En esta etapa se usará dos escaldadoras para lograr mayor flexibilidad y se puede usar el lactato de calcio para mejorar la textura.

Secado: en esta etapa el exceso de humedad en las papas se remueve mediante ventiladores de aire tibio en un túnel de secado antes de ser llevadas a la etapa de congelado para ser empacado como papa precocida.

Congelado: las papas precocidas son congeladas en el equipo IQF que mediante el sistema de congelación rápido permite congelar el producto, en 5 a 20 minutos, entre $2^{\circ} \mathrm{C}$ $\mathrm{y}-40^{\circ} \mathrm{C}$.

Empaquetado: una vez que las papas precocidas estén congeladas pasan a ser empaquetadas con bolsas termocontraibles cerradas al vacío y empacadas manualmente en cajas.

Almacenamiento: las cajas se colocan en el almacén, hasta ser despachadas. 


\subsubsection{Diagrama de proceso}

Figura 5.2

Diagrama de proceso de la papa prefrita congelada

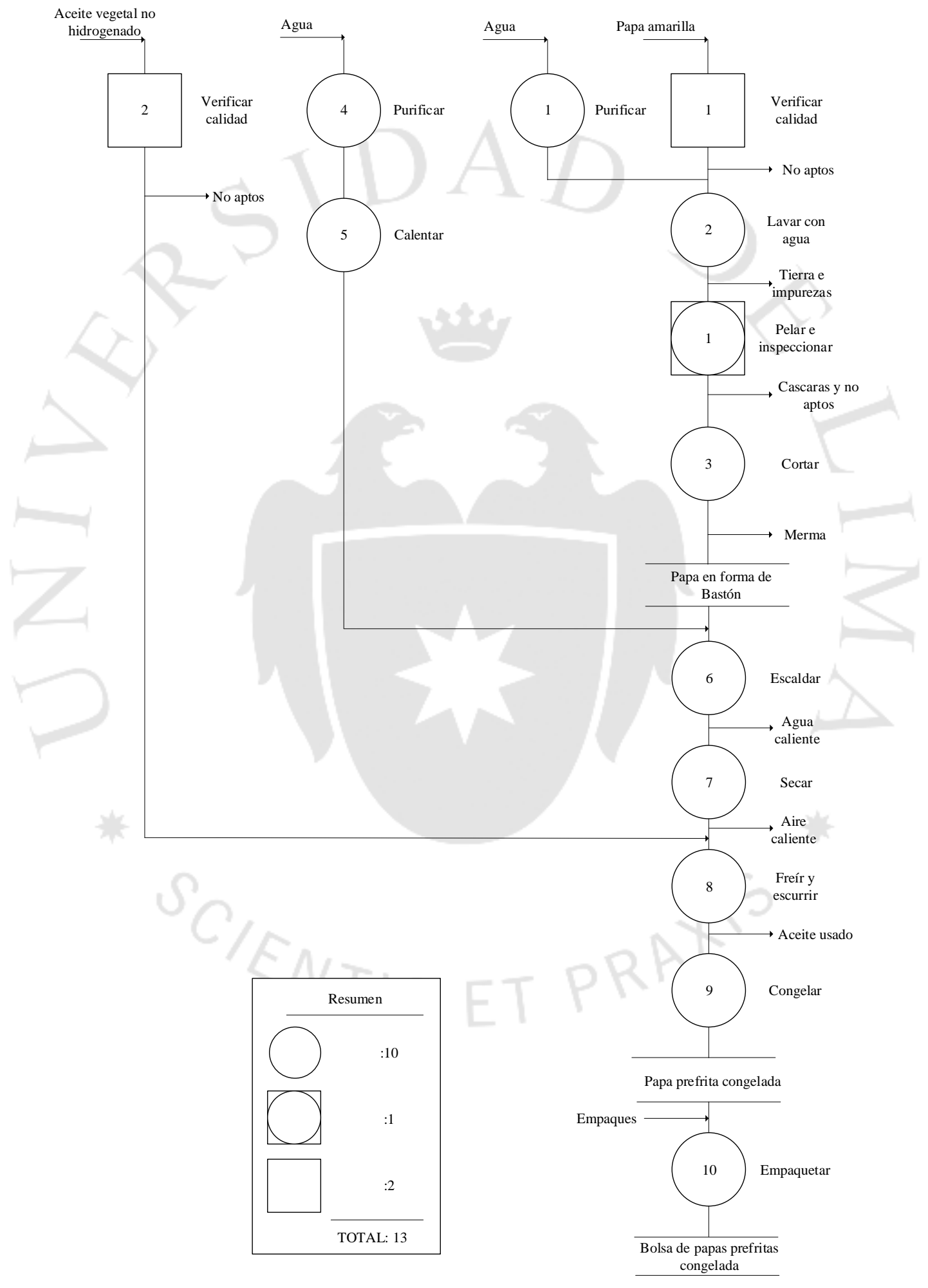

Elaboración Propia 
Figura 5.3

Diagrama de proceso de la papa precocida congelada

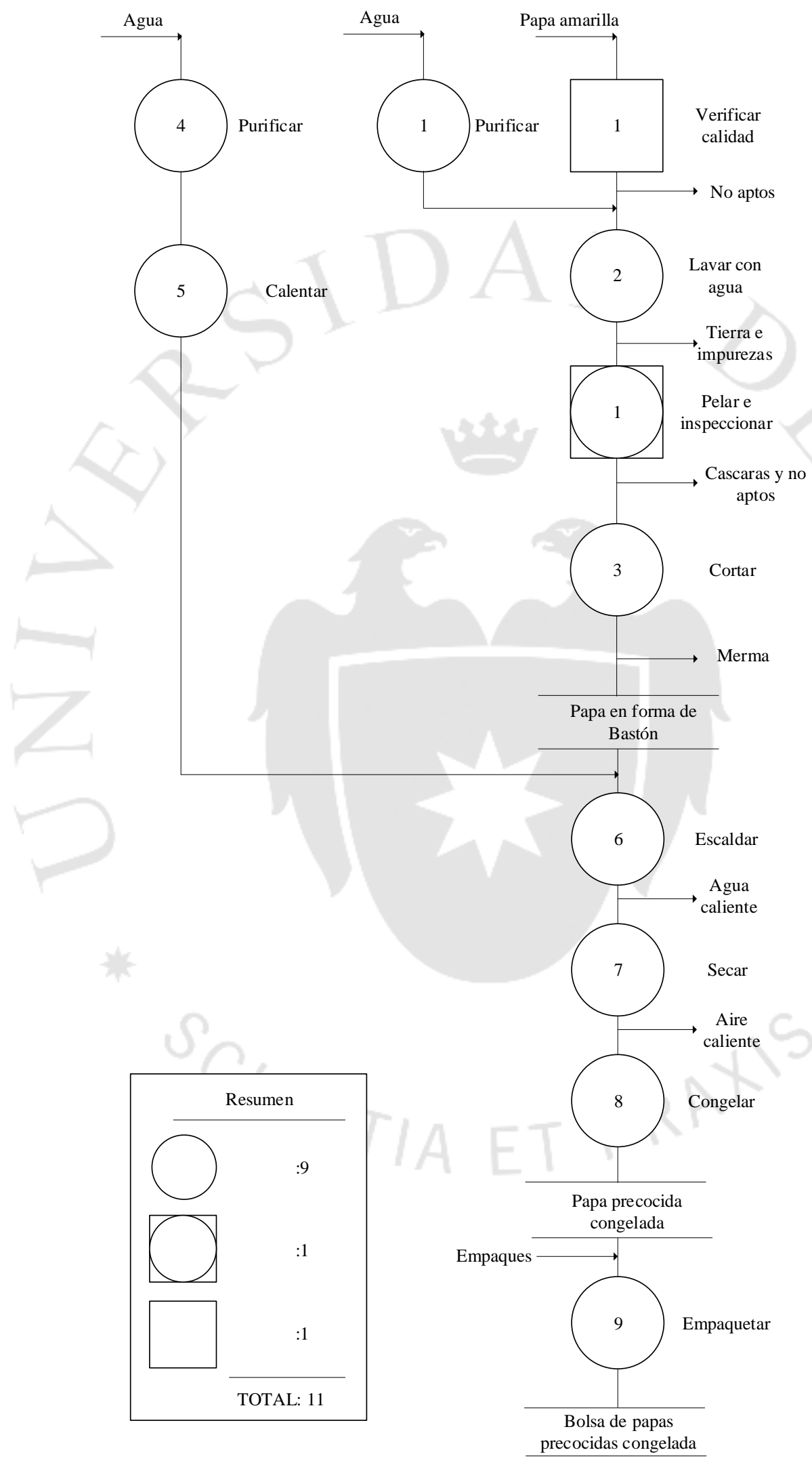

Elaboración Propia 


\subsubsection{Balance de materia}

Para la elaboración del balance de materia, se tomará como base el proyecto "Diseño de una línea de producción de papas Tipo Bastón Prefritas y Congeladas" de Lisbeth Estefanía Chávez Andrade y Elsa Victoria Vivas Méndez.

Tabla 5.3

Tabla de balance de materia

\begin{tabular}{|l|c|c|}
\hline Proceso & Merma (\%) & Rendimiento (\%) \\
\hline Selección & 2 & 98 \\
\hline Lavado & 0 & 100 \\
\hline Pelado & 20 & 80 \\
\hline Selección Manual & 1,25 & 98,75 \\
\hline Corte & 22,29 & 77,71 \\
\hline Escaldado & 12,71 & 87,28 \\
\hline Secado ligero & 1,94 & 98,06 \\
\hline Prefitura & 4,69 & 95,31 \\
\hline Escurrido & 1,76 & 98,24 \\
\hline Congelación & 0,5 & 99,5 \\
\hline empacado & 0,5 & 99,5 \\
\hline
\end{tabular}

Fuente: Chávez, L. y Vivas, E, (2014). 
Figura 5.4

Balance de materia

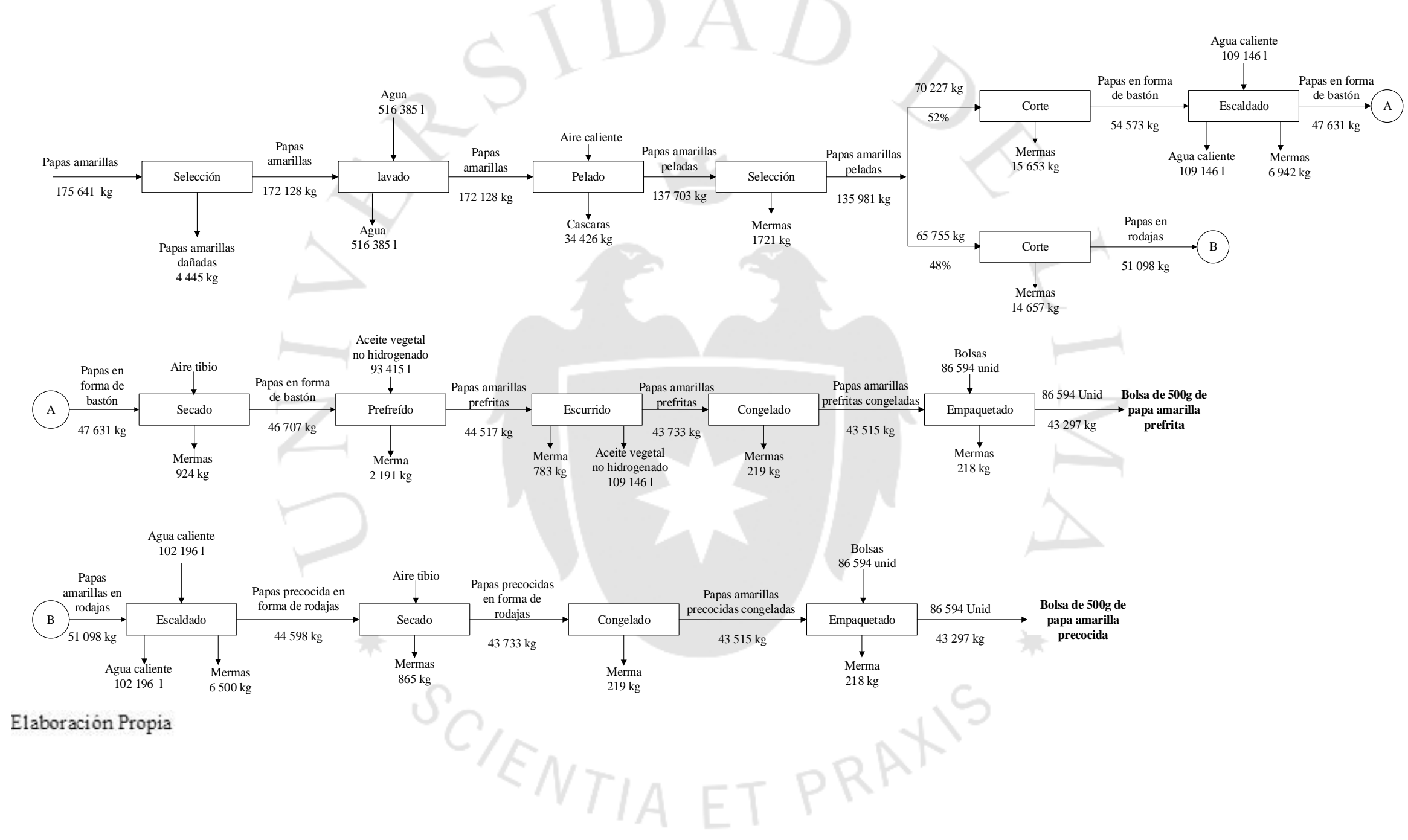




\subsection{Características de las instalaciones y equipos}

Las instalaciones estarán acondicionadas a una temperatura en que el producto final no se dañe u oxide. Por ejemplo, la bodega que recibirá el producto debe estar entre los 13 y $18^{\circ} \mathrm{C}$ y una humedad relativa entre $90 \%$ y $95 \%$ y el área de empaque a condiciones de $7^{\circ} \mathrm{C}$ y $65 \%$.

\subsubsection{Selección de la maquinaria y equipos}

Las máquinas elegidas para el proyecto son todas aquellas que se adecuan al tamaño de y requerimientos ambientales de la planta.

$\underline{\text { Maquinaria }}$

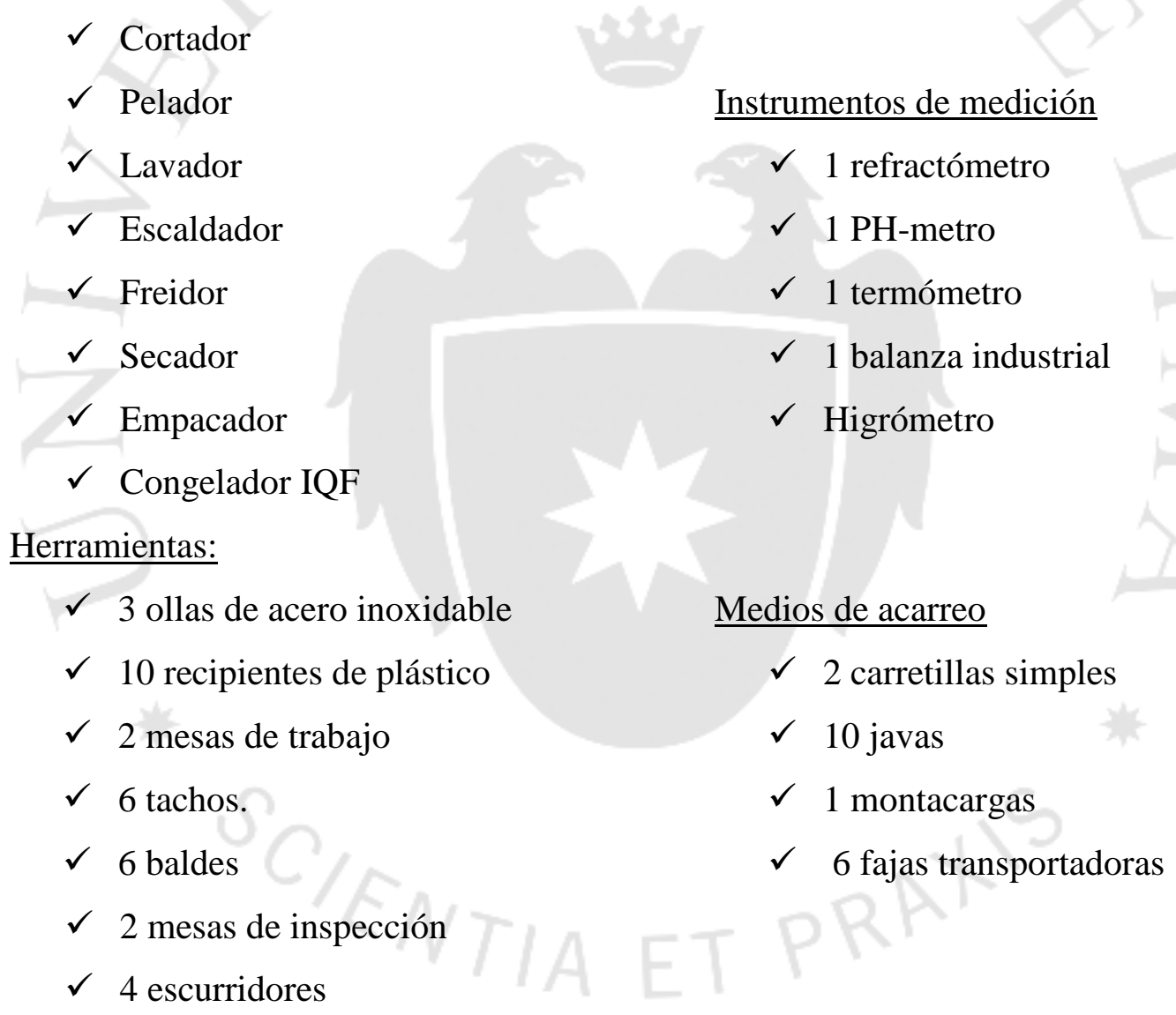




\subsubsection{Especificaciones de la maquinaria}

\section{Lavadora}

Tabla 5.4

Especificaciones técnicas de la lavadora

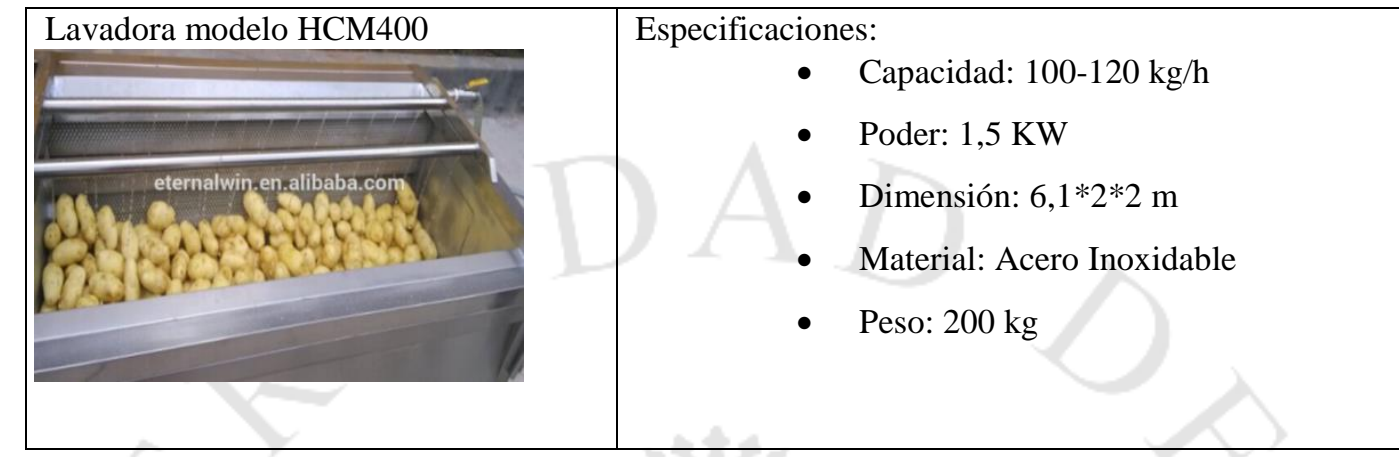

Fuente: adaptado de Alibaba, (2016).

\section{$\underline{\text { Peladora }}$}

\section{Tabla 5.5}

Especificaciones técnicas de la peladora

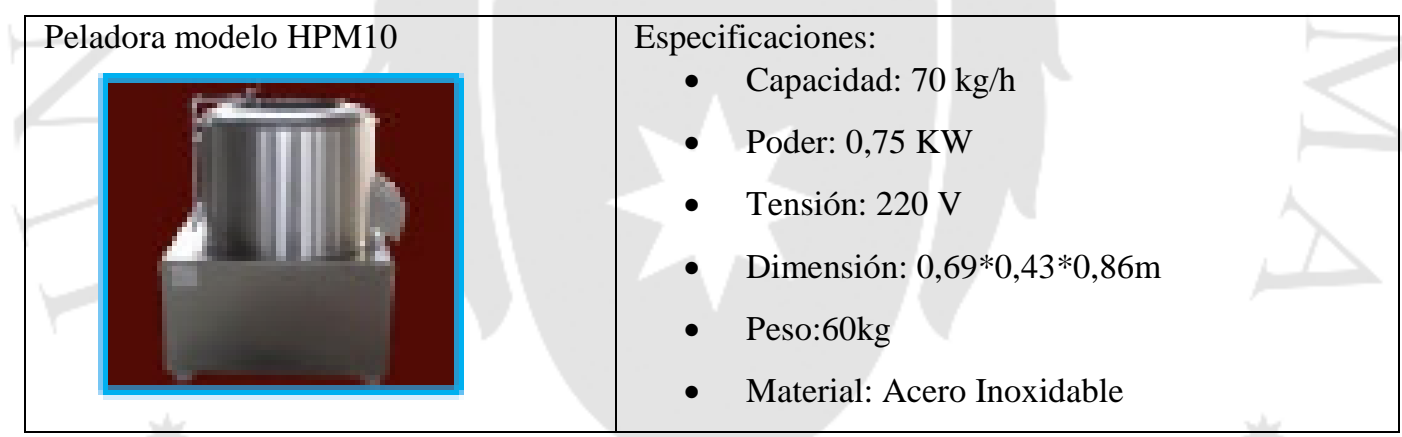

Fuente: adaptado de: Zhucheng Honest Industry (2016).

\section{Cortadora}

Tabla 5.6

Especificaciones técnicas de la cortadora

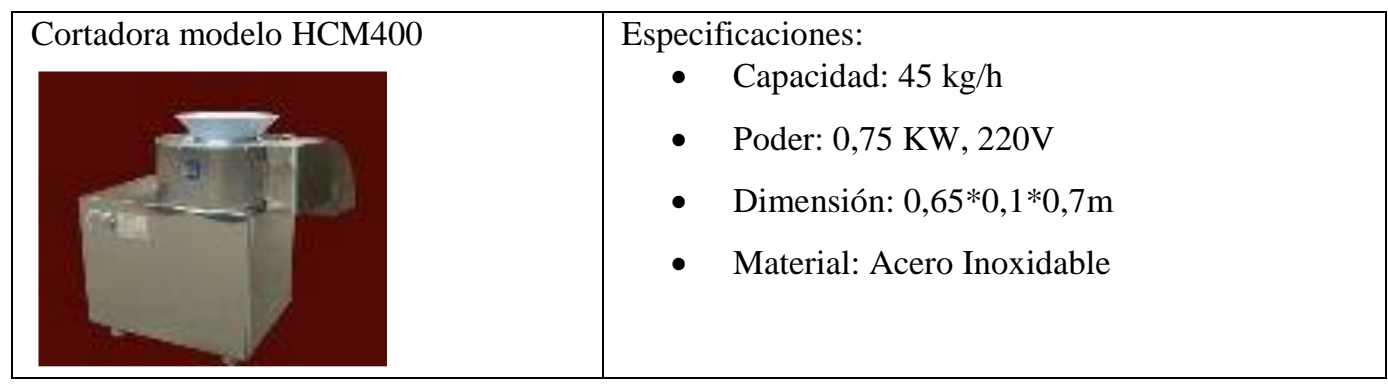

Fuente: adaptado de: Zhucheng Honest Industry (2016). 


\section{Escaldadora}

Tabla 5.7

Especificaciones técnicas de la escaldadora

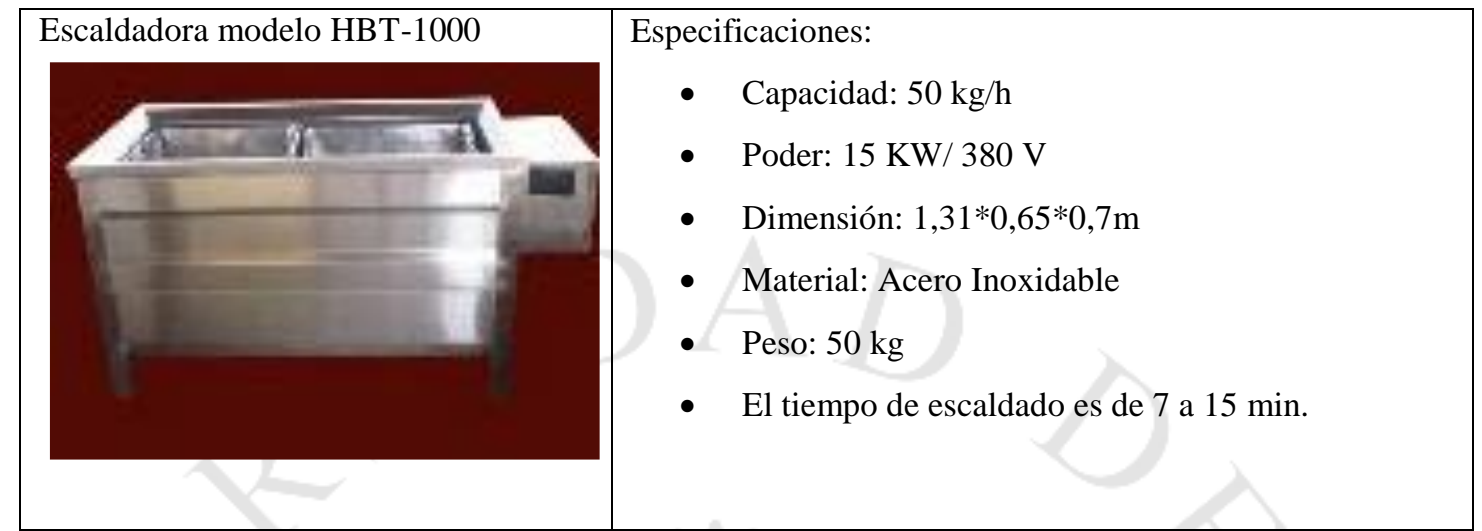

Fuente: adaptado de: Zhucheng Honest Industry (2016).

\section{Freidora}

\section{Tabla 5.8}

Especificaciones técnicas de la freidora

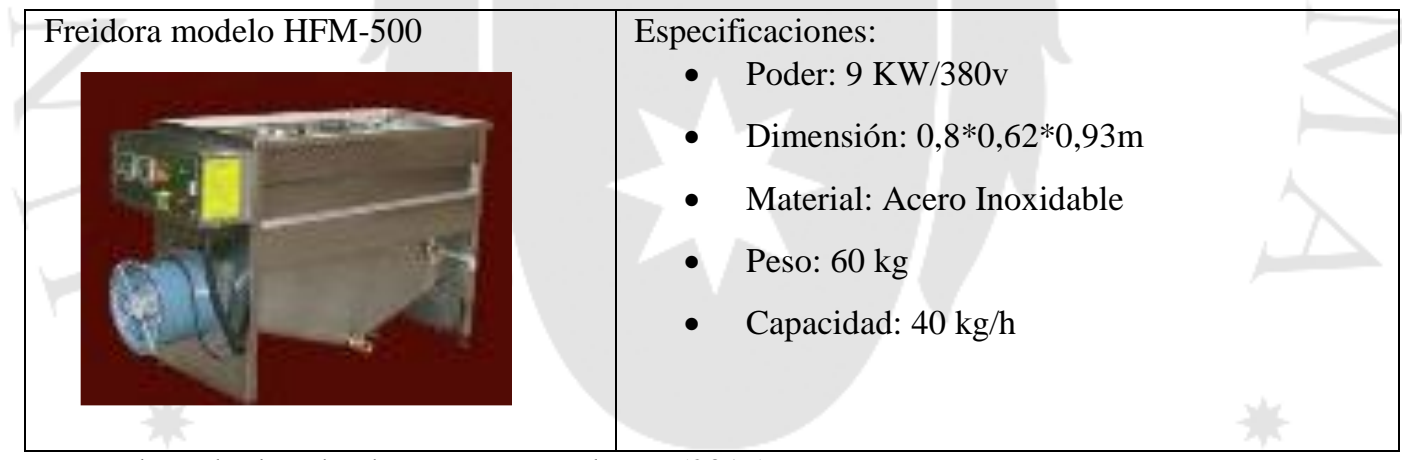

Fuente: adaptado de: Zhucheng Honest Industry (2016).

\section{Secador}

Tabla 5.9

Especificaciones técnicas del secador

\begin{tabular}{|c|c|}
\hline Secadora modelo Lyhj-102 & $\begin{array}{l}\text { Especificaciones: } \\
\text { - } \quad \text { Capacidad: } 30 \mathrm{~kg} / \mathrm{h} \\
\text { - } \\
\text { - } \\
\text { - } \\
\text { - } \\
\text { - } \\
\text { Desoder: } 0,75 \mathrm{KW} / 380 \mathrm{vg} \\
\text { Material: Acero Inoxión: } 1 * 0,8 * 1,38 \mathrm{~m}\end{array}$ \\
\hline
\end{tabular}

Fuente: adaptado de: Zhucheng Honest Industry (2016). 
Congeladora

Tabla 5.10

Especificaciones técnicas de la congeladora

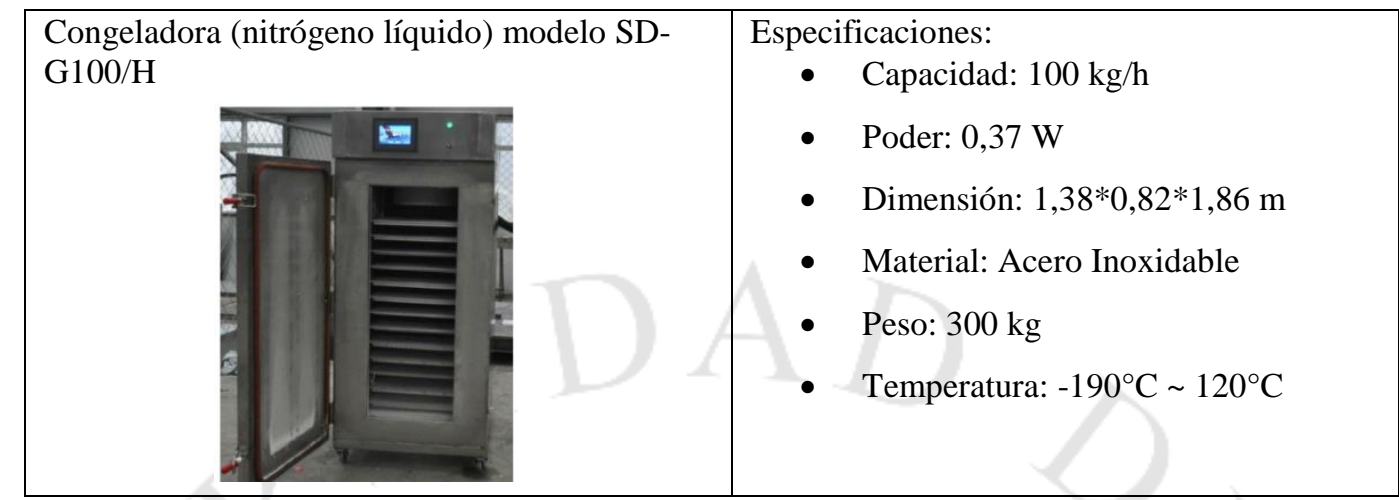

Fuente: adaptado de Alibaba, (2016).

\section{Empacadora}

Tabla 5.11

Especificaciones técnicas de la empacadora

\begin{tabular}{|c|c|}
\hline Empacadora modelo HPM-400 & 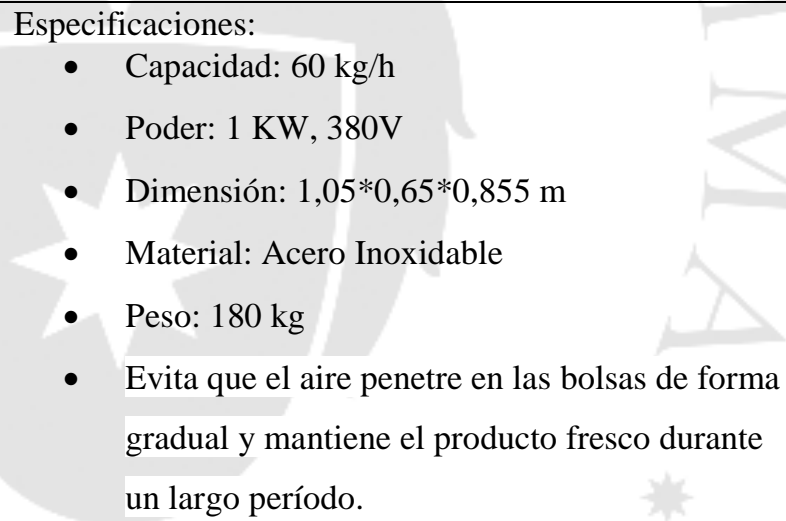 \\
\hline
\end{tabular}

Fuente: adaptado de: Zhucheng Honest Industry (2016).

\subsection{Capacidad instalada}

Para el cálculo del número de máquinas se ha considerado que habrá 1 turno por día de 8 horas efectivas cada uno, 22 días al mes (H=2 112 horas al año). Y se considerará un factor de utilización de 0,95 y un factor de eficiencia de 0,9 debido a que se asume que cada operario sabrá lo que hace y lo hace bien, además se considera un factor de corrección de $10 \%$, debido a que las máquinas nunca operan a su $100 \%$ por trabajos de mantenimiento o eventualidades. 


\subsubsection{Cálculo de la capacidad instalada}

Tabla 5.12

Capacidad de Planta

\begin{tabular}{|c|c|c|c|c|c|c|c|c|}
\hline Papa prefrita y precocida & QS (kg) & $\mathrm{U}$ & $\mathrm{E}$ & (h/año) & Kg/año & CO (T/año) & $\mathrm{FC}$ & COPT (ton/año) \\
\hline Lavadora $(\mathrm{kg})$ & 172128 & $95 \%$ & $90 \%$ & 2112 & 180576 & 181 & 0,50 & 82 \\
\hline Peladora $(\mathrm{kg})$ & 137703 & $95 \%$ & $90 \%$ & 2112 & 126403 & 126 & 0,63 & 724 \\
\hline Cortadora bastón $(\mathrm{Kg})$ & 54573 & $95 \%$ & $90 \%$ & 2112 & 81259 & 81 & 1,59 & 116 \\
\hline Cortadora rodajas $(\mathrm{Kg})$ & 51098 & $95 \%$ & $90 \%$ & 2112 & 81259 & 81 & 1,69 & 124 \\
\hline Escaldadora $1(\mathrm{~kg})$ & 54573 & $95 \%$ & $90 \%$ & 2112 & 90288 & 90 & 1,59 & 129 \\
\hline Escaldadora $2(\mathrm{~kg})$ & 51098 & $95 \%$ & $90 \%$ & 2112 & 90288 & 90 & 1,69 & 138 \\
\hline Secador $1(\mathrm{~kg})$ & 46707 & $95 \%$ & $90 \%$ & 2112 & 54173 & 54 & 1,85 & 90 \\
\hline Secador $2(\mathrm{~kg})$ & 43733 & $95 \%$ & $90 \%$ & 2112 & 54173 & 54 & 1,98 & 97 \\
\hline Freidora $(\mathrm{kg})$ & 44517 & $95 \%$ & $90 \%$ & 2112 & 72230 & 72 & 1,95 & 126 \\
\hline Congeladora $(\mathrm{kg})$ & 87029 & $95 \%$ & $90 \%$ & 2112 & 180576 & 181 & 1,00 & 162 \\
\hline Empacadora (unidades) & 173188 & $95 \%$ & $90 \%$ & 2112 & 108346 & 108 & 1,00 & 98 \\
\hline Producto Terminado $(\mathrm{kg})$ & 86594 & & & & & & & \\
\hline
\end{tabular}

La capacidad de la planta será: 72 ton /año

\section{Elaboración Propia}

Teniendo en cuenta, los datos de la tabla 5.12 la peladora viene a ser nuestro cuello de botella y por ende la capacidad de la planta (72 Ton/año) estará en función de ella.

\subsubsection{Cálculo detallado del número de máquinas requeridas}

Tabla 5.13

Cantidad de máquinas

\begin{tabular}{|c|c|c|}
\hline Papa prefrita y precocida & $\#$ maq & Precio $(\mathrm{S} /)$. \\
\hline Lavadora $(\mathrm{kg})$ & 1 & 3400 \\
\hline Peladora $(\mathrm{kg})$ & 1 & 799 \\
\hline Cortadora bastón $(\mathrm{Kg})$ & 1 & 1326 \\
\hline Cortadora rodajas $(\mathrm{Kg})$ & 1 & 1326 \\
\hline Escaldadora $1(\mathrm{~kg})$ & 1 & 5270 \\
\hline Escaldadora $2(\mathrm{~kg})$ & 1 & 5270 \\
\hline Secador $1(\mathrm{~kg})$ & 1 & 3842 \\
\hline Secador $2(\mathrm{~kg})$ & 1 & 3842 \\
\hline Freidora $(\mathrm{kg})$ & 1 & 5270 \\
\hline Congeladora $(\mathrm{kg})$ & 1 & 47600 \\
\hline \multirow[t]{2}{*}{ Empacadora (unidades) } & 1 & 4624 \\
\hline & 11 & 82569 \\
\hline
\end{tabular}

Elaboración Propia

El proyecto contará con 11 máquinas y tendrán un precio de compra de S/ 82569.

\subsection{Resguardo de la calidad e inocuidad del producto}

El producto propuesto pertenece al sector alimentario, lo cual nos advierte de la importancia de implementar un plan estricto de aseguramiento de la calidad e inocuidad. 
Se tomarán como base del estudio las buenas prácticas de manufactura (BPM), la norma ISO 9001, el plan HACCP y la Ley General de Salud N²6842, la cual indica cuales son las normal principales sobre la vigilancia y el control sanitario de alimentos y bebidas en protección de los consumidores.

\subsubsection{Calidad de la materia prima, de los insumos, del proceso y del producto}

Para controlar las características organolépticas del producto, se someterán los insumos a estudios físicos, bacteriológicos; además, se realizará el control del producto terminado y en proceso. El área de calidad se encargará de recolectar la información necesaria para poder determinar la calidad y la aprobación de los lotes de insumos recibidos y de productos terminados. De acuerdo con Zúñiga (2012) cualquier desviación en los parámetros técnicos y nutritivos determinará la aceptación de los productos.

En el presente proyecto, los insumos serán recibidos luego de la compra en el mercado de productores de Lima, en donde los productores de la costa y sierra venden sus productos. Las negociaciones, las normas de transacción y los estándares de calidad se tratarán con los vendedores mayoristas.

Para poder inspeccionar la materia prima que ingrese al proceso, se utilizará como referencia la norma técnica peruana 011.119. En este documento, se establecen medidas máximas de desviación. Primero, se tomará como referencia las medidas de la variedad Peruanita al no existir de la papa amarilla, por ser la más parecida en tamaño. Luego, se buscará que se cumplan los requisitos de sanidad, aspecto y tolerancias. La técnica de muestreo que se utilizará será la recomendada en la NTP-ISO 10725.

\section{Figura 5.5}

Rangos de diámetro y peso según variedad de papa

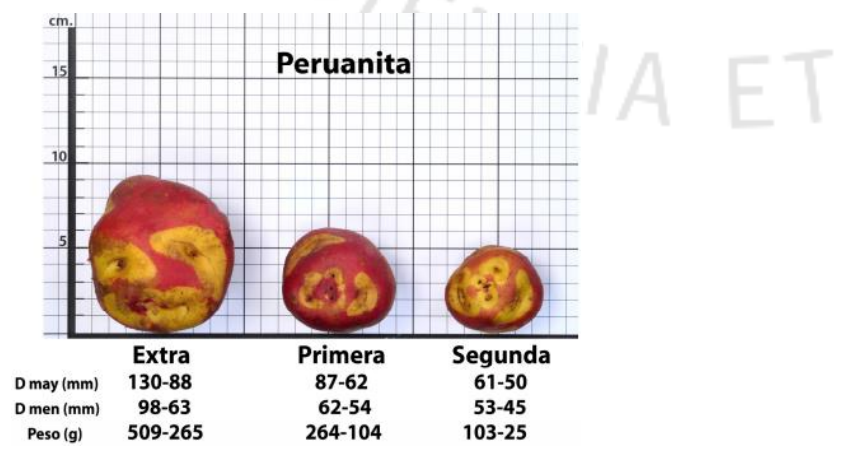

Fuente: adaptado de la Norma técnica peruana 011.119, (2010).

Los requisitos de sanidad a tomar en consideración son las presentadas en la NTPISO 10725 donde se menciona grados de calidad, aspecto y tolerancias. Véase Tabla 5.14. 
Tabla 5.14

Requisitos de sanidad, aspecto y tolerancias según calibres

\begin{tabular}{|l|c|c|c|}
\hline CARACTERÍSTICAS & \multicolumn{3}{|c|}{ GRADO DE CALIDAD (\% m/m) } \\
\hline & EXTRA & PRIMERA & SEGUNDA \\
\hline $\begin{array}{l}\text { 1. Inmadurez( papa pelada o } \\
\text { pelona con levantamiento de } \\
\text { piel), máximo }\end{array}$ & 1 & 1 & 3 \\
\hline $\begin{array}{l}\text { 2. Cortes, cicatrices, } \\
\text { magulladuras, grietas, } \\
\text { rajaduras, máximo }\end{array}$ & 2 & 2 & 3 \\
\hline 3. Brotamiento, maximo & 0 & 0 & 2 \\
\hline 4. Verdeamiento, máximo & 0 & 0 & 2 \\
\hline 5. Pudrición seca, máximo & 0 & 0 & 1 \\
\hline $\begin{array}{l}\text { 6. Pudrición húmeda, } \\
\text { máximo }\end{array}$ & 0 & 0 & 0 \\
\hline $\begin{array}{l}\text { 7. Comeduras, } \\
\text { perforaciones, galerias } \\
\text { (daños causados por insectos } \\
\text { y roedores), máximo }\end{array}$ & 2 & 2 & 2 \\
\hline $\begin{array}{l}\text { 8. Mezclas varietales, } \\
\text { máximo }\end{array}$ & 0 & 0 & 2 \\
\hline $\begin{array}{l}\text { MAXIMO PORCENTAJE } \\
\text { ACUMULADO }\end{array}$ & 5 & 5 & 15 \\
\hline
\end{tabular}

Fuente: NTP 011.119, (2010).

Para poder plasmar con efectividad las especificaciones de los insumos y el producto terminado se elaboraron dos cuadros de especificaciones técnicas de calidad.

\section{Tabla 5.15}

Cuadro de especificaciones técnicas de calidad de la papa amarilla

\begin{tabular}{|c|c|c|c|c|c|c|c|}
\hline \multicolumn{2}{|c|}{ Nombre del producto: } & \multicolumn{2}{|c|}{ Papa amarilla } & $\begin{array}{c}\text { Desarrollado } \\
\text { por: }\end{array}$ & \multirow{2}{*}{\multicolumn{3}{|c|}{ Juan Carlos Matta Vega }} \\
\hline \multicolumn{2}{|c|}{ Función: } & \multicolumn{2}{|c|}{ Alimento } & $\begin{array}{l}\text { Verificado } \\
\text { por: }\end{array}$ & & & \\
\hline \multicolumn{2}{|c|}{ Insumos requeridos: } & \multicolumn{2}{|c|}{ Papas } & $\begin{array}{l}\text { Autorizado } \\
\text { por: }\end{array}$ & \\
\hline \multicolumn{2}{|c|}{ Costo del producto: } & \multicolumn{2}{|c|}{3,25 nuevos soles $/ \mathrm{kg}$} & Fecha: & \multicolumn{3}{|c|}{$02 / 11 / 2017$} \\
\hline \multirow{2}{*}{$\begin{array}{c}\text { Característica } \\
\text { s del } \\
\text { producto }\end{array}$} & \multicolumn{2}{|c|}{ Tipo de característica } & $\begin{array}{c}\text { Norma } \\
\text { técnica } \\
\text { especificacio } \\
\text { nes }\end{array}$ & $\begin{array}{l}\text { Proceso: } \\
\text { muestra }\end{array}$ & \multirow{2}{*}{$\begin{array}{l}\text { Medio de } \\
\text { control }\end{array}$} & \multirow{2}{*}{$\begin{array}{l}\text { Técnica de } \\
\text { inspección }\end{array}$} & \multirow[t]{2}{*}{ NCA } \\
\hline & $\begin{array}{l}\text { Variables/atri } \\
\text { buto }\end{array}$ & $\begin{array}{l}\text { Nivel de } \\
\text { criticidad }\end{array}$ & $\mathrm{VN}+-$ Tol. & $\begin{array}{l}\text { Medición } \\
\quad \text { (valor } \\
\text { promedio) }\end{array}$ & & & \\
\hline Tamaño(mm) & Variable & Alto & $74,5+-12,5$ & & Vernier & Muestreo & 0,025 \\
\hline Peso (g) & Variable & Alto & $184+-80$ & & Balanza & Muestreo & 0,025 \\
\hline
\end{tabular}

Fuente: adaptado de NTP 011.119, (2010). 
Tabla 5.16

Cuadro de especificaciones técnicas de calidad de la papa prefrita

\begin{tabular}{|c|c|c|c|c|c|c|c|}
\hline \multicolumn{2}{|c|}{ Nombre del producto: } & \multicolumn{2}{|c|}{ Papa amarilla pre frita } & $\begin{array}{c}\text { Desarrollado } \\
\text { por: } \\
\end{array}$ & \multirow{2}{*}{\multicolumn{3}{|c|}{ Juan Carlos Matta Vega }} \\
\hline \multicolumn{2}{|c|}{ Función: } & \multicolumn{2}{|c|}{ Alimento } & $\begin{array}{l}\text { Verificado } \\
\text { por: }\end{array}$ & & & \\
\hline \multicolumn{2}{|c|}{ Insumos requeridos: } & \multicolumn{2}{|c|}{ Papas, sal } & $\begin{array}{c}\text { Autorizado } \\
\text { por: }\end{array}$ & & & \\
\hline \multicolumn{2}{|c|}{ Costo del producto: } & \multicolumn{2}{|c|}{5 nuevos soles } & Fecha: & \multicolumn{3}{|c|}{$02 / 11 / 2017$} \\
\hline \multirow{2}{*}{$\begin{array}{c}\text { Característica } \\
\text { s del } \\
\text { producto }\end{array}$} & \multicolumn{2}{|c|}{ Tipo de característica } & $\begin{array}{c}\text { Norma } \\
\text { técnica } \\
\text { especificacio } \\
\text { nes } \\
\end{array}$ & $\begin{array}{l}\text { Proceso: } \\
\text { muestra }\end{array}$ & \multirow{2}{*}{$\begin{array}{c}\text { Medio de } \\
\text { control }\end{array}$} & \multirow{2}{*}{$\begin{array}{l}\text { Técnica de } \\
\text { inspección }\end{array}$} & \multirow{2}{*}{ NCA } \\
\hline & $\begin{array}{l}\text { Variables/atri } \\
\text { buto }\end{array}$ & $\begin{array}{l}\text { Nivel de } \\
\text { criticidad }\end{array}$ & VN +- Tol. & $\begin{array}{l}\text { Medición } \\
\text { (valor } \\
\text { promedio) }\end{array}$ & & & \\
\hline $\begin{array}{c}\text { Tamaño } \\
\text { ancho(mm) }\end{array}$ & Variable & Alto & $9,5 \pm 1$ & & Vernier & Muestreo & 0,025 \\
\hline \begin{tabular}{|c|} 
Tamaño Cota \\
$(\mathrm{mm})$
\end{tabular} & Variable & Alto & $5,4 \pm 1$ & & Vernier & Muestreo & 0,025 \\
\hline
\end{tabular}

Fuente: adaptado de NTP 011.119, (2010).

\subsubsection{Estrategias de mejora}

\section{$\underline{\text { Plan HACCP }}$}

Para la implementación del plan HACCP, primero se debe identificar todos los peligros físicos, químicos y biológicos en los procesos presentados. Luego, se debe plantear medidas de prevención, escoger los puntos críticos de control y sus respectivos límites. Finalmente, se debe plantear una metodología para el aseguramiento del control.

Un punto crítico de control es una actividad o proceso, en el que el control puede ser aplicado y el que puede resultar en la prevención, eliminación o reducción de los riesgos a la seguridad de los alimentos.

La metodología para determinar cuáles son los puntos críticos de control que se desarrollará en el presente proyecto se basa en el árbol de decisión propuesto por The international HACCP Alliance. Este presenta 4 preguntas que sirven para determinar si una parte del proceso es un punto crítico de control. A continuación, se muestra el diagrama de flujo de la toma de decisión.

La metodología para la determinación de los puntos críticos de control que se desarrollará en el presente estudio es el árbol de decisión propuesto por The international HACCP Alliance. Este presenta cuatro preguntas que sirven para determinar si una parte del proceso es un punto crítico de control. En el anexo 5 se muestra el diagrama de flujo que describe la decisión. 
Para poder realizar el análisis de los puntos críticos, primero, se debe hacer un análisis de los peligros en el proceso y las medidas preventivas que se llevan a cabo.

Este análisis es usado para revisar las actividades listadas en el DOP y su objetivo es identificar los peligros que pudieran ocurrir y describir las medidas preventivas, si existen. El peligro puede ser clasificado como una propiedad biológica, química o física que puede dar inseguridad al consumidor del producto. Debe ser identificado el riesgo, basado en la experiencia, los datos epidemiológicos y la información técnica existente. Se debe tener mapeado los diferentes factores que podrían afectar la seguridad de los alimentos. En el Anexo 6 se muestra el análisis de peligros y las medidas preventivas.

Luego de haber descrito las etapas del proceso, se procede a seleccionar los puntos críticos de control y describirlos. 
Tabla 5.17

Cuadro de puntos críticos de control de ambos productos

\begin{tabular}{|c|c|c|c|c|}
\hline \multirow{4}{*}{$\begin{array}{l}\text { Puntos } \\
\text { críticos de } \\
\text { control }\end{array}$} & Peligro & \multirow{4}{*}{ Límites críticos } & \multirow{4}{*}{$\begin{array}{l}\text { Métodos de } \\
\text { monitoreo/frecuencia/persona } \\
\text { responsable }\end{array}$} & \multirow{4}{*}{$\begin{array}{c}\text { Acciones } \\
\text { correctivas/preventivas/persona } \\
\text { responsable }\end{array}$} \\
\hline & Biológico (B) & & & \\
\hline & Químico (Q) & & & \\
\hline & Físico $(\mathrm{F})$ & & & \\
\hline \multirow{3}{*}{ Freído } & $\begin{array}{l}\text { Q (sobreuso de aceite) - Insuficiente control de la } \\
\text { cantidad y tiempo de uso del aceite. Este puede resultar } \\
\text { en un alimento altamente cancerígeno. }\end{array}$ & Aceite medio oscuro. & $\begin{array}{l}\text { Hacer muestreos del aceite una vez } \\
\text { por día. }\end{array}$ & \multirow{3}{*}{$\begin{array}{l}\text { Control visual permanente al } \\
\text { momento de freír y control de calidad } \\
\text { al finalizar el freído. }\end{array}$} \\
\hline & $\begin{array}{l}\text { B (contaminación por contacto) - El estado de una papa } \\
\text { puede contaminar a las demás en caso de usar una en } \\
\text { estado putrefacto. }\end{array}$ & Papas medianamente amarillas. & \multirow{2}{*}{$\begin{array}{l}\text { Verificación del color de la papa al } \\
\text { salir del freído una o dos veces por } \\
\text { día. }\end{array}$} & \\
\hline & $\begin{array}{l}\text { F (sobre cocción) - La sobre cocción generar pérdida } \\
\text { de insumos y dinero. }\end{array}$ & Papas cerca de estar frita. & & \\
\hline \multirow[b]{2}{*}{ Escaldado } & $\begin{array}{l}\text { B - Sobrevivencia de microorganismos que tengan } \\
\text { repercusión en la seguridad pública y que puedan } \\
\text { quedar luego de que los cocine el consumidor. }\end{array}$ & \multirow[b]{2}{*}{$\begin{array}{l}\text { Temperatura de agua no } \\
\text { suficiente para eliminar } \\
\text { microbacterias }\end{array}$} & $\begin{array}{c}\text { Muestreo del producto, para } \\
\text { encontrar concentraciones } \\
\text { microbianas que excedan el límite } \\
\text { permitido. }\end{array}$ & $\begin{array}{c}\text { Utilizar detectores de temperatura } \\
\text { para verificar la temperatura del agua. }\end{array}$ \\
\hline & $\begin{array}{l}\text { B (crecimiento microbiológico) - Si no se mantiene la } \\
\text { temperatura del escaldado a un nivel aceptable es } \\
\text { posible que ocurra un crecimiento microbiológico. El } \\
\text { grado de temperatura debe ser el suficiente, para limitar } \\
\text { el crecimiento de agentes patógenos o bacterias que } \\
\text { comprometan a la salud humana. }\end{array}$ & & $\begin{array}{c}\text { Seguimiento continuo de los } \\
\text { controles de refrigeración. Lo harán } \\
\text { los empleados responsables del área } \\
\text { en el turno. }\end{array}$ & $\begin{array}{l}\text { Utilización de detectores de } \\
\text { microorganismos y control de calidad }\end{array}$ \\
\hline
\end{tabular}

Fuente: adaptado de Cipotato, (2016) y Consumer, (2016)

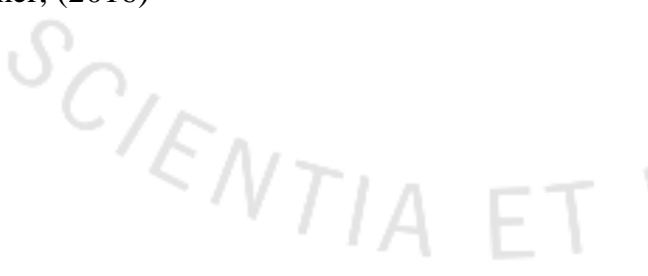




\subsection{Estudio de impacto ambiental}

\section{Tabla 5.18}

Matriz de Aspectos e Impactos Ambientales clasificados por actividad

\begin{tabular}{|c|c|c|c|}
\hline Actividad & Aspecto Ambiental & Impacto Ambiental & Medida Preventiva \\
\hline Selección & Generación de residuos & $\begin{array}{c}\text { Potencial } \\
\text { contaminación del } \\
\text { aire }\end{array}$ & $\begin{array}{c}\text { Segregación y gestión de } \\
\text { residuos }\end{array}$ \\
\hline Lavado & $\begin{array}{l}\text { Generación de tierra, } \\
\text { microbacterias }\end{array}$ & $\begin{array}{l}\text { Contaminación del } \\
\text { agua }\end{array}$ & $\begin{array}{c}\text { Filtración del agua después del } \\
\text { lavado }\end{array}$ \\
\hline $\begin{array}{l}\text { Pelado y } \\
\text { Cortado }\end{array}$ & $\begin{array}{c}\text { Generación de residuos } \\
\text { Orgánicos }\end{array}$ & $\begin{array}{c}\text { Potencial } \\
\text { contaminación de } \\
\text { suelos }\end{array}$ & $\begin{array}{c}\text { Segregación y gestión de } \\
\text { residuos }\end{array}$ \\
\hline Escaldado & $\begin{array}{l}\text { Generación de efluente } \\
\text { caliente }\end{array}$ & $\begin{array}{c}\text { Potencial } \\
\text { contaminación del } \\
\text { agua }\end{array}$ & Recircular el agua caliente \\
\hline Secado & $\begin{array}{l}\text { Generación de aire } \\
\text { caliente }\end{array}$ & $\begin{array}{l}\text { Afectación de la } \\
\text { salud de } \\
\text { trabajadores }\end{array}$ & $\begin{array}{c}\text { Ajuste en el proceso, para evitar } \\
\text { fuga y recirculación del aire } \\
\text { caliente }\end{array}$ \\
\hline Freído & $\begin{array}{c}\text { Generación de aceites } \\
\text { usados }\end{array}$ & $\begin{array}{c}\text { Contaminación del } \\
\text { agua }\end{array}$ & Segregación y gestión del aceite. \\
\hline Empaquetado & Generación de residuos & $\begin{array}{c}\text { Potencial } \\
\text { afectación a los } \\
\text { bosques }\end{array}$ & Uso de plásticos biodegradables. \\
\hline
\end{tabular}

\section{Elaboración Propia}

En la Tabla 5.18 se han identificado algunos aspectos ambientales significativos cuyas medidas preventivas estarán en la gestión de residuos de la empresa, cuyo objetivo es disminuir los efectos y posibles problemas que pueden ocurrir en la planta.

Para reducir el impacto ambiental causado por las actividades mencionadas en la Tabla 5.18, se aplicarán las siguientes medidas:

- Los aceites usados serán vendidos a empresas (como RP Ambiental) que transforman los aceites usados en biodiesel, de esta manera se generará ingresos y no se contaminará el ambiente.

- Los residuos orgánicos (cascaras, papas defectuosas y mermas de los procesos) serán transformados en compostaje para su posterior venta. 
- Programación de un cronograma de charlas de inducción sobre el manejo de residuos y sensibilización ambiental, que se deberá cumplir.

Algunas medidas preventivas son gestionar de manera eficiente los procesos mediante recirculaciones del aire caliente y agua ya que de esta manera no solo se cuida el planeta, sino que también se generar ahorros a la empresa, segregar los residuos de los procesos como cascaras, papas defectuosas, aceite usado y plásticos en contenedores adecuados para cada uno con la finalidad de no dañar a los trabajadores ni al ambiente y para un adecuado manejo posproducción.

La gestión ambiental de la planta tendrá como documento de referencia al decreto supremo No 017-2015-PRODUCE. Según se menciona en el documento, algunos instrumentos que se podrían utilizar para dicho fin son la declaración de Impacto ambiental, el estudio de impacto ambiental semi-detallado y detallado (EIA-d) según el Ministerio de la producción (2015).

\subsection{Seguridad y salud ocupacional}

Las normativas vigentes que se tendrán en cuenta se muestran a continuación:

- Ley 29783 Ley de seguridad y salud en el trabajo

- Reglamento de la ley de SST D.S. 005-2012-TR

- R.M. 040-2013-TR Formatos referenciales e información mínima de registros mínimos del sistema gestión de seguridad y salud en el trabajo

- Ley 30222. Ley modificatoria de la ley 29783.

- D.S. 006-2014.TR. Modificatoria del reglamento de ley 19783.

\subsection{Sistema de mantenimiento}

Para la puesta de marcha del proyecto, se requerirá de un sistema integral preventivo de las máquinas, equipos e instalaciones. Este sistema consistirá en mantener el adecuado nivel de operatividad y productividad, con una permanente disponibilidad al mínimo costo y brindando un alto grado de servicio y calidad a los clientes.

En ese sentido, se contará con un técnico de mantenimiento que tenga conocimientos sobre el mantenimiento preventivo y predictivo. La optima gestión en mantenimiento se basará en un adecuado planeamiento, ejecución y control de los 
trabajos que permitan al área de producción desarrollar sus actividades de forma normal, continua y eficiente. Para lograr una eficiente gestión de mantenimiento es necesario contar con la documentación esencial para los trabajos de mantenimiento:

- Manuales de las máquinas: se indicará como debe ser utilizada la máquina.

- Hojas de máquinas: se incluirá toda la información sobre los mantenimientos y las acciones tomadas sobre la máquina.

- Órdenes de trabajo: sirve para el control de mantenimiento

- Plan de trabajo de mantenimiento: detalle de las principales actividades o tareas para el correcto mantenimiento de las máquinas.

El servicio de mantenimiento de las máquinas, equipos e instalaciones se realizará en tres momentos: i) al inicio de cada turno: los operarios limpiaran y verificaran sus máquinas, ii) al final de cada turno: se efectuará la limpieza y lavado de las instalaciones y máquinas, y iii) al final de cada semana: se realizará la lubricación y el ajuste completo de las partes y piezas de todas las máquinas y equipos. Los dos primeros servicios o mantenimiento serán ejecutados por el operario supervisado por el técnico de mantenimiento y el último servicio será exclusivo del técnico de mantenimiento al ser un trabajo más especializada., todo esto de acuerdo con los planes de mantenimiento planificado.

El responsable de mantenimiento coordinará con el área de producción el momento disponible para realizar las actividades establecidas, de tal manera de no afectar con el programa de producción. Para la ejecución efectiva de los trabajos de mantenimiento será necesario el apoyo permanente del área de logística para la oportuna adquisición y disponibilidad de las herramientas, repuestos y materiales necesarios para los mantenimientos.

\subsection{Programa de producción}

\subsubsection{Factores para la programación de la producción}

Al tener un periodo de vida útil del proyecto de 5 años, periodo en el cual resulta adecuado para hacer las estimaciones pertinentes de costos, proyección de la demanda, oferta, depreciación de las máquinas y equipos de planta, condiciones del mercado y 
disponibilidad de insumos; para el proceso de introducción, crecimiento y maduración del producto.

Para la materia prima, insumos y materiales indirectos, se consideran como factores influyentes perecibles de los productos y la disponibilidad de infraestructura de almacenamiento. En tal sentido, se dispondrá de un almacenamiento para mantener en inventario el requerimiento de una semana de producción.

Para el producto terminado, se considera como factor de decisión el costo de almacenamiento. En tal sentido, se requerirá mantener un inventario mínimo de existencias en el almacén, debido al alto costo del almacenamiento congelado. Para el cumplimiento de lo anterior se buscará producir una cantidad de acuerdo con la tendencia de la demanda anual.

Se deberá tener en cuenta el stock de seguridad del 5\% (tabla 5.19) para el cálculo de la producción total, la cual reflejará la producción por año en los próximos cinco años, teniendo como base la demanda del proyecto y el supuesto crecimiento constante de este.

\section{Tabla 5.19}

Stock de seguridad

\begin{tabular}{|c|c|c|}
\hline Año & Demanda (TM) & Stock de seguridad (TM) \\
\hline 2016 & 66,74 & 3,34 \\
\hline 2017 & 71,99 & 3,60 \\
\hline 2018 & 77,03 & 3,85 \\
\hline 2019 & 81,89 & 4,09 \\
\hline 2020 & 86,59 & 4,33 \\
\hline
\end{tabular}

Elaboración Propia

El cálculo de la producción anual de kilogramos de producto (Tabla 5.20), tomara en cuenta la demanda, stock de seguridad y una efectividad de producción de $98 \%$ por lo cual las perdidas probables por eventualidades en el transporte o almacén, las cuales serán de $2 \%$ y que al final de cada año solo hay stock de seguridad. 


\subsubsection{Programa de producción}

Tabla 5.20

Programa de producción

\begin{tabular}{|l|c|c|c|c|c|}
\hline Año & Demanda (TM) & SS (TM) & Producción (TM) & Pérdidas (TM) & Producción final (TM) \\
\hline 2018 & 66,74 & 3,34 & 70,08 & 1,40 & 71,48 \\
\hline 2019 & 71,99 & 3,60 & 72,25 & 1,44 & 73,69 \\
\hline 2020 & 77,03 & 3,85 & 77,28 & 1,55 & 78,82 \\
\hline 2021 & 81,89 & 4,09 & 82,13 & 1,64 & 83,77 \\
\hline 2022 & 86,59 & 4,33 & 86,83 & 1,74 & 88,57 \\
\hline
\end{tabular}

Elaboracion Propia

La producción final en el año de mayor demanda, no supera la capacidad instalada de TM de producto terminado por año, por lo que no es necesario considerar más recursos para aumentarla. Además, el sistema de producción es FIFO, esto quiere decir que el stock de cada mes se renueva ya que es un producto perecible.

\subsection{Requerimiento de insumos, servicios y personal}

A continuación, se muestra el cálculo de la fracción de rendimiento total, que ha tomado como datos a los resultados del balance de materia.

Tabla 5.21

Cálculo de rendimiento de materiales

\begin{tabular}{|l|c|}
\hline Datos del diagrama de flujo & Cantidad de insumos (kg) \\
\hline Entrada de papas amarillas & 175641 \\
\hline Papas amarillas pre fritas & 43297 \\
\hline Papas precocidas & 43297 \\
\hline Producción total & 86594 \\
\hline Fracción de rendimiento total & 0,493 \\
\hline
\end{tabular}

Elaboracion Propia 


\subsubsection{Materia prima, insumos y otros materiales}

En la siguiente tabla, se muestra el cálculo del requerimiento de materia prima.

Tabla 5.22

Cálculo de requerimiento de materia prima

\begin{tabular}{|c|c|c|}
\hline Año & Producción final (TM) & Materia prima requerida (TM) \\
\hline 2018 & 71,48 & 142,96 \\
\hline 2019 & 73,69 & 147,39 \\
\hline 2020 & 78,82 & 157,65 \\
\hline 2021 & 83,77 & 167,55 \\
\hline 2022 & 88,57 & 177,13 \\
\hline
\end{tabular}

Elaboración Propia

A continuación, se muestra el cálculo de cantidad de envases por producto. Cabe señalar que la compra de envases se hace por metro cuadrado, ya que es un laminado que viene en bobinas.

Tabla 5.23

Cálculo de requerimiento de otros insumos.

\begin{tabular}{|l|c|c|}
\hline & & Magnitud \\
\hline Volumen de un empaque & 17,00 & $\mathrm{OZ}$ \\
\hline Volumen de un empaque & 502,75 & $\mathrm{~cm}^{3}$ \\
\hline Ancho del empaque & 1,00 & $\mathrm{~cm}$ \\
\hline Largo del empaque & 22,42 & $\mathrm{~cm}$ \\
\hline Cota del empaque & 22,42 & $\mathrm{~cm}$ \\
\hline Área del empaque (una cara) & 0,05 & $\mathrm{~m}^{2}$ \\
\hline Área del empaque total & 0,10 & $\mathrm{~m}^{2}$ \\
\hline Cantidad de empaques por caja máster & 29 & unidades $^{2}$ \\
\hline
\end{tabular}

Elaboración Propia

A continuación, se muestra la cantidad de envases primarios requeridos y cantidad de cajas máster. 
Tabla 5.24

Cálculo de la cantidad necesaria de otros insumos

\begin{tabular}{|l|c|c|c|c|c|}
\hline Año & $\begin{array}{l}\text { Producción } \\
\text { final (TM) }\end{array}$ & $\begin{array}{l}\text { Producción final } \\
\text { (unidades) }\end{array}$ & $\begin{array}{l}\text { Necesidad de } \\
\text { empaque por } \\
\text { unidad }\left(\mathrm{m}^{2}\right)\end{array}$ & $\begin{array}{l}\text { Cantidad de } \\
\text { empaque requerido } \\
\left(\mathrm{m}^{2}\right)\end{array}$ & $\begin{array}{l}\text { Cantidad de } \\
\text { cajas mater } \\
\text { requeridas }\end{array}$ \\
\hline 2018 & 71,48 & 142,96 & 0,10 & 14300 & 4767 \\
\hline 2019 & 73,69 & 147,39 & 0,10 & 14740 & 4914 \\
\hline 2020 & 78,82 & 157,65 & 0,10 & 15770 & 5257 \\
\hline 2021 & 83,77 & 167,55 & 0,10 & 16760 & 5587 \\
\hline 2022 & 88,57 & 177,13 & 0,10 & 17720 & 5907 \\
\hline
\end{tabular}

Elaboración Propia

\subsubsection{Servicios}

Energía eléctrica:

El cuadro siguiente muestra la potencia requerida anual para la producción de los tres productos propuestos.

Tabla 5.25

Cálculo de potencia anual requerida para la producción

\begin{tabular}{|c|c|c|c|c|}
\hline Equipos & $\begin{array}{c}\text { \# de } \\
\text { máquinas }\end{array}$ & $\begin{array}{c}\text { Potencia eléctrica } \\
(\mathrm{kW})\end{array}$ & $\begin{array}{c}\text { Horas de operación } \\
\text { anual }\end{array}$ & $\begin{array}{c}\text { Potencia } \\
\text { anual }\end{array}$ \\
\hline Lavadora & 1 & 1,5 & 2112 & 3168 \\
\hline Peladora & 1 & 0,75 & 2112 & 1584 \\
\hline Cortadora & 2 & 0,75 & 2112 & 3168 \\
\hline Escaldadora & 2 & 15 & 2112 & 63360 \\
\hline Freidora & 1 & 9 & 2112 & 19008 \\
\hline Secadora & 2 & 0,75 & 2112 & 3168 \\
\hline Congeladora & 1 & 0,37 & 2112 & 781 \\
\hline Empacadora & 1 & 1 & 2112 & 2112 \\
\hline Fajas & 8 & 0,5 & 2112 & 8448 \\
\hline \multicolumn{2}{|r|}{} & TOTAL & & 104797 \\
\hline
\end{tabular}

Elaboración Propia

Agua:

Es un insumo importante en la fabricación del producto, ya que se utiliza en el lavado de las papas y en la limpieza de la planta. Este recurso es importante, además, porque se consume en el área administrativa y en la aduana sanitaria. En la Tabla 5.26 siguiente, se muestra el requerimiento anual de agua. 
Tabla 5.26

Cuadro de requerimiento de agua

\begin{tabular}{|c|c|c|c|}
\hline Actividad & Capacidad $\left(\mathrm{m}^{3} /\right.$ hora $)$ & Tiempo de ope. (horas por día) & Consumo anual \\
\hline Lavado & 12,2 & 2112 & 25766,4 \\
\hline Limpieza & 1 & 13,2 & 13,2 \\
\hline Aduana sanitaria & 0,4 & 13,2 & 5,28 \\
\hline Área admin. & 0,375 & 2112 & 792 \\
\hline \multicolumn{2}{|c|}{ Total } \\
\hline
\end{tabular}

Elaboración Propia

Combustible:

El combustible se utiliza para calentar el agua, para los servicios y la aduana sanitaria.

En la Tabla 5.27 siguiente se muestra en requerimiento de combustible.

Tabla 5.27

Cuadro de requerimiento de combustible

\begin{tabular}{|c|c|c|}
\hline Tasa de reposición de gas $(\mathrm{kg} / \mathrm{mes})$ & Meses de trabajo & Consumo anual (kg/año) \\
\hline 40 & 12 & 240 \\
\hline
\end{tabular}

Elaboracion Propia

\subsubsection{Determinación del número de operarios y trabajadores indirectos}

Para definir la cantidad de trabajadores para el proceso de producción se debe considerar que para actividad mecanizada requiere de un operario, por esta razón el número de operarios será igual al número de máquinas necesarias más los procesos manuales.

Tabla 5.28

Cantidad de operarios para los procesos comunes

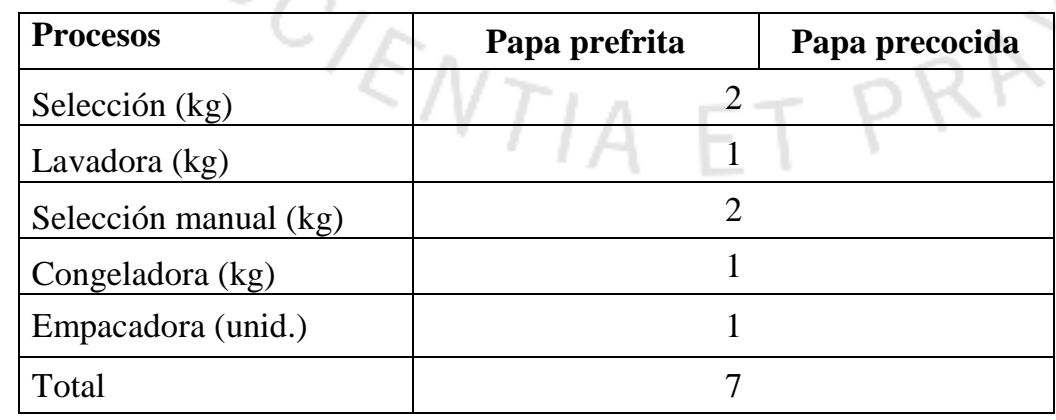

Elaboracion Propia 
Tabla 5.29

Cantidad de operarios para la papa prefrita

\begin{tabular}{|l|c|}
\hline Procesos & Papa prefrita \\
\hline Peladora $(\mathrm{kg})$ & 1 \\
\hline Cortadora bastón $2(\mathrm{~kg})$ & 1 \\
\hline Escaldadora $1(\mathrm{~kg})$ & 1 \\
\hline Secador $1(\mathrm{~kg})$ & 1 \\
\hline Freidora $(\mathrm{kg})$ & 1 \\
\hline Total & 5 \\
\hline
\end{tabular}

Elaboracion Propia

Tabla 5.30

Cantidad de operarios para la papa precocida

\begin{tabular}{|l|c|}
\hline Procesos & Papa precocida \\
\hline Peladora $(\mathrm{kg})$ & 1 \\
\hline Cortadora rodajas $(\mathrm{kg})$ & 1 \\
\hline Escaldadora $2(\mathrm{~kg})$ & 1 \\
\hline Secador $2(\mathrm{~kg})$ & 1 \\
\hline Total & 4 \\
\hline
\end{tabular}

Elaboración Propia

La cantidad total de operarios requeridos es 16.

\subsubsection{Servicios de terceros}

Se buscará una alianza estratégica con una empresa experta en el manejo de residuos orgánicos o recicladora.

\subsection{Disposición de planta}

\subsubsection{Características físicas del proyecto}

\subsubsection{Factor edificio}

Para contemplar los posibles riesgos, así como garantizar la calidad de nuestros productos, las instalaciones tienen que ir acorde a las normas nacionales de sanidad y salubridad. Por ello, el proceso se regirá por el Reglamento de DIGESA. Se detalla a continuación los siguientes puntos: 
- Las vías de acceso deben contar con una superficie pavimentada apta para el tráfico correspondiente, estas deben encontrarse dentro del recinto del establecimiento.

- La estructura y acabados serán hechos con materiales impermeables y resistentes a los roedores. Los pisos contarán con declives hacia las canaletas. Por otro lado, los techos deben ser construidos de tal manera que sea fácil su limpieza e impida la acumulación de suciedad, mohos y disminuyan la condensación de agua.

- La iluminación será de 540 lux para la etapa de selección y revisión, 220 lux en el área de producción y 110 lux en las demás áreas.

- Se contará con ventilación para prevenir el calor excesivo y la condensación de vapor de agua y permitir la adecuada temperatura en los ambientes. La corriente de aire no debe trasladarse desde una zona sucia a una limpia.

\subsubsection{Factor servicio}

Es un apoyo a las áreas productivas de la planta. Respecto a los operarios, las zonas adicionales serán los S.S.H.H, vestidores, aduana sanitaria y comedor. Para el personal administrativo se considera: S.S.H.H, sala de oficinas y oficinas. Adicionalmente se cuenta con estacionamiento junto al patio de maniobras. Por otro lado, con respecto al material es necesario un almacén de materias primas, así como de producto terminado (refrigerado a -18C). Además, se considera la implementación de instalaciones de agua, desagüe, energía eléctrica, vapor y gas natural. A continuación, el detalle de los servicios:

- Sanitarios para mujeres y hombres que incluya ducha: se considerara 2 baños de $50 \mathrm{~m}^{2}$ cada uno cada uno contará con 12 duchas, 5 lavatorios, 3 inodoros y en el baño de hombres con 2 urinarios (Norma 007-98-SA).

- Almacenes de materia prima e insumos de 20 m2cada uno.

- Ventilación para la instalación y casilleros personales.

- Comedor: se realizará por turnos, por lo que se considera a los operarios en el primer turno y el personal administrativo en el siguiente; teniendo en cuenta el área de $2 \mathrm{~m} 2$ por comensal, tendremos un resultado aproximado de $50 \mathrm{~m} 2$. También contará con bidón de agua y un horno microondas. 
- Recepción con un área aproximada de 10 m2.

- Oficinas administrativas: se tendrá cubículos, considerando el número de personas se tendrá como área $90 \mathrm{~m} 2$ aproximadamente (considera pasillos). Para el gerente general un área aproximada de $10 \mathrm{~m} 2$ y los jefes $7 \mathrm{~m} 2$

- Seguridad y tópico: se considera 7 m2para cada uno.

- Laboratorio: se considera un área de $15 \mathrm{~m} 2$ para los equipos y el ingeniero.

- Aduana sanitaria: para el lavado de botas y manos en un área de 6 m2.

- Estacionamiento: zona exclusiva para el parqueo de gerentes y jefes. Contará con 3 espacios para el estacionamiento diagonal, con un área total de $80 \mathrm{~m} 2$. Así mismo un patio de maniobras de $160 \mathrm{~m} 2$ y una oficina de vigilancia de $10 \mathrm{~m} 2$ dando un total de $250 \mathrm{~m} 2$ aproximadamente.

\subsubsection{Determinación de las zonas físicas requeridas}

Son tres áreas bien definidas: área administrativa, zona de producción, y patio de maniobras/estacionamiento.

Para el área administrativa se contará con oficinas para:

- Gerente general

- Jefe de administración y finanzas que contará con un supervisor de compras.

- Jefe de ventas que contará con un supervisor de ventas

- Jefe de producción que contará con un supervisor de operarios, calidad y un auxiliar de calidad.

- Secretaria general

Para el área de producción se contará con

- Área de producción

- Zona de aseo para operarios 


\subsubsection{Cálculo de áreas para cada zona}

El área del área productiva de la planta se calculará usando el método de Guerchet. Este método es utilizado desde hace décadas, que utiliza los elementos estáticos como la maquinaria y equipos y los elementos móviles como los operarios y equipos de acarreo de materiales para estimar el área requerida por estos mismos, en base a las necesidades y especificaciones de la planta.

Esta técnica parte del cálculo del área estática, para luego, en base al número de lados por los cuales se va a usar cada máquina, calcular una superficie gravitacional. Además, se consideran los espacios necesarios para el desplazamiento del personal y los materiales a través de la superficie evolutiva, usando el coeficiente de evolución ' $\mathrm{K}$ ' $(\mathrm{k}=0,6082)$, para finalmente tener un área requerida de $151,21 \mathrm{~m}^{2}$ (Tabla 5.31).

Tabla 5.31

\section{Análisis Guerchet}

\begin{tabular}{|c|c|c|c|c|c|c|c|c|c|}
\hline \multirow{2}{*}{$\begin{array}{c}\text { Elementos } \\
\text { Estáticos }\end{array}$} & \multicolumn{3}{|c|}{ Dimensiones (m) } & \multirow{2}{*}{$\mathrm{N}$} & \multirow{2}{*}{$\mathrm{n}$} & \multirow{2}{*}{ Ss } & \multirow{2}{*}{$\mathrm{Sg}$} & \multirow{2}{*}{$\mathrm{Se}$} & \multirow{2}{*}{ St } \\
\hline & $\mathrm{L}$ & A & $\mathrm{h}$ & & & & & & \\
\hline Punto de espera (parihuelas) & 0,80 & 1,20 & 1,22 & - & 2,00 & 0,96 & & 0,57 & 3,06 \\
\hline Mesa de selección & 2,60 & 0,80 & 0,85 & 4,00 & 3,00 & 2,08 & 8,32 & 6,18 & 49,75 \\
\hline Lavadora & 6,10 & 2,00 & 2,00 & 3,00 & 1,00 & 12,20 & 36,60 & 29,01 & 77,81 \\
\hline Peladora & 0,69 & 0,43 & 0,86 & 2,00 & 1,00 & 0,30 & 0,59 & 0,53 & 1,42 \\
\hline Cortadora & 0,65 & 0,51 & 0,70 & 2,00 & 1,00 & 0,33 & 0,66 & 0,59 & 1,59 \\
\hline Escaldadora & 1,31 & 0,65 & 0,70 & 2,00 & 1,00 & 0,85 & 1,70 & 1,52 & 4,07 \\
\hline Freidora & 0,80 & 0,62 & 0,93 & 2,00 & 1,00 & 0,50 & 0,99 & 0,88 & 2,37 \\
\hline Secador & 1,00 & 0,80 & 1,38 & 2,00 & 1,00 & 0,80 & 1,60 & 1,43 & 3,83 \\
\hline Congelador IQF & 1,38 & 0,82 & 1,86 & 1,00 & 1,00 & 1,13 & 1,13 & 1,35 & 3,61 \\
\hline Empacadora & 1,05 & 0,65 & 0,86 & 2,00 & 1,00 & 0,68 & 1,37 & 1,22 & 3,26 \\
\hline Punto de espera (cajas) & 0,40 & 0,35 & 0,30 & - & 2,00 & 0,14 & & 0,08 & 0,45 \\
\hline \multicolumn{10}{|l|}{ Móviles } \\
\hline Operarios & - & - & 1,65 & - & 16,00 & 0,50 & - & - & - \\
\hline Montacargas & 2,60 & 1,15 & 2,17 & - & 1,00 & 2,99 & - & - & - \\
\hline 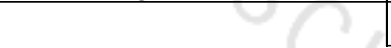 & & & & & & & Total & & 151,21 \\
\hline
\end{tabular}

Elaboración Propia

Para el cálculo de las otras zonas, se han considerado los criterios brindados por el libro: "Instalaciones de manufactura "de D. R. Sule, el cual brinda las pautas para determinar el tamaño recomendable para las áreas como: los vestidores, comedor, oficinas, entre otros. A continuación, se muestra los $\mathrm{m}^{2}$ requeridos para estas áreas: 


\section{Tabla 5.32}

Cálculo de áreas que no pertenecen a producción

\begin{tabular}{|l|l|}
\hline Áreas que no pertenecen a producción & Área aprox. En $\mathrm{m}^{2}$ \\
\hline Almacén de MP e insumos & 20 \\
\hline Sala de conferencias & 20 \\
\hline Oficinas administrativas & 100 \\
\hline SSHH administrativo varones y damas & $10(\mathrm{c} / \mathrm{u})$ \\
\hline Vestidor varones y damas & $50(\mathrm{c} / \mathrm{u})$ \\
\hline Comedor & 50 \\
\hline Garita de seguridad & 10 \\
\hline Patio de maniobras & 160 \\
\hline Estacionamiento & 80 \\
\hline Aduana de sanidad & 8 \\
\hline Total & 560 \\
\hline
\end{tabular}

Elaboración Propia

Con los cálculos obtenidos con Guerchet y la información de áreas de oficinas y áreas no productivas se halló que el área total requerida es de $711 \mathrm{~m}^{2}$.

\subsubsection{Dispositivos de seguridad industrial y señalización}

Basados en la ley de seguridad y salud en el trabajo $n^{\circ} 29783$ se procede a realizar una identificación visual en el plano de las señalizaciones y zonas seguras; con el fin de poder disminuir los riesgos y peligros a nuestros colaboradores. Para ello, la planta tendrá señales de seguridad para señalización y prevención de riesgos y peligros, como puertas de emergencia, líneas de tránsito en todas las áreas incluyendo el patio de maniobras y muchas más con la finalidad de mantener a todo el personal sano y seguro.

\subsubsection{Disposición general}

Con la finalidad de llevar a cabo la disposición general de la planta se evaluó primero los $\mathrm{m}^{2}$ requeridos para la zona de producción, el que se definió en función de las áreas estáticas, gravitacionales y de evolución de la maquinaria dándonos el metraje aproximado. Además, se contempló las áreas del patio de maniobras, vestidores, comedor, garita de seguridad, sala de conferencias, almacén de materia prima y de producto terminados; dándonos como resultado final el plano siguiente. 


\subsubsection{Disposición de detalle}

Figura 5.6

Plano general de la planta

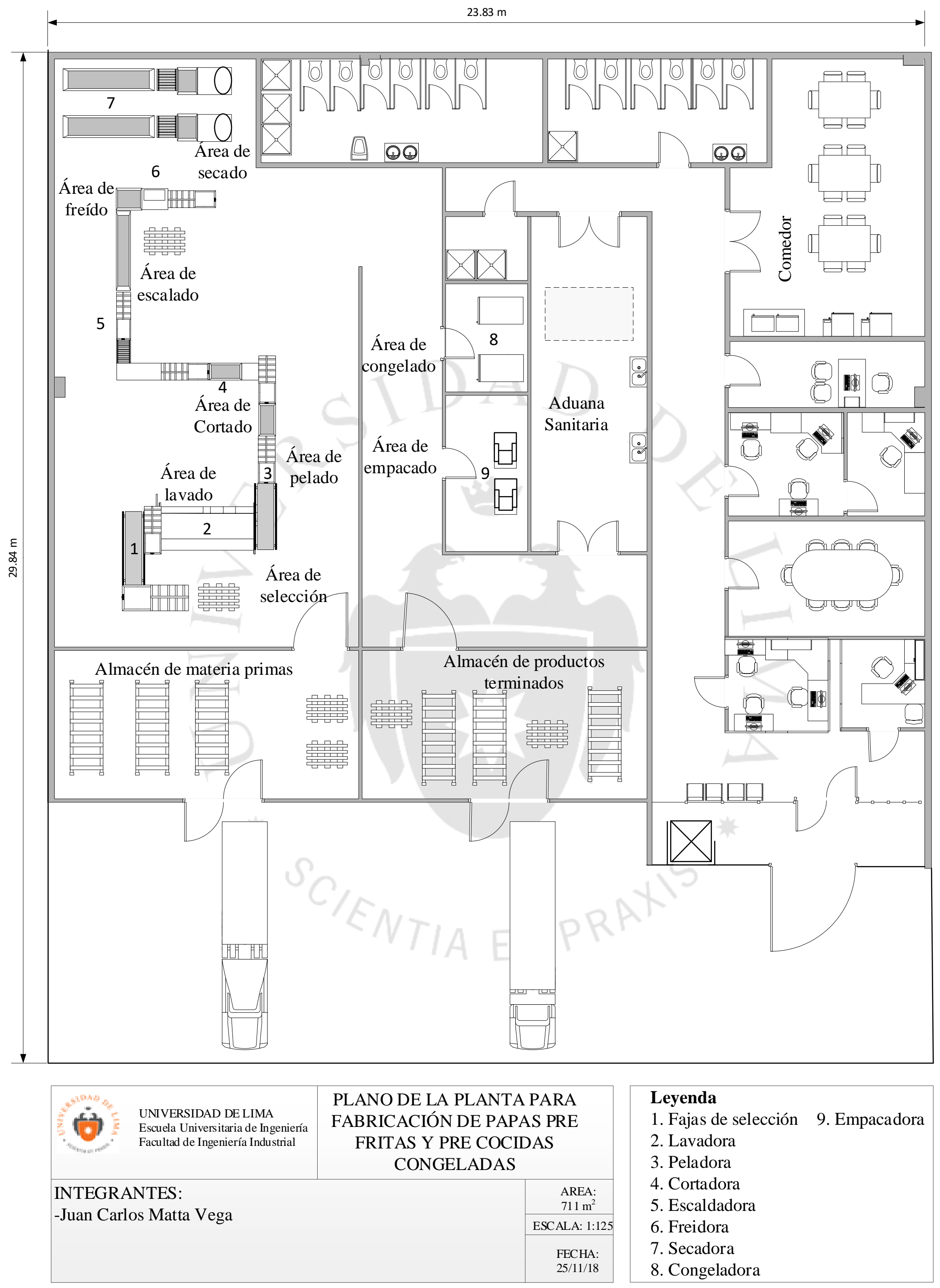

Elaboración Propia 
5.12. Cronograma de implementación del proyecto.

\section{Figura 5.7}

Diagrama de Gantt del proyecto

\begin{tabular}{|c|c|c|c|}
\hline $\begin{array}{l}\text { Estudio de } \\
\text { prefactibilidad }\end{array}$ & 60 dias & $\operatorname{mar} 01 / 01 / 19$ & $\operatorname{lun} 25 / 03 / 19$ \\
\hline Construcción de Planta & 30 dias & $\operatorname{mar} 26 / 03 / 19$ & $\operatorname{lun} 06 / 05 / 19$ \\
\hline Instalaciones Eléctricas & 15 dias & $\operatorname{mar} 07 / 05 / 19$ & $\ln 27 / 05 / 19$ \\
\hline $\begin{array}{l}\text { Traslado de } \\
\text { maquinarias }\end{array}$ & 10 dias & $\operatorname{mar} 07 / 05 / 19$ & $\operatorname{lun} 20 / 05 / 19$ \\
\hline $\begin{array}{l}\text { Instalación de } \\
\text { maquinaria }\end{array}$ & 10 dias & $\operatorname{mar} 28 / 05 / 19$ & $\operatorname{lun} 10 / 06 / 19$ \\
\hline $\begin{array}{l}\text { Contratación de } \\
\text { Personal }\end{array}$ & 30 dias & $\operatorname{mar} 11 / 06 / 19$ & $\operatorname{lun} 22 / 07 / 19$ \\
\hline $\begin{array}{l}\text { Capacitación de } \\
\text { Personal }\end{array}$ & 20 dias & $\operatorname{mar} 23 / 07 / 19$ & $\operatorname{lun} 19 / 08 / 19$ \\
\hline Prueba de la maquinaria & 14 dias & $\operatorname{mar} 20 / 08 / 19$ & vie $06 / 09 / 19$ \\
\hline
\end{tabular}

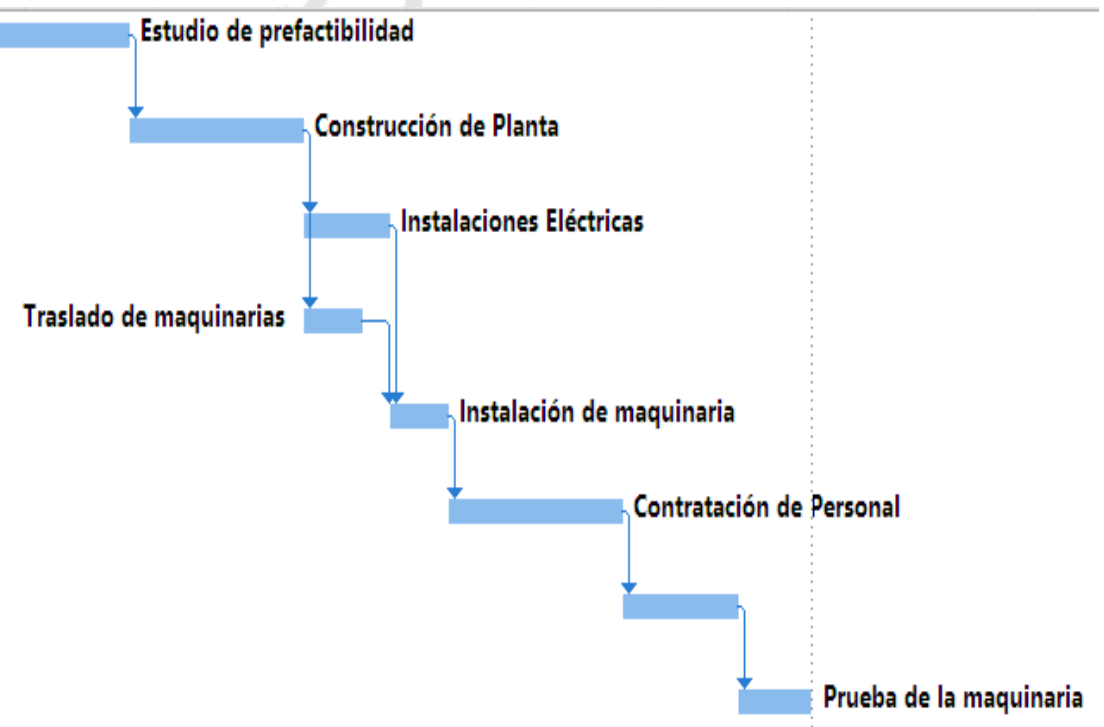

Elaboración Propia 


\section{CAPÍTULO VI: ORGANIZACIÓN Y ADMINISTRACIÓN}

\subsection{Formación de la organización empresarial}

Se constituirá como una empresa individual de responsabilidad limitada (EIRL), para lo cual se deberán seguir los siguientes pasos y gestionar la documentación:

- Búsqueda y reserva del nombre en INDECOPI y registros públicos.

- Elaborar la minuta de constitución. En esta se definirá a la empresa por la actividad industrial a la que se dedica; es decir, elaboración de productos alimenticios a base de papa.

- Escritura pública ante el notario.

- Inscripción en el registro de personas jurídicas.

- Tramitar el RUC y clave Sol ante la SUNAT.

- Emisión de boletas, factura, actas y recibos.

- Solicitar licencias de funcionamiento ante la municipalidad de Ate.

La empresa al ser de tipo EIRL, consta con un titular (dueño) que tiene el poder de decisión sobre los bienes y actividades de la empresa; y la Gerencia tiene como función la administración y representación; el dueño puede desempeñar ambas labores (Wendy Dávila,2015). Esta razón social es la más recomendada para empresas medianas, pequeñas y personales.

Bajo esta premisa el nombre la sociedad es Amkha E.I.R.L. El capital social será aportado por un accionista principal en efectivo, la ubicación es en Ate y su duración es indefinida.

\subsection{Requerimientos de personal y funciones.}

La empresa tendrá 5 niveles de organización: Gerente General, jefes, supervisores u operarios y personal de servicios que serán tercerizados con un costo promedio de $12 \mathrm{~S} / \mathrm{h}$. 


\section{Tabla 6.1}

\section{Cantidad de personal requerido y funciones}

\begin{tabular}{|c|c|c|}
\hline Personal & Cantidad & Función \\
\hline Gerente general & 1 & $\begin{array}{l}\text { Dirigir, designar todas las actividades, realizar evaluaciones } \\
\text { periódicas acerca del cumplimiento de los objetivos } \\
\text { acordados }\end{array}$ \\
\hline Secretaria general & 1 & $\begin{array}{l}\text { Atender los teléfonos, recibir documentos, atender visitas, } \\
\text { archivar documentas, etc. }\end{array}$ \\
\hline $\begin{array}{l}\text { Jefe de administración y } \\
\text { finanzas }\end{array}$ & 1 & $\begin{array}{l}\text { Encargado de reclutar y capacitar a los supervisores y } \\
\text { operarios, vigilar y controlar las finanzas de la empresa. }\end{array}$ \\
\hline Jefe de producción & 1 & $\begin{array}{l}\text { Encargado del seguimiento de la producción, supervisar a los } \\
\text { operarios. }\end{array}$ \\
\hline Jefe de ventas & 1 & $\begin{array}{l}\text { Encargado de generar órdenes de compra mediante la } \\
\text { publicidad, mercadeo y promociones. }\end{array}$ \\
\hline Asistentes & 4 & Encargado de apoyar en las labores de cada jefe. \\
\hline Supervisor de operarios & 1 & Apoya a los jefes en sus labores. \\
\hline Operarios & 16 & Encargado de la producción. \\
\hline Personal de seguridad & 2 & Encargado de la seguridad y control de tiempos del personal \\
\hline Personal de limpieza & 3 & Encargado de la limpieza integral de la empresa \\
\hline Total & 31 & \\
\hline
\end{tabular}

\section{Elaboracion Propia}




\subsection{Esquema de la estructura organización}

Figura 6.1

Estructura organizacional

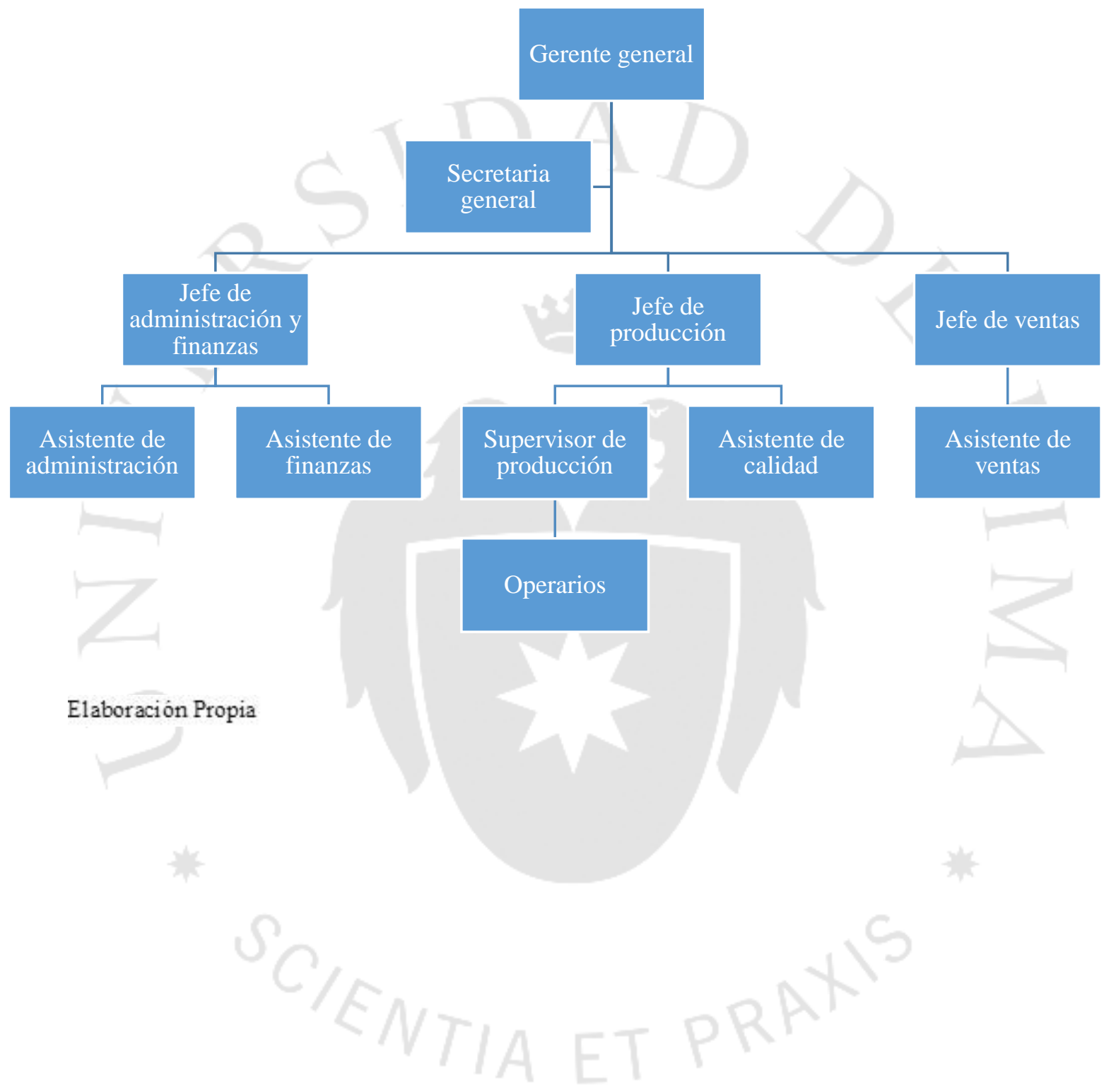




\section{CAPÍTULO VII: PRESUPUESTO Y EVALUACIÓN DEL PROYECTO}

\subsection{Inversiones}

Las inversiones definen los aspectos económicos y financieros de lo que implica la puesta en marcha del proyecto a lo largo de su horizonte de vida.

\subsubsection{Estimación de las inversiones de largo plazo}

Se considerará en tangibles a las maquinarias y en los intangibles a todos los gastos de licencias, estudio de prefactibilidad, etc. La inversión total del proyecto es de S/ 456193.

Tabla 7.1

Inversión en activos fijos en soles

\begin{tabular}{|l|l|l|l|}
\hline Inversión fija tangible & Total & Inversión fija intangible & Total \\
\hline Infraestructura & 100000 & Notaria & 360 \\
\hline Maquinaria y equipos & 82569 & Nominación social (Indecopi) & 36 \\
\hline Muebles y enseres & 30000 & Legalización de los libros contables & 322 \\
\hline Imprevistos & 10000 & Emisión de facturas y notas de crédito & 1400 \\
\hline Capital de trabajo & 199157 & Seguros, Software, pagina web & 10000 \\
\hline $\begin{array}{l}\text { Inversión fija tangible } \\
\text { total }\end{array}$ & $\mathbf{4 2 1}$ & Inversión fija intangible total & $\mathbf{1 2 ~ 1 1 8}$ \\
\hline Total & $\mathbf{7 5 6}$ & $\mathbf{4 3 3 ~ 8 4 4}$ & \\
\hline
\end{tabular}

Elaboración Propia

\subsubsection{Estimación de las inversiones de corto plazo}

El capital de trabajo es la cantidad de dinero necesario para realizar todas las actividades de la empresa con normalidad en el corto plazo:

Tabla 7.2

Capital de trabajo

\begin{tabular}{|l|l|l|l|}
\hline Activo corriente & Total & Pasivo corriente & Total \\
\hline Efectivo & 1495032 & Intereses por pagar & 31159 \\
\hline Cuentas por cobrar & 640728 & cuentas por pagar & 1167250 \\
\hline Inventario & 356324 & Remuneraciones por pagar & 623753 \\
\hline \multirow{2}{*}{ Activo corriente total } & \multirow{2}{*}{$\mathbf{4 9 2} \mathbf{0 8 4}$} & Impuestos por pagar & 470766 \\
\cline { 3 - 4 } & & Pasivo corriente total & $\mathbf{2 ~ 2 9 2 ~ 9 2 7}$ \\
\hline Capital de trabajo & $\mathbf{1 9 9} 157$ & \\
\hline
\end{tabular}

Elaboración Propia

El capital de trabajo a necesitar para la operación normal de la empresa es S/ 199157. 


\subsection{Costos de producción.}

Según la FAO, los costos de producción son gastos esenciales para mantener una línea de producción o un equipo en funcionamiento.

\subsubsection{Costos de las materias primas.}

Las materias primas por usar en el proyecto son: papa amarilla, aceite vegetal no hidrogenado (aceite de girasol) y agua.

\section{Tabla 7.3}

Costo materia prima

\begin{tabular}{|l|l|}
\hline Materia prima & Precio unitario \\
\hline Papa amarilla & $\mathrm{S} / 2,5 / \mathrm{kg}$ \\
\hline Aceite vegetal no hidrogenado & $\mathrm{S} / 2,6 / \mathrm{lt}$ \\
\hline Agua & $\mathrm{S} / 8,61 / \mathrm{m}^{3}$ \\
\hline Bolsas & $\mathrm{S} / 0,30 /$ unid \\
\hline Cajas & $\mathrm{S} / 0,18 /$ unid \\
\hline
\end{tabular}

Elaboracion Propia

\subsubsection{Costo de la mano de obra directa.}

Conformada por operarios, supervisor y jefe de producción (los montos mostrados en la

Tabla 7.4 incluyen todos los beneficios salarios).

\section{Tabla 7.4}

Costo de la mano de obra directa

\begin{tabular}{|l|l|}
\hline Concepto & Sueldo anual \\
\hline 16 operarios & S/ 261600 \\
\hline 1 supervisor de producción & S/ 24525 \\
\hline 1 jefe de producción & S/ 49050 \\
\hline Mano de obra directa total & 335175 \\
\hline
\end{tabular}

Elaboracion Propia

\subsubsection{Costo indirecto de fabricación}

Los costos indirectos de fabricación son todos aquellos materiales, personal y costos que no forman parte de la producción pero que influyen en su producción o venta, para este proyecto los costos indirectos son: personal administrativo, gas natural. Al ser el dueño de la empresa también el gerente general, no tendrá un sueldo sino utilidades. 


\section{Tabla 7.5}

Costo del personal administrativo

\begin{tabular}{|l|c|c|}
\hline Puesto & Sueldo & Sueldo mensual \\
\hline Secretaria General & S/ 19620 & S/ 1,200 \\
\hline Jefes & S/ 98 100 & S/ 3,000 \\
\hline Asistente x 4 & S/ 98 100 & S/ 1,500 \\
\hline Personal de seguridad & S/ 31 065 & S/ 950 \\
\hline Personal de limpieza & S/ 41693 & S/ 850 \\
\hline Costo total & S/ 288 578 & \multicolumn{1}{|c}{} \\
\cline { 1 - 2 } & &
\end{tabular}

Elaboración Propia

Tabla 7.6

Costo de insumo indirecto

\begin{tabular}{|c|c|}
\hline Insumo indirecto & Costo \\
\hline Gas natural & S/4 000 x año aprox. \\
\hline
\end{tabular}

Elaboracion Propia

\subsection{Presupuesto operativo.}

\subsubsection{Presupuesto de ingreso por ventas.}

Se utilizó la demanda del proyecto en toneladas de papa amarilla prefrita. Asimismo, se consideró un precio de Lima de S/.16 por una presentación de $0,5 \mathrm{~kg}$, ya que ingresaremos al mercado con un precio alto pues es un producto nuevo el que, conforme pasen los años, se disminuirá en $5 \%$ su precio.

Tabla 7.7

Presupuesto de ingresos

\begin{tabular}{|l|c|c|c|c|c|}
\cline { 2 - 6 } \multicolumn{1}{c|}{} & $\mathbf{2 0 1 8}$ & $\mathbf{2 0 1 9}$ & $\mathbf{2 0 2 0}$ & $\mathbf{2 0 2 1}$ & $\mathbf{2 0 2 2}$ \\
\hline $\begin{array}{l}\text { Demanda del } \\
\text { proyecto (ton) }\end{array}$ & 66,74 & 71,99 & 77,03 & 81,89 & 86,59 \\
\hline Precio (S/.) & 16,0 & 15,2 & 14,4 & 13,7 & 13,0 \\
\hline $\begin{array}{l}\text { Ingresos Por } \\
\text { Ventas }\end{array}$ & S/. 2135760 & S/. 2188390 & S/. 2224511 & S/. 2246679 & S/. 2257003 \\
\hline
\end{tabular}

Elaboración Propia

\subsubsection{Presupuesto operativo de costos.}

Compuesto por materia prima, mano de obra directa y los costos indirectos de fabricación (se considera el gasto por los almacenes en frio). 
Tabla 7.8

Presupuesto operativo de costos

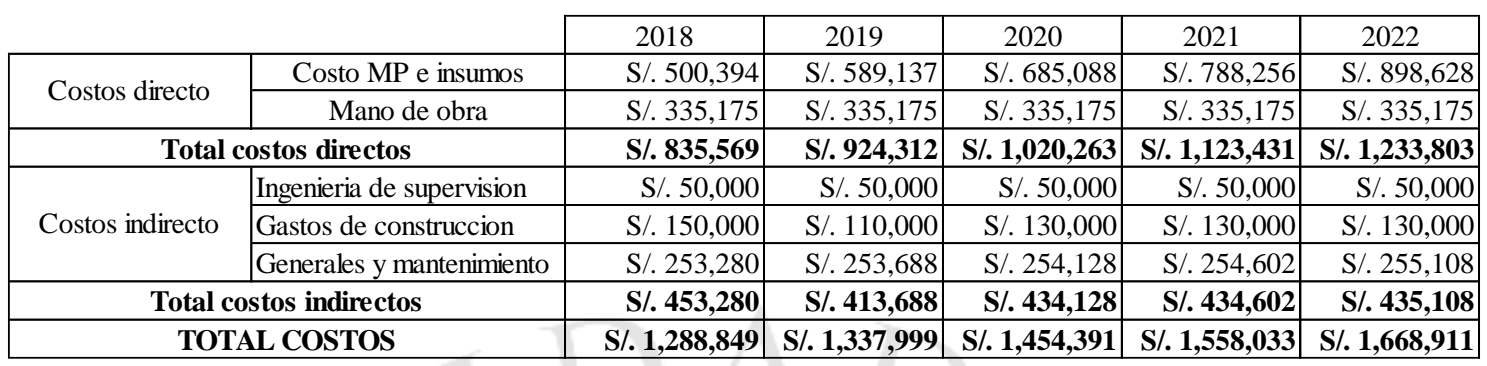

Elaboracion Propia

\subsubsection{Presupuesto operativo de gastos.}

Incluye a los sueldos del personal administrativo y de ventas, publicidad y la depreciación.

Tabla 7.9

Presupuesto operativo de gastos

\begin{tabular}{|c|c|c|c|c|c|c|}
\hline & & \multirow{2}{*}{2018} & \multirow[b]{2}{*}{2019} & \multirow[b]{2}{*}{2020} & & \multirow[b]{2}{*}{2022} \\
\hline & & & & & & \\
\hline \multirow{3}{*}{$\begin{array}{c}\text { Gastos administrativos } \\
\text { y de ventas }\end{array}$} & Sueldos administrativos & $\mathrm{S} / 340417,50$ & $\mathrm{~S} / 340417,50$ & $\mathrm{~S} / 340417,50$ & $\mathrm{~S} / 340417,50$ & $\mathrm{~S} / 340417,50$ \\
\hline & Publicidad y promocion & S/213576 & $\mathrm{S} / 218839$ & $\mathrm{~S} / 222451$ & $\mathrm{~S} / 224668$ & $\mathrm{~S} / 225700$ \\
\hline & Depreciacion & S/ 16256,90 & S/ 16256,90 & S/ 16256,90 & $\mathrm{~S} / 16256,90$ & S/ 16256,90 \\
\hline & Total & $\mathrm{S} / 570250,40$ & $\mathrm{~S} / 575513,36$ & S/ 579125,49 & $\mathrm{~S} / 581342,32$ & $\mathrm{~S} / 582374,73$ \\
\hline
\end{tabular}

Elaboracion Propia

\subsection{Presupuestos financieros}

El presupuesto financiero tiene que ver con los recursos económicos y financieros esenciales para desarrollar los procesos.

\subsubsection{Presupuesto de servicio de deuda.}

Este es uno de los puntos más importantes para el proyecto, ya que la inversión puede verse restringida por la capacidad financiera, al usar activos importantes tanto para terreno de la planta, máquinas, equipos, insumos, entre otros; por tal razón se tiene que analizar las líneas de crédito existentes en el sistema financiero nacional. 
Actualmente en el Perú existe varias entidades financieras (privadas y pública) que dan apoyo al desarrollo de proyectos. En el caso de entidades privadas se cuenta con la siguiente información:

Tabla 7.10

Información entidades bancarias privadas

\begin{tabular}{|l|c|l|}
\cline { 2 - 3 } \multicolumn{1}{c|}{} & TEA & \multicolumn{1}{c|}{ Máximo Monto de Préstamo } \\
\hline Financiera Edyficar & $22,42 \%-79,59 \%$ & S/.300 000 \\
\hline Banco de Crédito (BCP) & $25 \%-60 \%$ & S/.750 000 \\
\hline Banco de Comercio & $10.26 \%$ & S/.66 000 \\
\hline Banco Financiero & $14,45 \%-75,40 \%$ & S/. 300000 \\
\hline
\end{tabular}

Fuente: adaptado de Web de bancos, (2016)

Adicionalmente, en lo que concierne a entidades públicas se tiene a la COFIDE (Corporación financiera de desarrollo), única entidad pública que busca apoyar a empresarios en temas de financiamiento para el desarrollo de un negocio o el inicio de un nuevo proyecto de cualquier tipo. Esta corporación cuenta con líneas de financiamiento dependiendo si un proyecto está en su fase inicial o de diseño, o su fase operacional, se muestra a continuación algunas de estas líneas de financiamiento:

Tabla 7.11

Líneas de financiamiento

\begin{tabular}{|c|c|c|c|}
\hline Linea & Destino & Monto Maximo & Plazo para pago \\
\hline \multirow{4}{*}{$\begin{array}{l}\text { MC Habitat } \\
\text { Productivo }\end{array}$} & Maquina & \multirow{4}{*}{$\$ 10000$} & \multirow{9}{*}{4 a 10 años } \\
\hline & Equipo & & \\
\hline & Capital de trabajo & & \\
\hline & Nuevos proyectos & & \\
\hline \multirow{3}{*}{ PROPEM - BID } & Costos de diseño & \multirow{3}{*}{$\$ 300000$} & \\
\hline & Servicio de apoyo & & \\
\hline & Capital de trabajo & & \\
\hline \multirow{2}{*}{ Micro global } & Activo fijo & \multirow{2}{*}{$\$ 10000$} & \\
\hline & Capital de trabajo & & \\
\hline
\end{tabular}

Elaboracion Propia

En conclusión, se muestra un ambiente crediticio favorable para el proyecto ya que se tienen múltiples opciones para la adquisición de créditos a largo plazo. También se tomará en cuenta un capital propio para iniciar la primera fase del proyecto y adicionalmente se le añadirá el financiamiento que se pudiera obtener por parte de las 
entidades mencionadas anteriormente. Para el proyecto, el financiamiento será por el Banco de Comercio. La conformación del capital se detallará a continuación.

Tabla 7.12

Conformación del capital

\begin{tabular}{|l|c|c|}
\hline \multicolumn{1}{|c|}{ Entidad } & \% de participación & Monto \\
\hline Cap. Social & $30 \%$ & S/. 130153 \\
\hline Financiamiento & $70 \%$ & S/. 303691 \\
\hline Totales & $100 \%$ & S/. 433844 \\
\hline
\end{tabular}

Elaboración Propia

La información del préstamo a considerar se detalla a continuación:

Tabla 7.13

Información del préstamo

\begin{tabular}{|c|c|c|}
\hline TEA promedio & $10.26 \%$ & 1 año de gracia parcial \\
\hline Periodo & 4 años & Cuotas estáticas \\
\hline
\end{tabular}

Fuente: adaptado de Banco de comercio (2018)

Con base a los datos mostrados en el cuadro anterior, se muestra el cuadro de servicio de la deuda durante los 4 años en mención:

Tabla 7.14

Servicio de deuda

\begin{tabular}{|c|c|c|c|c|c|}
\hline Periodo & S. Inicial & Cuota & Interés & Amortización & S.Final \\
\hline 1 & $\mathrm{~S} / .303,691$ & $\mathrm{~S} / .31,159$ & $\mathrm{~S} / .31,159$ & $\mathrm{~S} / .-$ & $\mathrm{S} / .303,691$ \\
\hline 2 & $\mathrm{~S} / .303,691$ & $\mathrm{~S} / .122,678$ & $\mathrm{~S} / .31,159$ & $\mathrm{~S} / .91,519$ & $\mathrm{~S} / .212,172$ \\
\hline 3 & $\mathrm{~S} / .212,172$ & $\mathrm{~S} / .122,678$ & $\mathrm{~S} / .21,769$ & $\mathrm{~S} / .100,909$ & $\mathrm{~S} / .111,262$ \\
\hline 4 & $\mathrm{~S} / .111,262$ & $\mathrm{~S} / .122,678$ & $\mathrm{~S} / .11,416$ & $\mathrm{~S} / .111,262$ & $\mathrm{~S} / .0$ \\
\hline
\end{tabular}

Elaboracion Propia 


\subsubsection{Presupuesto de estado resultados.}

Tabla 7.15

Estado de resultados

\begin{tabular}{|l|c|c|c|c|c|}
\hline Estado de resultados & $\mathbf{2 0 1 8}$ & $\mathbf{2 0 1 9}$ & $\mathbf{2 0 2 0}$ & $\mathbf{2 0 2 1}$ & $\mathbf{2 0 2 2}$ \\
\hline Ventas & $2,135,760$ & $2,188,390$ & $2,224,511$ & $2,246,679$ & $2,257,003$ \\
\hline$(-)$ costo de ventas & $-1,213,030$ & $-1,312,050$ & $-1,428,435$ & $-1,532,164$ & $-1,643,214$ \\
\hline Utilidad bruta & $\mathbf{9 2 2 , 7 3 0}$ & $\mathbf{8 7 6 , 3 4 0}$ & $\mathbf{7 9 6 , 0 7 6}$ & $\mathbf{7 1 4 , 5 1 5}$ & $\mathbf{6 1 3 , 7 9 0}$ \\
\hline$(-)$ gastos de administración y ventas & $-570,250$ & $-575,513$ & $-579,125$ & $-581,342$ & $-582,375$ \\
\hline$(-)$ otros gastos & $-10,000$ & $-10,000$ & $-10,000$ & $-10,000$ & $-10,000$ \\
\hline Utilidad operativa & $\mathbf{3 4 2 , 4 8 0}$ & $\mathbf{2 9 0 , 8 2 6}$ & $\mathbf{2 0 6 , 9 5 1}$ & $\mathbf{1 2 3 , 1 7 2}$ & $\mathbf{2 1 , 4 1 5}$ \\
\hline$(-)$ gastos financieros & $-31,159$ & $-31,159$ & $-21,769$ & $-11,416$ & \\
\hline$(+)$ valor de mercado & & & & & 130,000 \\
\hline$(-)$ depreciacion & $-16,257$ & 16,257 & 16,257 & 16,257 & 16,257 \\
\hline$(-)$ amortizacion de intangibles & $-2,424$ & $-2,424$ & $-2,424$ & $-2,424$ & $-2,424$ \\
\hline Utilidad antes de imp. & $\mathbf{2 9 2 , 6 4 1}$ & $\mathbf{2 7 3 , 5 0 1}$ & $\mathbf{1 9 9 , 0 1 5}$ & $\mathbf{1 2 5 , 5 9 0}$ & $\mathbf{1 6 5 , 2 4 8}$ \\
\hline$(-)$ impuesto a la renta & $-86,329$ & $-80,683$ & $-58,709$ & $-37,049$ & $-48,748$ \\
\hline$(-)$ Participacion de trabajadores & $-23,411$ & $-21,880$ & $-15,921$ & $-10,047$ & $-13,220$ \\
\hline Utilidad neta & $\mathbf{1 8 2 , 9 0 0}$ & $\mathbf{1 7 0 , 9 3 8}$ & $\mathbf{1 2 4 , 3 8 4}$ & $\mathbf{7 8 , 4 9 4}$ & $\mathbf{1 0 3 , 2 8 0}$ \\
\hline
\end{tabular}

Elaboracion Propia

\subsubsection{Presupuesto de estado de situación financiera}

Para las ventas, se tendrá una política de cobro de un $80 \%$ en efectivo y el resto en cuentas por cobrar (crédito).

Tabla 7.16

Estado de situacion financiera

\begin{tabular}{|c|c|c|c|}
\hline Estado de situación financiera & $\mathbf{2 0 1 8}$ & & $\mathbf{2 0 1 8}$ \\
\hline Activo corriente & $\mathbf{2 , 4 9 2 , 0 8 4}$ & Pasivo corriente & $\mathbf{2 , 2 9 2 , 9 2 7}$ \\
\hline Efectivo & $1,495,032$ & Intereses por pagar & 31,159 \\
\hline Cuentas por cobrar & 640,728 & cuentas por pagar & $1,167,250$ \\
\hline Inventario & 356,324 & $\begin{array}{c}\text { Remuneraciones por } \\
\text { pagar }\end{array}$ & 623,753 \\
\hline & & Impuestos por pagar & 470,766 \\
\hline Activo no corriente & $\mathbf{4 1 7 , 5 8 7}$ & Pasivo no corriente & $\mathbf{3 0 3 , 6 9 1}$ \\
\hline Tangibles & 421,726 & Deuda & 303,691 \\
\hline Intangibles & 12,118 & Patrimonio & $\mathbf{3 1 3 , 0 5 4}$ \\
\hline Depreciación acumulada & 16,257 & utilidad neta & 182,900 \\
\hline Activo total & $\mathbf{2 , 9 0 9 , 6 7 2}$ & Pasivo y Patrimonio total & $\mathbf{2 , 9 0 9 , 6 7 2}$ \\
\hline
\end{tabular}

Elaboracion Propia 


\subsubsection{Flujo de caja de corto plazo}

Tabla 7.17

Flujo de caja de corto plazo

\begin{tabular}{|l|c|c|c|c|c|}
\cline { 2 - 6 } \multicolumn{1}{c|}{} & Año 1 & Año 2 & Año 3 & Año 4 & Año 5 \\
\hline Ingresos & $2,135,760$ & $2,188,390$ & $2,224,511$ & $2,246,679$ & $2,257,003$ \\
\hline
\end{tabular}

\begin{tabular}{|l|r|r|r|r|r|}
\hline \multicolumn{1}{|l|}{ Egresos } & \multicolumn{1}{|l|}{} \\
\hline Pagos a proveedores & $-1,213,030$ & $-1,312,050$ & $-1,428,435$ & $-1,532,164$ & $-1,643,214$ \\
\hline Pagos a MOD & $-335,175$ & $-335,175$ & $-335,175$ & $-335,175$ & $-335,175$ \\
\hline Pagos a MOI & $-288,578$ & $-288,578$ & $-288,578$ & $-288,578$ & $-288,578$ \\
\hline
\end{tabular}

\begin{tabular}{|l|r|r|r|r|r|}
\hline Saldo inicial & 298,978 & 252,587 & 172,324 & 90,762 & $-9,963$ \\
\hline Flujo neto & 298,978 & 855,256 & $1,027,579$ & $1,118,342$ & $1,108,379$ \\
\hline Financiamiento & 303,691 & - & - & - & - \\
\hline Saldo final & 602,669 & 855,256 & $1,027,579$ & $1,118,342$ & $\mathbf{1 , 1 0 8 , 3 7 9}$ \\
\hline
\end{tabular}

Elaboración Propia

\subsection{Flujo de fondos netos.}

\subsubsection{Flujo de fondos económicos.}

Es la cantidad de dinero que genera una empresa a través de sus operaciones.

Tabla 7.18

Flujo de fondos económicos

\begin{tabular}{|l|r|r|r|r|r|r|}
\hline Añes & 0 & 1 & \multicolumn{1}{c|}{2} & \multicolumn{1}{c|}{3} & \multicolumn{1}{c|}{4} & \multicolumn{1}{c|}{5} \\
\hline \hline Utilidad neta & & 182,900 & 170,938 & 124,384 & 78,494 & 103,280 \\
\hline Depreciacion tangible & & 16,257 & 16,257 & 16,257 & 16,257 & 16,257 \\
\hline Inversion inicial & $433,844.34$ & & & & & \\
\hline Amortizacion de intangibles & & 2,424 & 2,424 & 2,424 & 2,424 & 2,424 \\
\hline Valor en libros & & & & & & 130,000 \\
\hline Intereses & $-22,278$ & $-22,278$ & $-15,565$ & $-8,162$ & & \\
\hline FFE & $-411,565.86$ & 179,302 & 174,054 & 134,903 & 97,174 & 251,961 \\
\hline
\end{tabular}

\subsubsection{Flujo de fondos financieros.}

Es la circulación de efectivo de una empresa fruto de su actividad económica.

Tabla 7.19

Flujo de fondos financieros

\begin{tabular}{|l|r|r|r|r|r|r|}
\hline Años & \multicolumn{1}{|c|}{0} & \multicolumn{1}{c|}{1} & \multicolumn{1}{c|}{2} & \multicolumn{1}{c|}{3} & \multicolumn{1}{c|}{5} \\
\hline Utilidad neta & & 182,900 & 170,938 & 124,384 & 78,494 & 103,280 \\
\hline depreciacion tangible & & 16,257 & 16,257 & 16,257 & 16,257 & 16,257 \\
\hline Amortizacion de intangibles & & 2,424 & 2,424 & 2,424 & 2,424 & 2,424 \\
\hline Deuda & $303,691.03$ & & & & & \\
\hline Valor en libros & & & & & & \\
\hline Capital de trabajo & & & & & & 130,000 \\
\hline amortizacion & & & $-91,519$ & $-100,909$ & $-111,262$ & \\
\hline inversion inicial & $433,844.34$ & & & & & \\
\hline FFF & $-130,153.30$ & 201,581 & 98,099 & 42,156 & $-14,088$ & 451,118 \\
\hline
\end{tabular}

Elaboracion Propia 


\section{CAPÍTULO VIII: EVALUACION ECONÓMICA Y FINANCIERA}

\subsection{Evaluación económica: VAN, TIR, B/C, PR.}

Se empleó el flujo de fondos económico y el costo de oportunidad como tasa de descuento que fue calculado tomando en cuenta la tasa de rentabilidad promedio del mercado para productos congelados y el riesgo del proyecto y de los accionistas sabiendo que estos tienen un mayor riesgo al promedio por ser un nuevo producto.

Para la evaluación económica y financiera, se necesita COK (costo de oportunidad), por lo que se empleará el Método CAPM.

\section{Determinación del COK}

$$
C O K=r_{f}+\beta *\left(r_{m}-r_{f}\right)
$$

Dónde:

$r f$ : tasa libre de riesgo

rm: tasa promedio de mercado

$\beta$ : factor de riesgo

El valor de $r m$ se halló en base a la rentabilidad sobre patrimonio de una empresa conocida del rubro que es Alicorp, el $r f$ se obtiene del rendimiento de los bonos del tesoro de USA a 10 años y el $\beta$ se obtuvo del promedio del sector de procesamiento de alimentos de Estados Unidos (Aswath Damodaran).

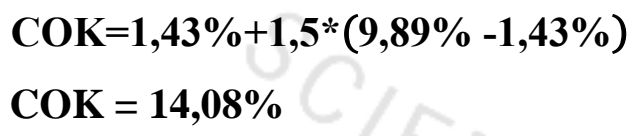

Tabla 8.1

Calculo de VAN, TIR, B/C, PR económico

\begin{tabular}{|l|c|}
\hline VAN & 158,057 \\
\hline TIR & $29.1 \%$ \\
\hline PR (años) & 2.43 \\
\hline B/C & 1.38 \\
\hline COK & $14.08 \%$ \\
\hline
\end{tabular}

Elaboración Propia 
En la evaluación económica se asume que todo el capital es de los accionistas por lo que no se consideran prestamos de terceros.

\subsection{Evaluación financiera: VAN, TIR, B/C, PR.}

Se empleó el flujo de fondos financieros y el costo de oportunidad hallado en el punto anterior.

Tabla 8.2

Calculo de VAN, TIR, B/C, PR financiero

\begin{tabular}{|c|c|}
\hline VAN & 375547 \\
\hline TIR & $113,1 \%$ \\
\hline PR (años) & 2,64 \\
\hline B/C & 3,89 \\
\hline
\end{tabular}

Elaboración Propia

\subsection{Análisis de ratios e indicadores económicos y financieros del proyecto.}

- VAN: teniendo en cuenta que el $70 \%$ sería financiado por medio de una institución bancaria, el flujo de fondos económicos arroja un VAN de S/.158 057 y el financiero un VAN de S/.375 547, confirmando que el proyecto es económica y financieramente viable.

- TIR: el proyecto presenta una TIR económica de 29,1\% que comparándola con el costo de oportunidad resulta ser mayor, permitiendo que el proyecto sea llamativo para los inversionistas. De la misma manera la TIR financiera es de $113,1 \%$, sobrepasando el costo de oportunidad de los accionistas, generando un retorno más del esperado.

- B/C: es la comparación relativa de los beneficios y costos actualizados a un valor presente. Por cada sol invertido se obtendrían S/. 1,38 en la evaluación económica y S/. 3,89 en la evaluación financiera.

- PR: el periodo de recupero sería de 2,43 años según la evaluación económica y 2,64 años según la evaluación financiera, lo que significa que la inversión puede ser recuperada en mediano plazo. 


\subsection{Análisis de sensibilidad del proyecto.}

Antes de calcularlo, primero se halló el porcentaje de ocurrencia de los escenarios pesimistas y optimistas, usando la regresión mostrada anteriormente.

Tabla 8.3

Variación y sensibilidad

\begin{tabular}{|r|r|r|r|c|}
\cline { 2 - 5 } \multicolumn{1}{c|}{} & \multicolumn{1}{c|}{ DIA } & Proyectado & Diferencia & Variacion \\
\hline 2011 & 9870,64 & 9834,00 & 36,64 & $0,37 \%$ \\
\hline 2012 & 15079,19 & 15348,00 & $-268,81$ & $-1,75 \%$ \\
\hline 2013 & 19942,40 & 19913,04 & 29,36 & $0,15 \%$ \\
\hline 2014 & 23870,60 & 23953,73 & $-83,13$ & $-0,35 \%$ \\
\hline 2015 & 27960,30 & 27644,50 & 315,80 & $1,14 \%$ \\
\hline 2016 & 33522,80 & 31078,42 & 2444,38 & $7,87 \%$ \\
\hline 2017 & 31949,00 & 34312,48 & $-2363,48$ & $-6,89 \%$ \\
\hline
\end{tabular}

\begin{tabular}{|c|c|c|}
\hline Sensibilidad & Ocurrencia & Variacion \\
\hline Optimista & $57,14 \%$ & $2,26 \%$ \\
\hline Pesimista & $42,86 \%$ & $-2,83 \%$ \\
\hline
\end{tabular}

Elaboración Propia

Tabla 8.4

Demanda y proyección

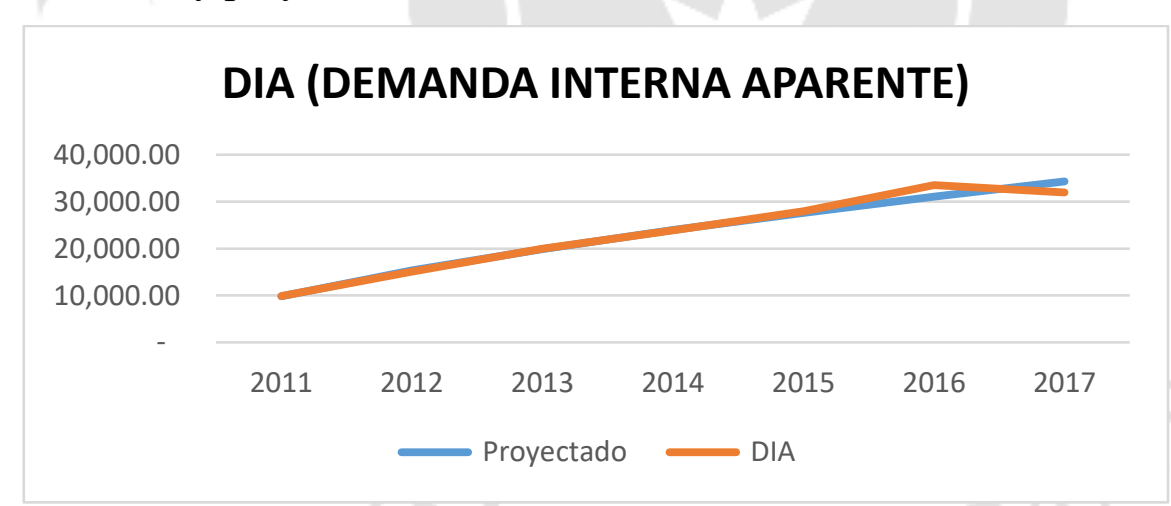

Elaboración Propia

Tabla 8.5

Análisis de sensibilidad

\begin{tabular}{|c|c|}
\hline \multicolumn{2}{|c|}{ Optimista } \\
\hline VAN & 471421 \\
\hline TIR & $138,16 \%$ \\
\hline PR & 2,16 \\
\hline B/C & 4,62 \\
\hline
\end{tabular}

\begin{tabular}{|c|c|}
\hline \multicolumn{2}{|c|}{ Pesimista } \\
\hline VAN & 255370 \\
\hline TIR & $80,68 \%$ \\
\hline PR & 4,26 \\
\hline B/C & 2,96 \\
\hline
\end{tabular}

Elaboración Propia 
Como se puede ver en la Tabla 8.5, la variación de demanda afecta en gran magnitud a los indicadores financieros, de tal manera que, si la demanda disminuye $2,83 \%$, el van disminuiría a S/ 255370 y en el caso optimista al aumentar la demanda en $2,26 \%$ el van aumentaría a S/ 471421 , por lo que se puede concluir que la demanda es uno de los factores que más pueden afectar al proyecto. 


\section{CAPÍTULO IX: EVALUACION SOCIAL}

\subsection{Identificación de las zonas y comunidades de influencia.}

El proyecto se situará en el departamento de Lima, en el distrito de Ate, por lo consiguiente, el grado de interrelación con las distintas variables socioambientales, se ha divido en dos: directa e indirecta.

El área influencia directa (AID), corresponderá con el pueblo más cercano a la planta procesadora, donde la zona de construcción, acondicionamiento y acabados son los de mayor intensidad.

El área de influencia indirecta (AII), corresponderá a todas aquellas áreas que se podrían verse afectadas en el mediano y largo plazo. En este contexto, se abarca el sistema de agua y a las comunidades nativas y/o campesinas.

Tabla 9.1

Características de las necesidades básicas de Huancayo

\begin{tabular}{|c|c|c|c|c|c|}
\hline Distrito & Poblacion 2007 & $\begin{array}{c}\text { \% Poblac. } \\
\text { Rural }\end{array}$ & $\begin{array}{c}\text { \% Poblac. Sin } \\
\text { desag }\end{array}$ & $\begin{array}{l}\text { \% Poblac. sin } \\
\text { electricidad }\end{array}$ & tasa desnutricion \\
\hline Huancayo & 112054 & $2 \%$ & $5 \%$ & $5 \%$ & $19 \%$ \\
\hline Carhuacallanga & 840 & $1 \%$ & $93 \%$ & $68 \%$ & $60 \%$ \\
\hline Chacapampa & 1212 & $58 \%$ & $21 \%$ & $45 \%$ & $44 \%$ \\
\hline Chicche & 1271 & $50 \%$ & $26 \%$ & $24 \%$ & $36 \%$ \\
\hline Chilca & 77392 & $5 \%$ & $5 \%$ & $8 \%$ & $36 \%$ \\
\hline Chongos Alto & 1686 & $32 \%$ & $14 \%$ & $29 \%$ & 31 \\
\hline Chupuro & 2012 & $82 \%$ & $27 \%$ & $20 \%$ & $43 \%$ \\
\hline Colca & 1994 & $45 \%$ & $29 \%$ & $27 \%$ & $52 \%$ \\
\hline
\end{tabular}

Fuente: Mapa de pobreza de FONCODES, (2007).

Elaboración: Maximixe

Según lo descrito en la Tabla 9.1, el área de influencia directa es el distrito de Ate, mientras que la influencia indirecta son las comunidades agrícolas de Huancayo en el mediano o largo plazo. 


\subsection{Análisis de indicadores sociales.}

\subsubsection{Valor agregado}

Es el valor adicional que adquieren los insumos y materias primas al pasar por un proceso productivo. Incluye: sueldos, salarios, intereses, depreciación, utilidades e impuestos

Para obtener la Tasa Social de Descuento se tomó como referencia la determinada por el Ministerio de Economía y Finanzas que es de $8 \%$ actualizado al 2017. La organización encargada dentro del MEF para determinar esta tasa es el SNIP, la cual certifica la calidad de los Proyectos de Inversión Pública (PIP) mediante un conjunto de principios, métodos, procedimientos, etc.

Para hallar el Valor Agregado se toma como referencia el Estado de resultados y para este caso se sumarán siguientes cuentas:

(+) Costo de la Mano de Obra

(+) Gastos Administrativos y Ventas

(+) Gastos Financieros

(+) Depreciación Anual

(+) Utilidad Antes de Impuestos

Tabla 9.2

Valor agregado

\begin{tabular}{|l|r|r|r|r|}
\hline Valor Agreg. & $\mathbf{2 0 1 8}$ & $\mathbf{2 0 1 9}$ & $\mathbf{2 0 2 0}$ & $\mathbf{2 0 2 1}$ \\
\hline Costo Mano de Obra & $\mathrm{S} / 335,175$ & $\mathrm{~S} / 335,175$ & $\mathrm{~S} / 335,175$ & $\mathrm{~S} / 335,175$ \\
\hline Depreciación & $\mathrm{S} / 16,257$ & $\mathrm{~S} / 16,257$ & $\mathrm{~S} / 16,257$ & $\mathrm{~S} / 16,257$ \\
\hline Gastos Admin. & $\mathrm{S} / 288,578$ & $\mathrm{~S} / 288,578$ & $\mathrm{~S} / 288,578$ & $\mathrm{~S} / 288,578$ \\
\hline Gastos financieros & $\mathrm{S} / 31,159$ & $\mathrm{~S} / 31,159$ & $\mathrm{~S} / 21,769$ & $\mathrm{~S} / 11,416$ \\
\hline Utilidad Antes de impuestos & $\mathrm{S} / 273,501$ & $\mathrm{~S} / 199,015$ & $\mathrm{~S} / 125,590$ & $\mathrm{~S} / 165,248$ \\
\hline Valor Agregado Anual & $\mathrm{S} / \mathbf{9 4 4 , 6 6 9}$ & $\mathrm{S} / \mathbf{8 7 0 , 1 8 3}$ & $\mathrm{S} / \mathbf{7 8 7 , 3 6 8}$ & $\mathrm{S} / \mathbf{8 1 6 , 6 7 3}$ \\
\hline
\end{tabular}

Elaboracion Propia

Valor Agregado actualizado (8\%)

S/ 2846053 


\subsubsection{Densidad de capital}

Relación entre la inversión del capital y el empleo generado.

$$
\begin{aligned}
& \text { Densidad de Capital }=\frac{\text { Inv. Total }}{\# \text { de empleados }} \\
& \begin{aligned}
\text { Densidad de Capital } & =\frac{433844}{31} \\
& =13994,98 \quad \mathrm{~S} / . / \text { empleado }
\end{aligned}
\end{aligned}
$$

Por cada 13 994,98 soles de inversión se generará 1 puesto de trabajo. Al ser un proyecto de poco requerimiento de personal generara una mayor densidad de capital.

\subsubsection{Intensidad de capital}

Mide el grado de aporte del proyecto a la población, con la finalidad de generar valor agregado sobre los insumos.

$$
\begin{aligned}
\text { Intensidad de Capital } & =\frac{\text { Inv. Total }}{\text { Valor Agregado }} \\
& =\frac{433844}{2846053}=\mathrm{S} / 0,152
\end{aligned}
$$

Por cada S/ 0,152 soles que se invertirá en el proyecto se le retribuirá con un 1 sol a la sociedad, esto indica que la empresa genera buenos retornos de las inversiones.

\subsubsection{Relación producto - capital}

Mide la relación entre valor agregado generado y la inversión total.

$$
\text { Producto }- \text { Capital }=\frac{\text { Valor Agregado }}{\text { Inv. Total }}=\frac{2846053}{433844}=6,56
$$

Por cada 6,56 soles que se le da a la sociedad se invierte 1 sol, lo que indica que el proyecto es viable económica, financiera y socialmente. 


\section{CONCLUSIONES}

- El Perú cuenta con una enorme variedad de papas; pero aun así estamos por detrás en producción de países como China y Holanda, esta es una de las causas y que ha impulsado su importación en general.

- El producto básico es la papa amarilla precocida en rodajas y prefrita en forma de bastón, su presentación será en empaques termocontraibles cerrados al vacío, lo que permitirá conservarse hasta por 4 meses congelado.

- La evaluación de la macrolocalización dio por ganador a Lima y la microlocalización a Ate.

- El tamaño de planta está limitado por el tamaño-mercado que es 173188 bolsas/año.

- La cantidad de máquinas y operarios que se requerirá será de 11 y 16 respectivamente y su capacidad de planta es 192 ton/año.

- Para la reducción del impacto se segregará y gestionará los residuos generados en los procesos, recirculaciones en procesos como el agua caliente, filtración del agua antes del lavado y el uso de plástico biodegradables.

- En el 2022 según el programa de producción se producirá 88,57 toneladas tomando en cuenta el mercado, las mermas y el stock de seguridad.

- El análisis de Guerchet se obtuvo que el área total para la planta es de 706 m2.

- La empresa tendrá de nombre Amkha y se constituirá como una empresa individual de responsabilidad limitada (EIRL) con un accionista.

- La inversión total será de S/433 844 que considera a los activos tangibles e intangibles y el capital de trabajo será S/199 157.

- En la evaluación financiera se obtuvo un VAN de S/ 375 547, TIR de 113,1\% y un periodo de recupero de 2,64 años, lo que significa que el proyecto si es rentable. 


\section{RECOMENDACIONES}

- Para el proceso de producción es recomendable tener 2 líneas de producción con la finalidad de tener la planta más ordenada y para evitar errores.

- Para una mayor reducción del costo de producción se recomienda hacer alianzas estratégicas con empresas empaquetadoras y distribuidoras.

- Para la localización de la planta se debe considerar el alquiler de un local con un amplio patio de maniobras.

- Para la reducción del impacto ambiental se debe considerar hacer alianzas estratégicas con las empresas recicladoras.

- Para la ingeniería del proyecto se recomienda tener la menor cantidad de maquinaria para reducir el espacio y costos.

- Para la evaluación financiera del proyecto se debe tener en cuenta que el monto del préstamo está condicionado a las empresas financieras. 


\section{REFERENCIAS}

Academia del Área de Plantas Piloto de Alimentos. (2008). Introducción a la tecnología de alimentos. México, D.F.: Limusa.

Asfahl, C. R. (2010). Seguridad industrial y administración de la salud. Naucalpan de Juárez: Pearson Educación.

Austin, G. T. (1989). Manual de procesos químicos en la industria. México, D.F.: McGraw Hill.

Baca, G. (2013). Introducción a la Ingeniería Industrial. México D.F: Patria.

Ballou, R. H. (2004). Logística: administración de la cadena de suministro. México, D.F.: Pearson Educación.

Bartholomai, A. (1991). Fábricas de alimentos: procesos, equipamiento, costos. Zaragoza: Acribia.

Beer, F. P. (2013). Mecánica de materiales. México: McGraw-Hill.

Besterfield, D. H. (2009). Control de calidad. Naucalpan de Juárez: Pearson Educación.

Calidda. (10 de noviembre de 2016). Regulación y Tarifas. Recuperado de https://www. calidda.com.pe/tarifas/Paginas/Tarifario.aspx

Cipotato. (02 de noviembre de 2016). Plagas y enfermedades de la papa. Recuperado de http://cipotato.org/es/lapapa/plagas-y-enfermedades-de-la-papa/

Collazos Cerrón, J. (2002). El estudio de mercado en los proyectos de inversión. Lima: San Marcos.

Consejo Nacional del Ambiente (Perú). (1999). Principios de evaluación de impacto ambiental. Lima: CONAM.

Díaz, B., Jarufe, B. y Noriega, M. (2007). Disposición de planta. Lima: Universidad de Lima, Fondo editorial.

DIGESA. (25 de setiembre de 1998). Normas legales. Recuperado de ftp://ftp2.minsa.gob.pe/normaslegales/1998/DS007-1998.pdf

Garmendia Salvador, A. (2006). Evaluación de impacto ambiental. Madrid: Pearson, Prentice Hall.

Giraldo, C. M. (2009). Estudio de prefactibilidad para el montaje de una planta procesadora de papa criolla de carácter mixto en Cundinamarca. Recuperado de 
https://www.scribd.com/document/243619856/estudio-prefactibilidad-plantaprocesadora-papa-criolla-pdf

González F., F. J. (2011). Teoría y práctica del mantenimiento industrial avanzado. Madrid: FC Editorial.

Goñi Delion, J. C. (2011). Máquinas, instrumentos y procesos de manufactura. Lima: Universidad de Lima, Fondo Editorial.

Konz, S. (1990). Diseño de sistema de trabajo. México, D.F.: Limusa-Noriega.

Koo, W. (2017). Papa Preparada Prefrita Perú Importación 2016 diciembre. Agrodata. Recuperado de https://www.agrodataperu.com/2017/01/papa-fecula-peruimportacion-2016-diciembre.html.

León Carrasco, J. C. (2016). Consumo per cápita de papa en Perú debería llegar a los 100 kilos en el 2021. Agraria. Recuperado de http://agraria.pe/noticias/con sumo-per-capita-de-papa-en-peru-deberia-11156

Manahan, S. E. (2007). Introducción a la química ambiental. Barcelona: Reverté; México, D.F.: Universidad Nacional Autónoma de México.

Maximixe Consult S.A. (2010). Elaboración del estudio de Mercado de la trucha en Arequipa, Cusco, Lima, Huancayo y Puno. Ministerio de la Producción. Recuperado de www.slideshare.net/isaacmamanimorales/estudio-mercadotrucha Minagri. (22 de mayo del 2017). Perú es imbatible en la producción de papa en Latinoamérica. Recuperado de http://www.Minagri.gob.pe/portal/publicacionesy-prensa/noticias-2017/19273-peru-es-imbatible-en-la-produccion-de-papa-enlatinoamerica

Ministerio de la producción. (5 de junio del 2015). Decreto Supremo Nº17-2015Produce. Recuperado de http://www.produce.gob.pe/documentos/mypeindustria/diggam/ ds017-2015-produce.pdf

Mintzberg, H. (2010). Safari a la estrategia: una visita guiada por la jungla del management estratégico. Buenos Aires: Granica.

Moscoso Vergara, D. M. (2010). Elaboración de un plan de marketing para la corporación CODESTAAE de la provincia de CARCHI, para la comercializar el producto pre procesado, papa bastón, en el sector centro norte de QUITO. (Tesis de titulación, Universidad Internacional SEK, Quito) Recuperada de http://repositorio.uisek.e du.ec/bitstream/123456789/577/1/DANIELA\%20MOSCOSO.pdf

Mott, R. L. (2008). Mecánica de fluidos. México, D.F.: Pearson Educación: Prentice Hall. 
Murphy, R. M. (2007). Introducción a los procesos químicos: principios, análisis y síntesis. México: McGraw-Hill.

Muther, R. (1970). Distribución de planta. Barcelona: Hispano Europea.

Nakajima, S. (1991). Introducción al TPM: mantenimiento productivo total. Madrid: Tecnologías de Gerencia y Producción.

Organización de las Naciones Unidas para la Agricultura y la Alimentación. (2002). Sistemas de calidad e inocuidad de los alimentos. Madrid. Ministerio de Sanidad y Consumo.

Pastor Fernández, A. (2013). Sistemas integrados de gestión. Cádiz: Universidad de Cádiz.

Radio Nacional. (20 de agosto del 2015). Perú posee el 63\% de variedades de papa del mundo, señalan. Recuperado de http://www.radionacional.com.pe/noticias/nacio nal-en-la-noticia/posee-el-63-de-variedades-de-papa-del-mundo-se-alan.

Rengifo, T. (29 de marzo del 2017). Tendencias del mercado de lo natural. La República. Recuperado de http://larepublica.pe/marketing/860310-tendencias-del-mercadode-lo-natural.

Schey, J. A. (2002). Procesos de manufactura. México, D.F.: McGraw Hill.

Seoánez Calvo, M. (1999). Manual de gestión medioambiental de la empresa. Madrid. Mundiprensa.

Smith, W. F. (2014). Fundamentos de la ciencia e ingeniería de materiales. México D. F.: McGraw-Hill.

Sule, D. R. (2001). Instalaciones de manufactura: ubicación, planeación y diseño. México, D.F.: International Thomson.

United States Department of Agriculture. (abril de 1997). International HACCP Alliance. Recuperado de http://www.haccpalliance.org/sub/haccpmodels/rawgro ud.pdf

Valdivia Navarro, M. A. (2015). Estudio de prefactibilidad para la instalación de una planta productora de nugget de pavita y omega 3 para consumo en Lima Metropolitana. (tesis para optar el título de Ingeniero Industrial). Universidad de Lima.

WordPress. (2014). Consumo y mercadeo de la papa en Argentina. Recuperado de https://consumoymercadodepapa.wordpress.com/2014/11/28/consumo-ymercadeo-de-la-papa-en-argentina/ 


\section{BIBLIOGRAFÍA}

Beraún, C. (30 de mayo de 2015). Día de la Papa: Huánuco es la segunda región con mayor producción. Diario Correo. Recuperado de http://diariocorreo.pe/edicion/ huanuco/dia-de-la-papa-huanuco-es-la-segunda-region-con-mayor-produccion$591209 /$

El laboratorio Profeco reporta. (2008). Papas fritas envasadas. [Versión PDF]. Recuperado de www.profeco.gob.mx/revista/pdf/est_08/5663\%20papas.pdf.

FAO. (10 de setiembre de 2015). Año internacional de la Papa. Recuperado de http://www.fao.org/potato-2008/es/lapapa/hojas.html

León Carrasco, J. C. (27 de mayo de 2015). Perú lidera producción de papa en Latinoamérica. Agraria.pe. Recuperado de http://agraria.pe/noticias/peru-lideraproduccion-de-papa-en-latinoamerica-8337.

Mayo, A. (06 de octubre de 2014). "Domesticamos la papa hace más de 8 mil años". La república. Recuperado de http://larepublica.pe/06-10-2014/domesticamos-lapapa-hace-mas-de-8-mil-anos

Mora Gutiérrez, L. A. (2009). Mantenimiento: planeación, ejecución y control. México, D.F.: Alfaomega.

Ordinola, M; Fonseca, C. (17 de Setiembre de 2012). Papas nativas: Aportes para la seguridad alimentaria, nutrición y generación de ingresos en zonas altas del Perú.

Ortiz, M. (10 de setiembre de 2015). Papa importada le gana terreno a la nacional en las pollerías. El comercio. Recuperado de http://elcomercio.pe/economia/negocios/p apa-importada-le-gana-terreno-nacional-pollerias-noticia-1832604

Pajares, G. (30 de mayo del 2015). Día Nacional de la Papa: ¿Cuál es la mejor para hacer papas fritas? Perú 21. Recuperado de http://peru21.pe/vida21/dia-nacional-papacual-mejor-hacer-papas-fritas-videos-2219864

Papicrock. (10 de setiembre de 2015). Papas amarillas pre fritas congeladas con cascara cortadas en tiras. Recuperado de http://www.papicrock.com.pe/producto s/papas-amarillas-pre-fri-congeladas-con-cascara-cortadas-en-tiras.html 
Pontificia Universidad Católica del Perú. (29 de mayo del 2014). Perú: primer productor de papa en América Latina con 4,700,000 toneladas al año. Recuperado de http:/ /www.pucp.edu.pe/climadecambios/index.php?tmpl=articulo\&id=1684

Render, B. (2014). Principios de administración de operaciones. México D. F.: Pearson.

Sabbah, S. A. (31 de mayo de 2013). La papa: baja en grasas, rica en vitamina C y carotenoides. RPP. Recuperado de http://www.rpp.com.pe/2013-05-31-la-papabaja-en-grasas-rica-en-vitamina-c-y-carotenoides-noticia_600022.html

Vázquez, L. (10 de setiembre de 2015). Beneficios de la papa. VIX. Recuperado de http://www.vix.com/es/imj/salud/2010/10/23/beneficios-de-la-papa 


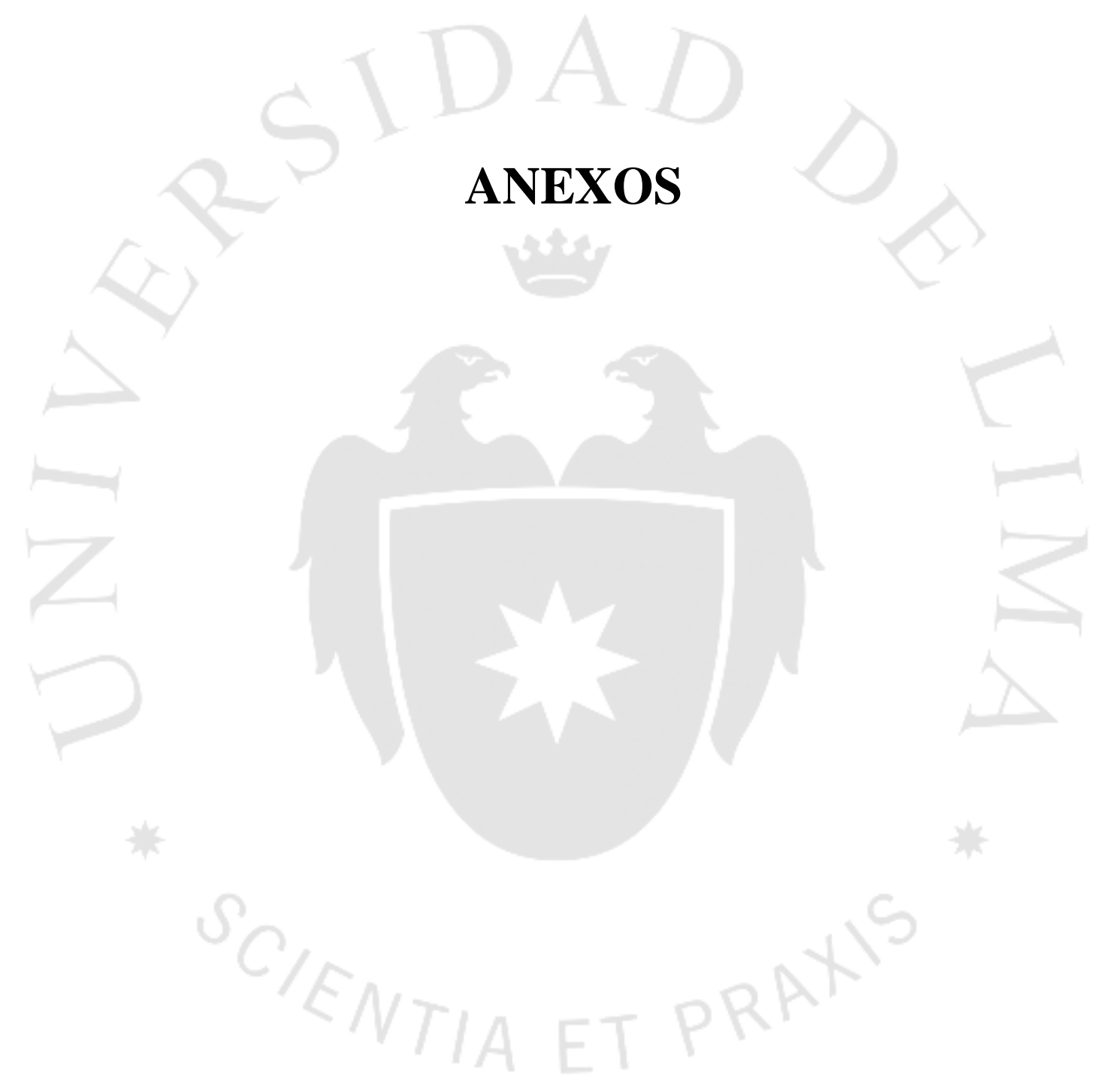




\section{Anexo 1: Encuesta}

Encuesta sobre demanda de papa amarilla precocida y prefrita congelada en Lima Moderna

1. ¿Consume papas fritas o cocidas? Sí No

2. ¿Compraría usted papas amarillas prefritas o precocida congeladas? Sí No

3. ¿Qué cantidad consideraría la más adecuada para este tipo de producto? $1 / 2 \mathrm{~kg}()$

$1 \mathrm{~kg}()$

$2 \mathrm{~kg}()$

4. ¿Estaría dispuesto a pagar $\mathrm{S} / 10,5$ por un paquete de $1 \mathrm{~kg}$ de papas amarillas prefritas?

Si ( ) No ( )

5. ¿Dónde preferiría comprar nuestro producto?

Supermercado ( )

Mercado ( )

Bodega () 


\section{Anexo 2: Resultados de la encuesta}

La intensidad de compra hallada en la encuesta fue de $80 \%$, pues respondieron que si comprarían al menos una vez al mes.

Intención de compra fue de $60 \%$, ya que respondieron que si comprarían nuestro producto.

Gráfico anexo 2: Resultados de encuesta

Intensidad de compra

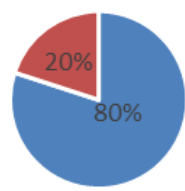

Intención de compra

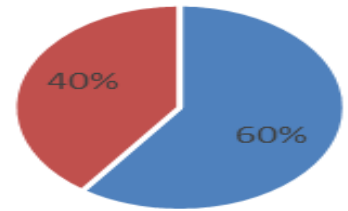

- si compraria al menos una vez al mes

- Nunca - SI NO 


\section{Anexo 3: Proforma máquinas}

Empresa: Zhucheng Honest Industry and Trade co., Ltd

\section{Precio, nombre y especificación}

$\begin{array}{llllll}\text { No. } & \text { Machine } & \text { Specification } & \text { Power } & & \text { Price } \\ 01 & \text { Peeling Machine } & \text { HPM10 } & 0.75 \mathrm{KW} / 220 \mathrm{~V} & \text { USD } & 235 \\ 02 & \text { Chips Slicing Machine } & \text { HCM } 400 & 0.75 \mathrm{KW} / 220 \mathrm{~V} & \text { USD } & 390 \\ 03 & \text { Chips Blanching Machine } & \text { HBT-1000 } & 15 \mathrm{kw} / 380 \mathrm{v} & \text { USD } & 1550 \\ 04 & \text { Chips Dehydrating Machine } & \text { HDM } 500 & 0.75 \mathrm{kw} / 380 \mathrm{v} & \text { USD } & 1130 \\ 05 & \text { Chips/Fries Frying Machine } & \text { HFM-500 } & 9 \mathrm{kw} / 380 \mathrm{v} & \text { USD } & 1550 \\ 06 & \text { Chips Fried De oiling Machine } & \text { HDO500 } & 0.75 \mathrm{kw} / 380 \mathrm{v} & \text { USD } & 1130 \\ 07 & \text { Chips Flavoring Machine } & \text { HSM } 800 & 0.75 \mathrm{kw} / 220 \mathrm{v} & \text { USD } & 705 \\ 08 & \text { Nitrogen Packaging Machine } & \text { HPM-400 } & 1 \mathrm{kw} / 380 \mathrm{v} & \text { USD } & 1360 \\ & & & \text { Package cost } & \text { USD } & 450 \\ & & \text { FOB Qingdao Port, China } & \text { USD } & 8500\end{array}$

\section{Anexo 4: Costos de normativas}

- Certificado de principios de higiene de Codex Alimentarius: S/ 586,3

- Validación técnica oficial del plan HACCP. S/. 985.3

- Certificado de libre comercialización de alimentos S/. 70,8

- Registro sanitario de alimentos de consumo humano. S/. 390 
Anexo 5: Diagrama de flujo para la elección de los PCC

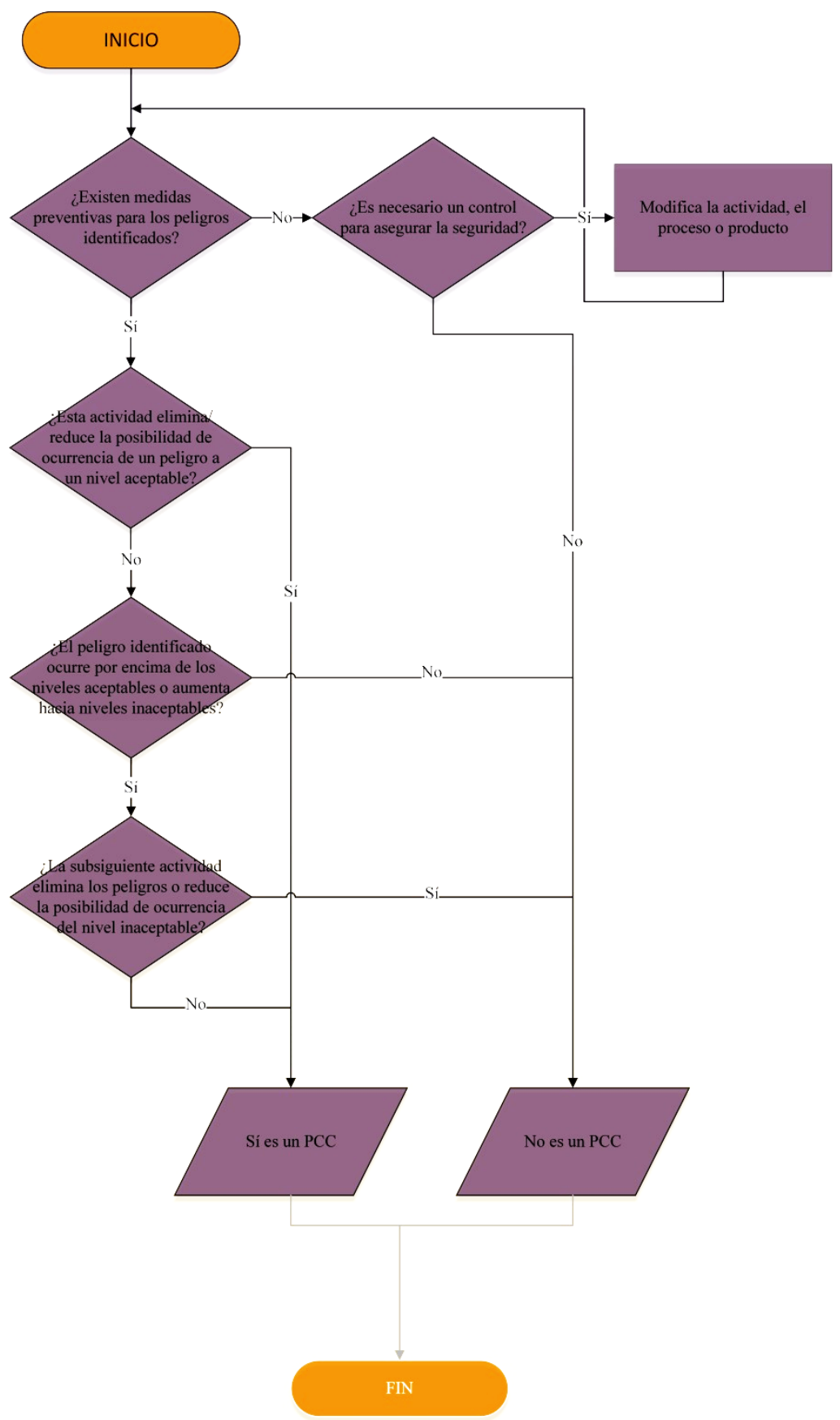

Elaboracion Propia 


\section{Anexo 6: Análisis de peligros/medidas preventivas}

\begin{tabular}{|c|c|c|}
\hline \multicolumn{3}{|c|}{ Análisis de peligros/medidas preventivas } \\
\hline \multicolumn{3}{|c|}{ Categoría del proceso: Alimentos precocidas } \\
\hline \multicolumn{3}{|c|}{ Productos: Papas prefritas y precocidas } \\
\hline Actividad & $\begin{array}{l}\text { Peligros } \\
\text { Biológicos }(\mathrm{B}) \\
\text { Químico }(\mathrm{Q}) \\
\text { Físico }(\mathrm{F})\end{array}$ & Métodos preventivos \\
\hline \multirow{3}{*}{$\begin{array}{l}\text { Recepción } \\
\text { de pedidos }\end{array}$} & $\begin{array}{l}\text { B (crecimiento microbiológico) - } \\
\text { insuficiente control de temperatura. Este } \\
\text { puede provocar un crecimiento } \\
\text { microbiológico inaceptable. }\end{array}$ & $\begin{array}{l}\text { Mantener el producto a una temperatura } \\
\text { lo suficientemente baja, como para que no } \\
\text { haya crecimiento bacteriológico }\end{array}$ \\
\hline & $\begin{array}{l}\mathrm{F} \text { (golpes del producto) los golpes pueden } \\
\text { originar cortes en las papas; lo que las } \\
\text { hace más propensas a contaminarse. }\end{array}$ & $\begin{array}{l}\text { Hacer una inspección visual del estado e } \\
\text { integridad de los contenedores que llegan. }\end{array}$ \\
\hline & $\begin{array}{l}\text { B (crecimiento por contacto) - El estado } \\
\text { del contenedor con el que llega la papa } \\
\text { puede ser causa de su contaminación. }\end{array}$ & $\begin{array}{l}\text { Aceptar únicamente a proveedores } \\
\text { certificados para sus contenedores. }\end{array}$ \\
\hline $\begin{array}{l}\text { Almacenaje } \\
\text { de materia } \\
\text { prima }\end{array}$ & $\begin{array}{l}\text { B (crecimiento microbiológico) - } \\
\text { insuficiente control de temperatura. Este } \\
\text { puede provocar un crecimiento } \\
\text { microbiológico inaceptable y limpieza de } \\
\text { los racks. }\end{array}$ & $\begin{array}{l}\text { Monitorear la temperatura del almacén de } \\
\text { materia prima y asegurarse que la papa no } \\
\text { exceda el nivel máximo de crecimiento } \\
\text { bacteriológico. La temperatura se debe } \\
\text { mantener debajo de los } 18^{\circ} \mathrm{C} \text {. }\end{array}$ \\
\hline \multirow{2}{*}{ Congelado } & $\begin{array}{l}\text { B (contaminación) - Las maquinas } \\
\text { utilizadas, en el proceso, puede } \\
\text { contaminar a las papas de } \\
\text { microorganismos. }\end{array}$ & $\begin{array}{c}\text { Análisis microbiológico de los materiales } \\
\text { utilizados e inspección visual del estado } \\
\text { de los recipientes. }\end{array}$ \\
\hline & $\begin{array}{l}\text { No mantener la temperatura de los } \\
\text { productos a un nivel aceptable, puede } \\
\text { ocurrir el crecimiento microbiológico. }\end{array}$ & $\begin{array}{l}\text { Monitorear que la temperatura } \\
\text { permanezca en } 18^{\circ} \mathrm{C} \pm 1 \text {, para que se } \\
\text { pueda limitar el crecimiento } \\
\text { microbiológico. }\end{array}$ \\
\hline Envio & $\begin{array}{l}\text { B (crecimiento microbiológico) - } \\
\text { Potencial para el incremento de la flora } \\
\text { bacteriana y patógenos puedan proliferar } \\
\text { durante el transporte. }\end{array}$ & $\begin{array}{l}\text { Mantener el producto a una temperatura } \\
\text { lo suficientemente baja, como para que no } \\
\text { haya crecimiento bacteriológico }\end{array}$ \\
\hline
\end{tabular}

